SANDIA REPORT

SAND89-2256 - UC -252

Unlimited Release

Printed November 1989

\title{
High Temperature Borehole Televiewer Software User Manual
}

\author{
Leonard E. Duda
}

Prepared by

Sandia National Laboratories

Albuquerque, New Mexico 87185 and Livermore, California 94550

for the United States Department of Energy

under Contract DE-AC04-76DP00789

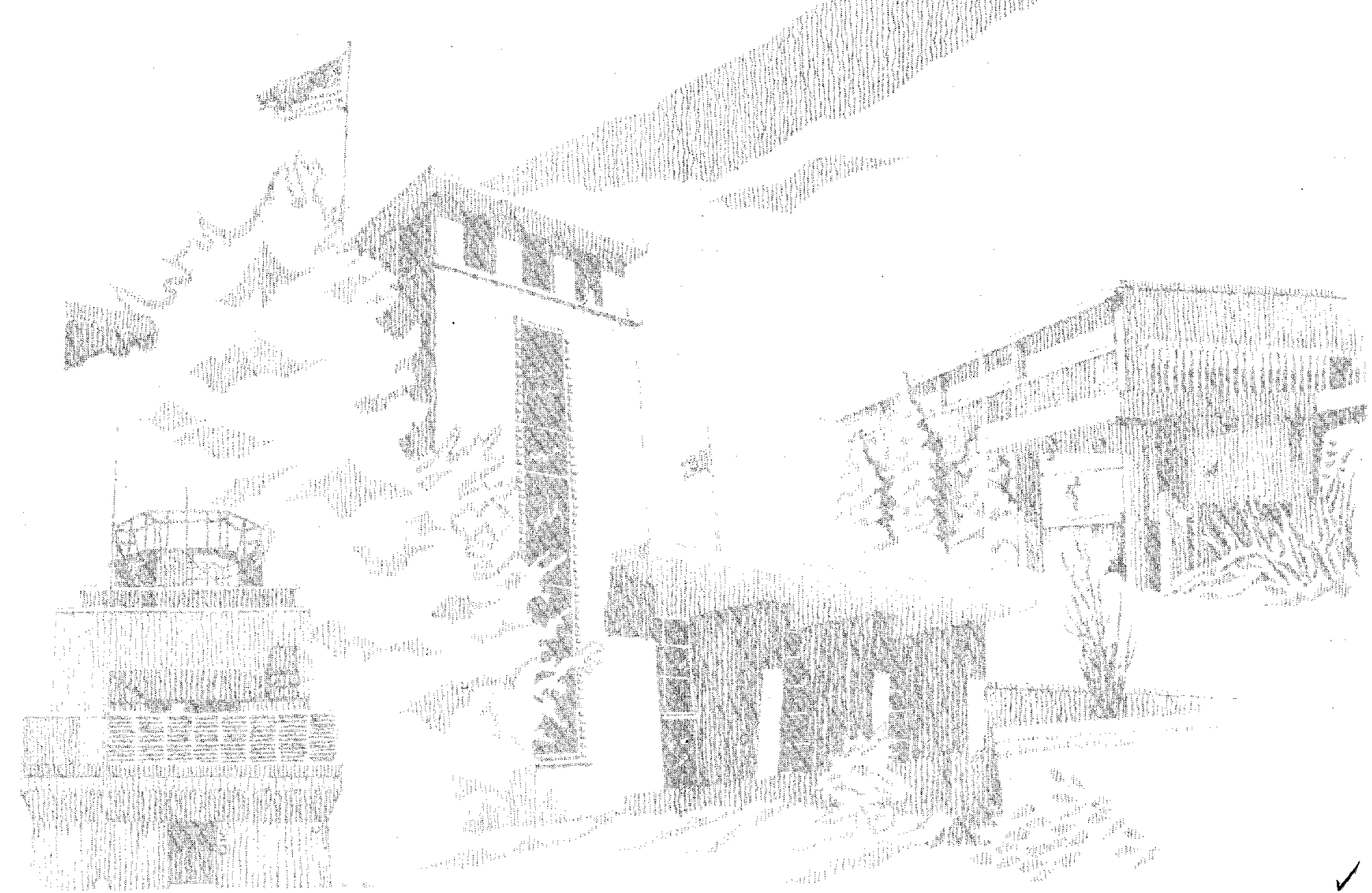


Issued by Sandia National Laboratories, operated for the United States Department of Energy by Sandia Corporation.

NOTICE: This report was prepared as an account of work sponsored by an agency of the United States Government. Neither the United States Government nor any agency thereof, nor any of their employees, nor any of their contractors, subcontractors, or their employees, makes any warranty, express or implied, or assumes any legal liability or responsibility for the accuracy, completeness, or usefulness of any information, apparatus, product, or process disclosed, or represents that its use would not infringe privately owned rights. Reference herein to any specific commercial product, process, or service by trade name, trademark, manufacturer, or otherwise, does not necessarily constitute or imply its endorsement, recommendation, or favoring by the United States Government, any agency thereof or any of their contractors or subcontractors. The views and opinions expressed herein do not necessarily state or reflect those of the United States Government, any agency thereof or any of their contractors.

Printed in the United States of America. This report has been reproduced directly from the best available copy.

Available to DOE and DOE contractors from Office of Scientific and Technical Information PO Box 62

Oak Ridge, TN 37831

Prices available from (615) 576-8401, FTS 626-8401

Available to the public from

National Technical Information Service

US Department of Commerce

5285 Port Royal Rd

Springfield, VA 22161

NTIS price codes

Printed copy: A05

Microfiche copy: A01 
SAND89-2256

Unlimited Release

Printed November 1989

\title{
HIGH TEMPERATURE BOREHOLE TELEVIEWER SOFTWARE USER MANUAL
}

Leonard E. Duda

Geothermal Research Division

Sandia National Laboratories

Albuquerque, NM 87185

\begin{abstract}
The High Temperature Borehole Televiewer is a downhole instrument which provides acoustic pictures of the borehole walis that are suitable for casing inspection and fracture detection in geothermal wells. The Geothermal Drilling organization has funded the development of a commercial tool survivable to temperatures of $275^{\circ} \mathrm{C}$ and pressures of $5000 \mathrm{psi}$. A real-time display on an IBM-compatible PC was included as part of the development effort. This report contains a User Manual which describes the operation of this software. The software is designed in a menu format allowing the user to change many of the parameters which control both the acquisition and the display of the televiewer data. An internal data acquisition card digitizes the waveform from the tool at a rate of 100,000 samples per second. The data from the tool, both the range or arrival time and the amplitude of the return signal, are displayed in color on the CRT screen of the computer during the logging operation. This data may be stored on the hard disk for later display and analysis. The software incorporates many features which aid in the setup of the tool for proper operation. These features include displaying and storing the captured waveform data to check the voltage and time windows selected by the user. The report provides the detail of the important data acquisition and display operations performed by the software. The results of two field tests of the televiewer system are described. Some of the more interesting data from the field tests are discussed. Finally, the report concludes with a list of suggested improvements or modifications to the software and hardware.
\end{abstract}




\section{ACKNOWLEDGEMENTS}

The author gratefully acknowledges the support of $R$. D. Meyer, R. D. Jacobson, J. E. Uhl and R. P. Wemple for the field tests of this instrumentation. Gene A. Suemnicht of Unocal Geothermal provided the use of two wells in the Salton Sea geothermal area for these tests. Stephen knudsen provided assistance in programming the algorithm for the extraction of the amplitude information from the digitized data. Finally, the many useful discussions and assistance provided by Jim Uhl are greatly appreciated. This work was supported by the U. S. Department of Energy at Sandia National Laboratories under Contract DE-AC04-76DP00789. 
TABLE OF CONTENTS

I. INTRODUCTION $\ldots \ldots \ldots \ldots \ldots \ldots \ldots \ldots \ldots \ldots \ldots \ldots \ldots \ldots \ldots \ldots \ldots$

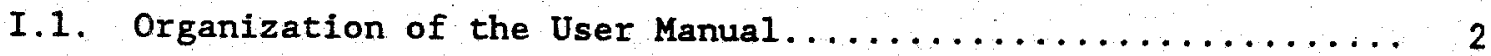

II. OPERATION OF THE BHTV SOFTWARE. $\ldots \ldots \ldots \ldots \ldots \ldots \ldots \ldots \ldots \ldots \ldots \ldots$

II.1. Starting the HT-BHTV program................ 3

II.2. Connection of Input/Output devices ............... 4

II.3. User-Controlled Software Flags.................. 5

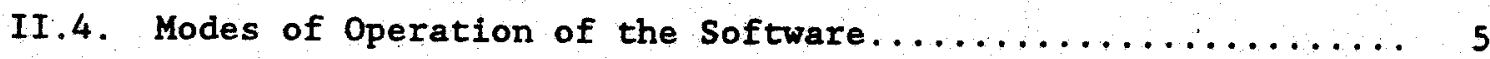

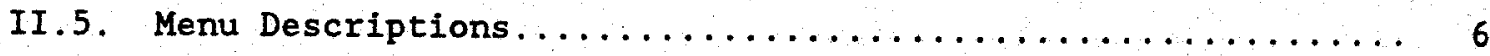

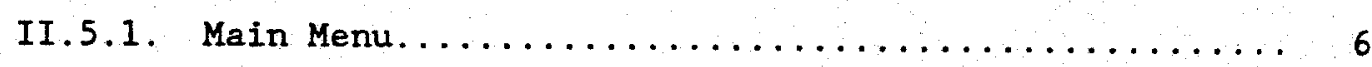

II.5.2. Depth Encoder Setup Menu. ................. 10

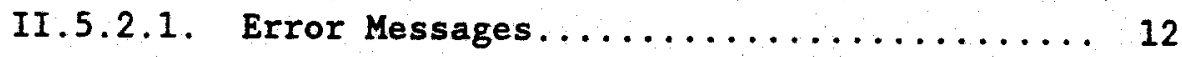

II.5.3. Tool Setup Menu. .................... 13

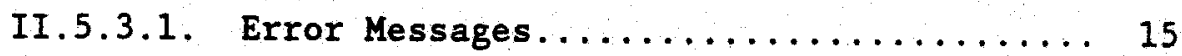

II.5.4. Data Acquisition Menu.................. 16

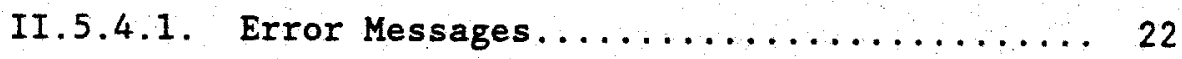

II.5.5. Logging/Data Display Setup Menu.............. 27

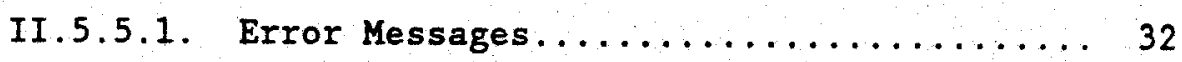

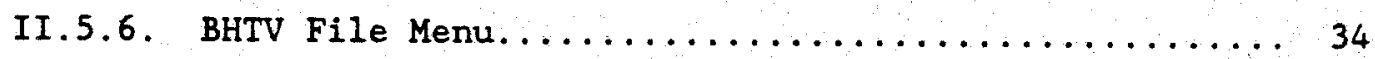

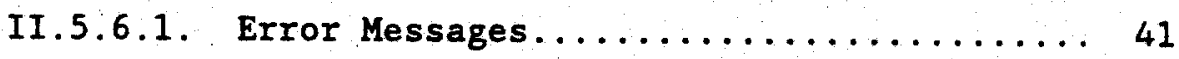

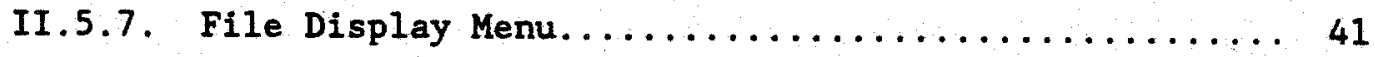

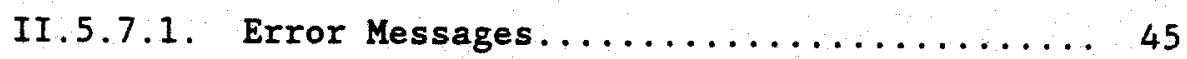

II.5.8. Test Parameter/Setup File Menu............. 47

II.5.8.1. Error Messages............... 50

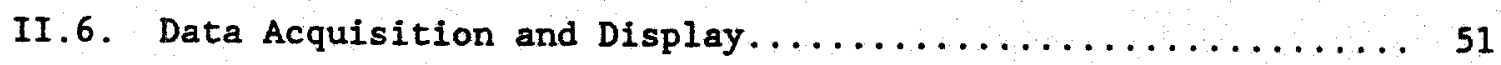

II.6.1. Error Messages.................... 53

II.6.2. Description of the CRT Screen for Data Display..... 55

II.6.2.1. Data Display Area............. 55

II.6.2.2. Depth Annotation Area............ 58

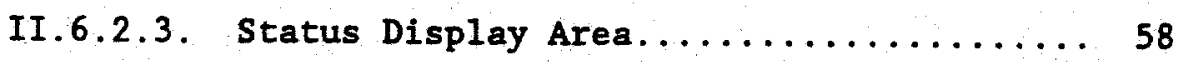

II.6.2.4. Special Key Display Area...........61 
TABLE OF CONTENTS

Page

II.6.2.5. Range/Magnitude Color Code Area........63 63

II.6.2.6. Display Scale Line............. 63

II.6.2.7. Menu Display Line............... 64

II.6.2.8. Message Display Line........... 64

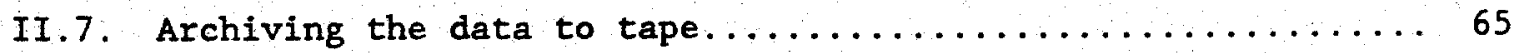

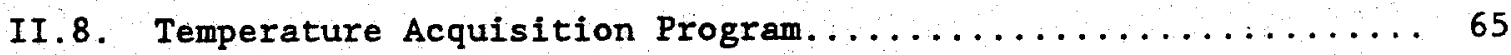

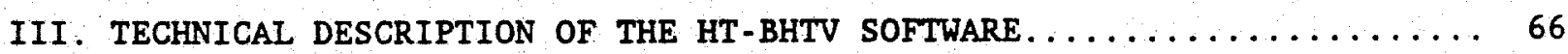

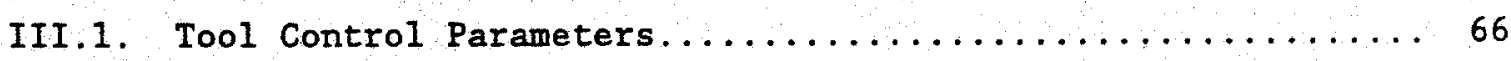

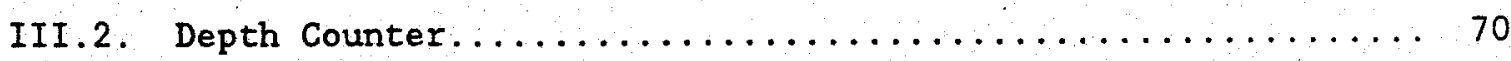

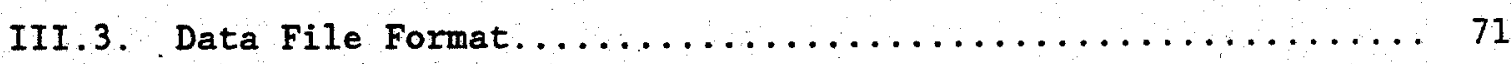

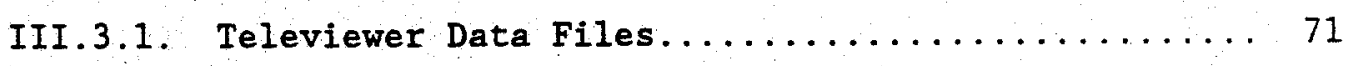

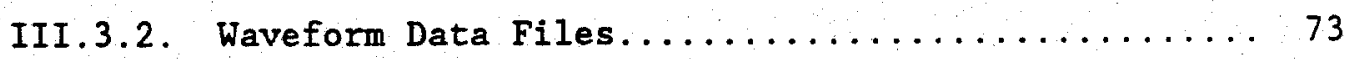

III.3.3. Data Acquisition Setup Files............. 73

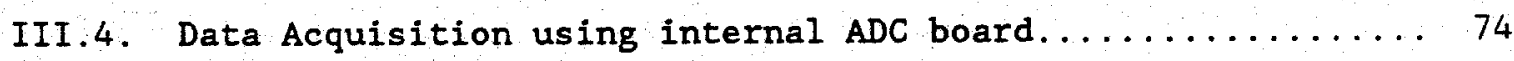

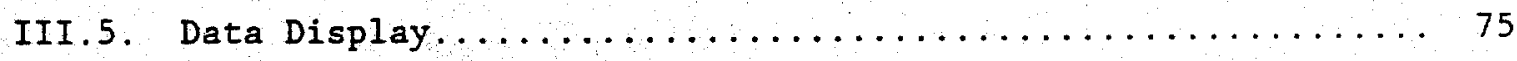

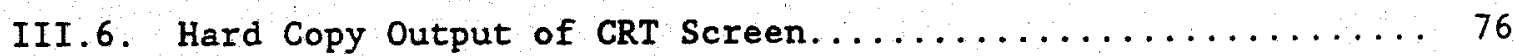

IV. FIELD TESTS OF THE HT-BHTV TOOL $\ldots \ldots \ldots \ldots \ldots \ldots \ldots \ldots \ldots \ldots \ldots$

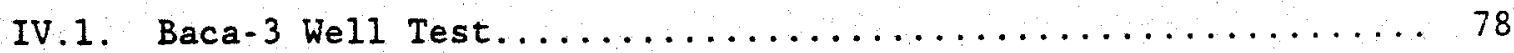

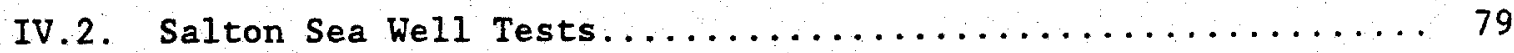

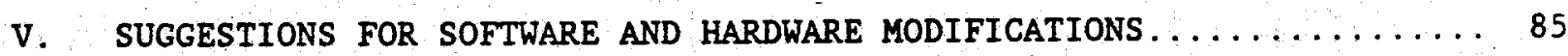

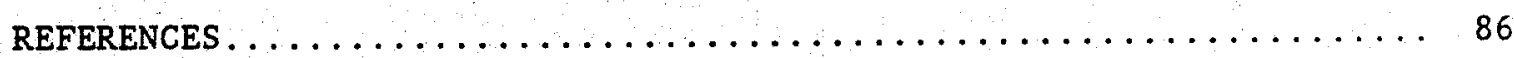

Appendix A. HT-BHTV Software Listing $\ldots \ldots \ldots \ldots \ldots \ldots \ldots \ldots \ldots \ldots$ A-1

Appendix B. HT-BHTV Software Units - Procedure and Function Listing. B-1

Appendix $\mathrm{C}$. Hardware Requirements .................. $\mathrm{C}-1$ 


\section{LIST OF FIGURES}

Figure

Page

II.1. Diagram of the menus in the HT-BHTV software. Note that the Data Acquisition Menu is accessed only from the Tool Setup Menu. The Data Display/Acquisition section is not a menu but it performs all the operations previously set in the other menus.......................... 8

II.2. CRT screen display for the Main Menu................. 9

II.3. Example of the default CRT screen display for the Depth Encoder Setup Menu shown when the Depth Flag variable is

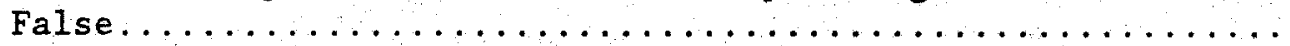

II.4. An example of the CRT screen display for the Tool Setup Menu showing the default settings of the HT-BHTV tool

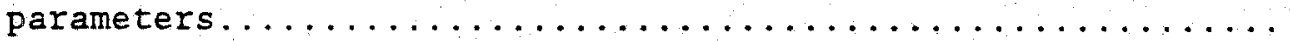

II.5. An example of CRT screen displayed for monitoring the HTBHTV temperatures. The three temperatures available from the tool are shown including the unaltered data (in bits) and the calculated temperature in ${ }^{\circ} \mathrm{C}$. The elapsed time shows the time required to obtain the three temperature values from the tool. This time typically has a value

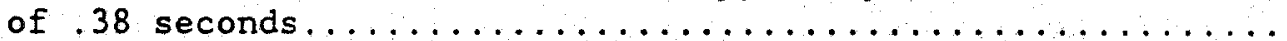

II.6. An example of the CRT screen displayed for the Data Acquisition Menu using the default settings of the data

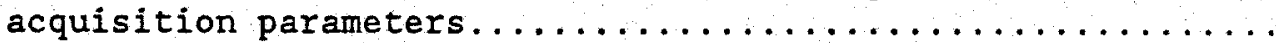

II.7. An example of the positions of the sync threshold, range threshold, and the range window values on a model waveform acquired by the HT-BHTV tool from the ADC board.........

II.8. An example of the CRT screen displayed when the Data Acquisition Test item is selected on the Data Acquisition

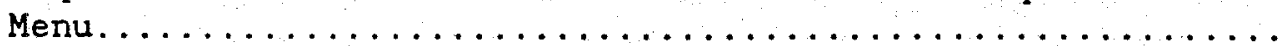

II.9. An example of the CRT screen displayed when the Display acquired waveform item is selected on the Data Acquisition Menu. The default value of 20 video frames is used

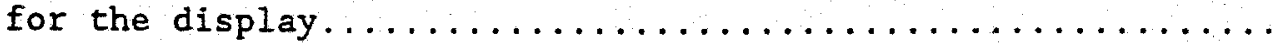

II.10. An example of the CRT screen displayed when the Display acquired waveform item is selected on the Data Acquisition Menu. A value of 5 video frames is used for the

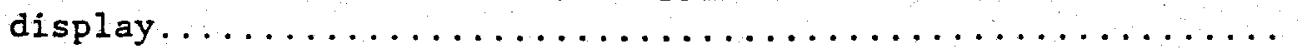


LIST OF FIGURES

Figure

II.11. An example of the CRT screen displayed when the Display acquired waveform item is selected on the Data Acquisition Menu. A value of 200 video frames is used for the

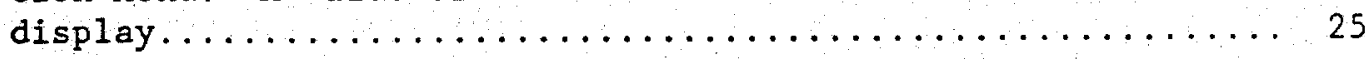

II.12. An example of the CRT screen displayed for the Logging/Data Display Setup Menu with the default values

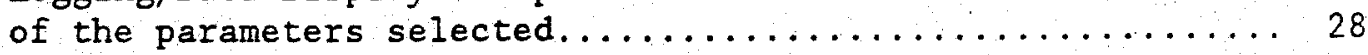

II.13. An example of the CRT screen displayed for the BHTV File Menu when no file has been assigned................ 35

II.14. An example of the CRT screen displayed for the BHTV File Menu when a NEW file is selected.................. 36

II.15. An example of the CRT screen displayed for the BHTV File Menu when a ód file is selected................. 37

II.16. An example of the CRT screen display for the listing of HT-BHTV files on the hard disk which are available for

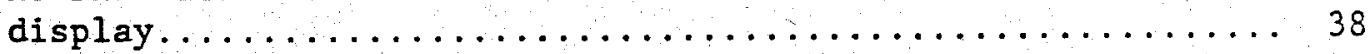

II.17. An example of the CRT screen displayed for the File Display Menu for the initial or default display.......... 42

II.18. An example of the CRT screen displayed for the File Display Menu for the Depth Interval display.............

II.19. An example of the CRT screen displayed for the File Display Menu for the Record Number Interval display......... 44

II. 20. An example of the CRT screen displayed for the Test Parameter/Setup File Menu using the default settings of the flag variables .......................... 48

II.21. CRT screen displayed when the Data Acquisition/Display option is selected in the Main Menu. This example shows the display when the Data Mode variable in the Logging/ Data Display Setup Menu is set to either TEST or BHTV...... 52 


\section{LIST OF FIGURES}

Figure

II.22. CRT screen displayed when the Data Acquisition/Display option is selected in the Main Menu and the Data Mode variable in the Logging/Data Display Setup Menu is set to FILE. This example shows the display when the entire file is to be viewed.

II.23. The Data Display CRT screen for the NORMAL Display Size mode. The numbered areas of the display are explained in

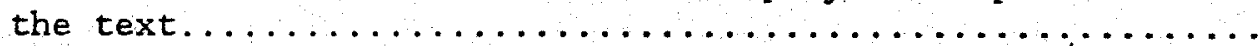

II.24. The Data Display CRT screen for the EXPANDED Display size mode. The numbered areas of the display are explained in

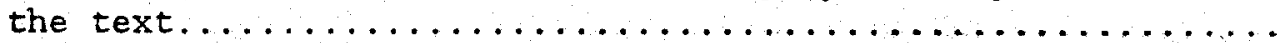

III.1. Schematic diagram of the interconnection of the hardware required for the HT-BHTV system at the surface.......... 68

IV.1. HT-BHTV data obtained during the logging of the sinclair22 well in the Salton Sea Geothermal area illustrating a

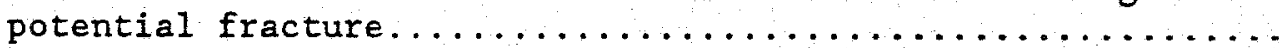

IV.2. HT-BHTV data obtained during the logging of the Sinclair22 well in the Salton Sea Geothermal area illustrating a the effect produced by changing the display window..........

IV.3. HT-BHTV data obtained during the logging of the Sinclair22 well in the Salton Sea Geothermal area illustrating the filtering operation of the display window.......... 84 
LIST OF TABLES

Table

Page

II.1. Devices connected to HT-BHTV computer system......... 4

II.2. List of the menus available in the HT-BHTV software...... 6

II.3. Summary of the possible settings of the user-controlled software flag and operational mode variables and the resultant operation of the software................ 54

II.4. Listing of the eight display sections of the CRT graphics Data Display. Refer to Figures II.23 and II.24 for the positions of these areas on the screen.............. 55

II.5. The information displayed when a screen dump is requested of the software. The information shown here is an example of the information displayed in the FILE Data Mode......62 62

II.6. The default color table used in the HT-BHTV software. The number of the color refers to the default color palette used in Turbo Pascal Version 4.0. Note that color number 0 is black which is used for data outside of the data acquisition or the display windows $\ldots \ldots \ldots \ldots \ldots \ldots 63$

III.1. Listing of the HT-BHTV software units $\ldots \ldots \ldots \ldots \ldots \ldots \ldots \ldots 67$

III.2. Summary of some useful addresses for the INS 8250 UART used on IBM PC compatible computers............... 69

III.3. Command byte sent to the HT-BHTV tool by the computer..... 70

III.4. Summary of Depth Counter commands................ 71

III.5 Summary of information contained in each individual record of the four televiewer data files.............. 72

III.6 Summary of information contained in the Setup Files stored and read by the Test Parameter/Setup File Menu....... 73

III.7 Conversion table used in the software to convert the CRT screen color to a PaintJet printer color............ 77

IV.1. Summary of the data recorded during the Baca-3 well test

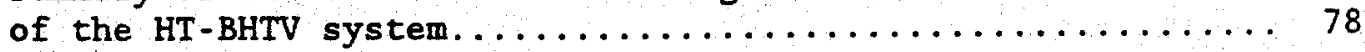

IV.2. Summary of the data recorded during the Salton Sea test of the High Temperature Borehole Televiewer.............80 80

viii 


\section{INTRODUCTION}

The acoustic borehole televiewer (BHTV) is a downhole logging tool which uses a beam of ultrasonic energy from a rotating transducer to produce an acoustic picture of the inside circumference of a wellbore. Since its introduction in 1968, considerable effort has been made to interpret and improve the images of the borehole that are obtained from this tool [1, 2, 3]. The televiewer has been used for fracture detection, casing inspection, and for checking the integrity of casing-cement seals. The data from this tool is typically displayed in two forms. The received amplitude or magnitude of the reflected signal can be displayed to show the reflectivity of the borehole wall. Alternatively, the arrival or transit time of the received signal can be displayed to provide an estimate of the range, in time, or the size, in radius if the sound velocity of the borehole fluid is known. In 1983, researchers at Sandia National Laboratories completed the modifications to a commercially available tool extending its operational range to a temperature of $275^{\circ} \mathrm{C}$ and a pressure of $5000 \mathrm{psi}$ for use in a geothermal environment [4]. The tool modifications included the development of a rotating head transformer, a high temperature transducer, and a redesign of the electronics for high temperature operation.

The Geothermal Drilling Organization jointly funds projects of interest to the geothermal industry using DOE and industry funds [5]. One of these projects was the development of a high temperature borehole televiewer using the modifications from the Sandia BHTV project and incorporating a real-time computer display of the data received from the tool. This report is the user manual for the software developed for the GDO-sponsored borehole televiewer. This software was developed with the goal of providing as simple an environment as possible but still retaining the flexibility of allowing the user to control as many parameters as desired. This software acquires, displays and stores the data obtained from the televiewer in real time - that is, as the tool is logging the borehole.

The software was written in Turbo Pascal Version 4.0 specifically for a Compaq Deskpro $386 / 20$ computer. Data from the tool is digitized using a Metrabyte DAS-20 data acquisition card at a digitizing rate of 100,000 samples/s. Depth information is obtained from a Red Lion Gemini 2000 counter via a RS-232 serial interface using a baud rate of 2400 . The High Temperature Borehole Televiewer (HT-BHTV) may use either a magnetometer or an internal tool mark pulse as a heading reference for the data from the tool. The tool also has two transducers, one at $1.3 \mathrm{MHz}$ and another at $400 \mathrm{kHz}$, for high and low resolution details. The software allows the user to select the heading reference, transducer frequency, and the gain of the tool. In addition, three temperatures from the tool may be monitored via a 300 baud RS-232 serial line. These temperatures include two internal temperatures which monitor the condition of the heat-shield encased electronics and an external borehole fluid temperature. The software allows the user to monitor the data from the tool during the logging operation and to display the stored data for later analy. sis. 
The digitized range and amplitude data obtained from the HT-BHTV tool are displayed on the CRT screen as a single horizontal line. This line represents a single rotation of the tool. The data line provides an unfolded view of the inside diameter of the borehole. The leftmost position of the display indicates the position of the mark pulse or magnetic north when the magnetometer is used. The range data shown on the display are the round-trip distances of the returned signal in units of microseconds. If the sound velocity in the fluid is known, the diameter of the borehole may be estimated from the time of the return signal.

\section{I.1. Organization of the User Manual}

This manual is organized into several sections allowing the user a rapid reference for information pertaining to the software operation. Section II describes the operation of the software. Each of the menus is discussed in detail explaining the various options allowed by the software. At first glance, the number of options allowed in the software appears to make the operation of the tool by the software very difficult. However, the software was designed to allow the user to control many of its parameters. With a little understanding of the capabilities of both the software and the HT-BHTV tool, the user will quickly discover the usefulness of this software approach. Also described in Section II is the screen display of the data obtained from the tool. Section II concludes with a short discussion of data backup and briefly describes a temperature acquisition program that can be used to acquire tool temperatures during a logging operation. Because of the limitations involved with the high speed data acquisition/display process and the low speed communication over the serial interface line with the tool, this version of the software cannot simultaneously acquire acoustic and temperature data from the tool using a single computer. A second computer system (any IBM $P C$ compatible system can be used) is required for the temperature acquisition. Section III provides more detail on certain aspects of the software operation. It describes the communication procedure with the tool and the depth counter. The format of the files used for data storage is described. More detail is provided about the data acquisition using the digitizing board and the processing performed on the tool data before its display on the CRT screen. Finally, some discussion is given concerning the color printing of the CRT screen. Section IV summarizes the results of two field tests which were used to test the tool and software under actual logging conditions. Some data is presented illustrating the capabilities of the HT-BHTV system to detect wellbore features. Section $V$ concludes the user manual with a brief discussion of possible improvements that can be made in both the software and the computer-related hardware. An appendix is included providing a description of the hardware requirements of the computer system. 


\section{OPERATION OF THE BHTV SOFTWARE}

The software for the High Temperature Borehole Televiewer (HT-BHTV) is written in a menu-driven format which allows ease of use and provides a flexible operation for the user. In this section, the capabilities of each menu are explained, the information displayed on the CRT screen when the data is being acquired and/or displayed is discussed, and the section concludes with a brief discussion of data storage on tape and temperature acquisition from the tool.

\section{II.1. Starting the HT-BHTV program}

The HT-BHTV software is designed so that the user requires little knowledge of the program file structure for the correct operation of the software. A complete description of the file structure used in the software may be found in Section III of this manual. Briefly, the data stored by this program is contained in the directory labeled BHTVDATA. The program requires two text files (containing the extension. TXT) in the directory containing the main program. These files are labeled VDISK.TXT and BHTVPATH.TXT. The former file contains the path name for the virtual RAM disk drive which temporarily stores the data obtained from the tool. The latter file contains the path name for the hard disk drive containing the BHTVDATA directory which contains all the data from the tool. Note also that no TSR (terminate stay resident) programs (for example, Sidekick) should be present on the system.

The computer system has an internal Analog-to-Digital Converter (ADC) card installed in one of the available slots. This card digitizes the waveform data from the HT-BHTV tool (see Section III for a further discussion of the data acquisition process and Appendix A for the hardware requirements of the system). This digitized data are used by the software to find the range and magnitude values of the data according to certain user-supplied threshold values and time windows. Because of an unknown memory conflict when this board is used, the user must first, in effect, initialize the system with this board before any data can be obtained from the tool. If this prior initialization is not performed, the computer will lock up requiring either a cold or warm boot (these are described later in this section) to restart. If the ADC card will not be used, this initialization procedure is not necessary. The initialization procedure is begun by typing at the $\mathrm{C}>$ prompt:

\section{C> BHTVINIT}

The first time, the system will display the screen for the Data Acquisition Test from the Data Acquisition Menu (refer to Section II.5.4). However, the test may fail this first time. Typing the above command again should produce a working display if the HT-BHTV is working and properly connected. If a working display is obtained, the system has been properly initialized and the HT-BHTV software may be started by pressing any key. 
To start the HT-BHTV program without initializing the ADC board, type in the following followed by a return at the $C>$ prompt:

\section{C> HTBHTV}

This command calls a batch file of the same name which sets the computer into the proper directory and the starts the HT-BHTV program contained in the file BHTVMAIN. EXE. This procedure is used when the ADC board will not be used in the software operation. For example, when only stored data will be displayed. This procedure is also used for displaying stored data when the ADC board is not present on the computer system.

If a failure occurs in the software, two things will happen. The computer will exit the software and return to the operating system. The software may simply be restarted as shown above. If, however, the software fails to respond in either a menu or the data display operation then the user must first press $C t 1-C$ or $C t 1$-Break. If pressing these keys result in exiting the software, then the program can be restarted. If these keys produce no response, then either a warm or cold boot of the system is required. A warm boot is accomplished by resetting the computer by pressing Ctl-Alt-Del. If there is no response, then it is necessary for a cold boot of the system. Turn the computer off, wait a few seconds, and turn the computer on. The HTBHTV software may then be started using the procedure described above.

\section{II.2. Connection of Input/Output devices}

The HT-BHTV software requires several Input/Output (I/O) devices for the acquisition of the tool and depth data. The complete hardware requirements of the system are listed in Appendix A. Table II.2 summarizes the devices and the connections to the computer.

Table II.2. Devices connected to HT-BHTV computer system.

\begin{tabular}{|c|c|}
\hline Computer port & Device \\
\hline $\begin{array}{l}\text { COM1 } \\
\text { COM2 } \\
\text { LPT1 }\end{array}$ & $\begin{array}{l}\text { Serial converter for Depth Counter } \\
\text { Serial I/O of HT-BHTV Tool } \\
\text { Color printer (parallel interface) }\end{array}$ \\
\hline
\end{tabular}




\section{3. User-Controlled Software Flags}

There are three software flags that are controlled by the user. These three flags are the Tool Flag, the Depth Flag, and the Temperature Flag. Each flag is a boolean-type variable having a value of either True or False. The flags are accessed by the Test Parameter/Setup File Menu. When the Tool Flag is set to True, the software will expect the HT-BHTV tool to be connected and operating. When data acquisition and display is selected, the program will attempt to acquire data from the HT-BHTV tool. (WARNING: If the tool is not connected and operating and the Tool Flag is set to True, it is possible to lock up the computer so that either a warm or cold boot is required for computer restart.) If the Tool Flag is set to False, the software will not attempt to access the tool and will display simulated data if that is the function selected. The Depth Flag controls access to the depth counter system. When set to True, the depth counter system must be connected and activated. In this setting the program will acquire the depth information from the counter when required. When set to False, the software will simulate depth data when required by the program operation. The Temperature Flag is used for the acquisition of temperature data from the HT-BHTV tool. It is used in conjunction with the Tool Flag to specify to the software where to obtain the temperature data. If both the Tool Flag and the Temperature Flag are True, the temperature data will be obtained from the HT-BHTV tool. If the Tool Flag is set to False and the Temperature Flag is set to True, the program will simulate the temperature data. If the Temperature Flag is False, no temperature data will be acquired or displayed.

\section{II.4. Modes of Operation of the Software}

The software has three modes of operation which direct it for the proper acquisition, storage, or retrieval of data. These three modes are called the TEST, BHTV, and FILE mode. The current mode value is stored in the Data Mode variable and is selected from the Logging Setup menu which will be described in more detail later in this section. In the TEST and the BHTV mode, the setting of the Tool Flag directs the software to either acquire data from the HT-BHTV tool or to compute simulated data. The TEST mode displays the data from the tool or the simulated data. The BHTV mode displays the data as in the TEST mode but, in addition, the data is stored in the file designated previously in the File Menu. The FILE mode is used to retrieve and display data previously stored to the hard disk. The setting of the Tool Flag is unimportant to the operation of this mode. If the File Display Menu is called and a file has been opened in the BHTV File Menu, then the software automatically sets the operational mode to FIIE. Table II.3 in Section II.6 on the Data Acquisition and Display operation of this software summarizes the possible settings of the flag and Data Mode variables. 


\section{II.5. Menu Descriptions}

The software consists of a set of eight menus divided according to their function. Table II.2 lists these eight menus. The function and operation of each of these menus will be discussed.

Table II.2. List of the menus available in the HT-BHTV software.

Main Menu

Depth Encoder Setup Menu

Tool Setup Menu

Data Acquisition Menu

Logging/Data Display Setup Menu

BHTV File Menu

File Display Menu

Test Parameter/Setup File Menu

In the next part of this section, the operation of each menu is described. Figure II.1 gives a block diagram of each of these menus including the Data Acquisition/Display unit of the software.

\section{II.5.1. Main Menu}

The Main Menu is the menu displayed when the software is started and provides the link to all the other menus available in the software. . The menu displayed on the CRT screen is shown in Figure II.2. All except the Data Acquisition/Display selection call up another menu. As shown in Figure II.1, the Data Acquisition Menu can only be accessed through the Tool Setup Menu. This was done in this manner because the function of the Data Acquisition Menu is to set up the parameters of the $A D C$ and to test the data acquisition from the tool. The Data Acquisition/Display selection is, of course the major function of this software. Its operation will be described following the description of the other menus. In this and all other menus in the software, the user may move among the items in the menu using the up or down arrow keys or by using a number key if the items have a number. The current item is highlighted and may be selected by pressing the return key. The items shown in the Main Menu CRT screen display in Figure II. 2 will be briefly described.

Menu Item: 1) Setup/Initialize BHTV Tool

Function: Enters the Tool Setup Menu which permits the user to modify the various tool parameters. Also, the Data Acquisition Menu is accessed from this item. 
Menu Item: 2) Setup/Check Depth Encoder System

Function: Enters the Depth Encoder Setup Menu from which the operation of the depth counter system can be checked.

Menu Item: 3) Set Logging Parameters

Function: Enters the Logging/Data Display Setup Menu. This menu allows the user to change many parameters affecting the display of the televiewer data on the CRT screen.

Menu Item: 4) Set Up Files for Data Storage

Function: Enters the BHTV File Menu which selects the file for display or data storage. In addition, pertinent information about the hard disk on the computer is displayed.

Menu Item: 5) Begin Data Acquisition and Display

Function: Selecting this item directs the software to begin the acquisition and/or display of televiewer data. The operations actually performed here depend on the conditions specified by the user in the eight menus in the HI-BHTV software.

Menu Item: 6) Display Stored Data

Function: Enters the File Display Menu which allows the user to select a portion of a data file to display. Either a depth or a record number interval may be selected.

Menu Item: 7) Display/Modify Test Parameters

Function: Enters the Test Parameter/Setup File Menu. This menu sets the user-controlled software flags and also allows the user to store or read a previously stored file containing certain software parameters. 


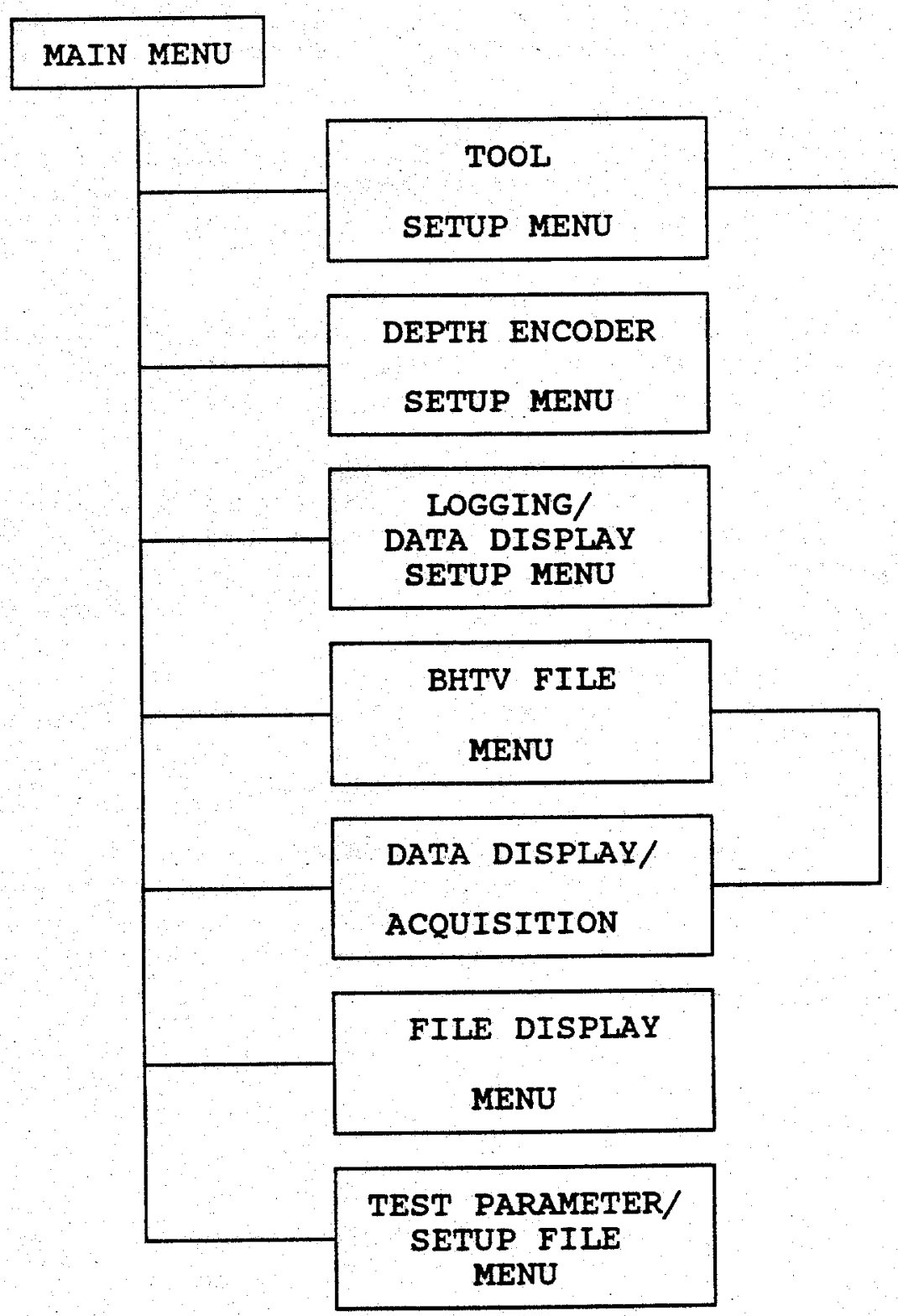

Figure II.1. Diagram of the menus in the HT-BHTV software. Note that the Data Acquisition Menu is accessed only from the Tool Setup Menu. The Data Display/Acquisition section is not a menu but it performs all the operations previously set in the other menus. 


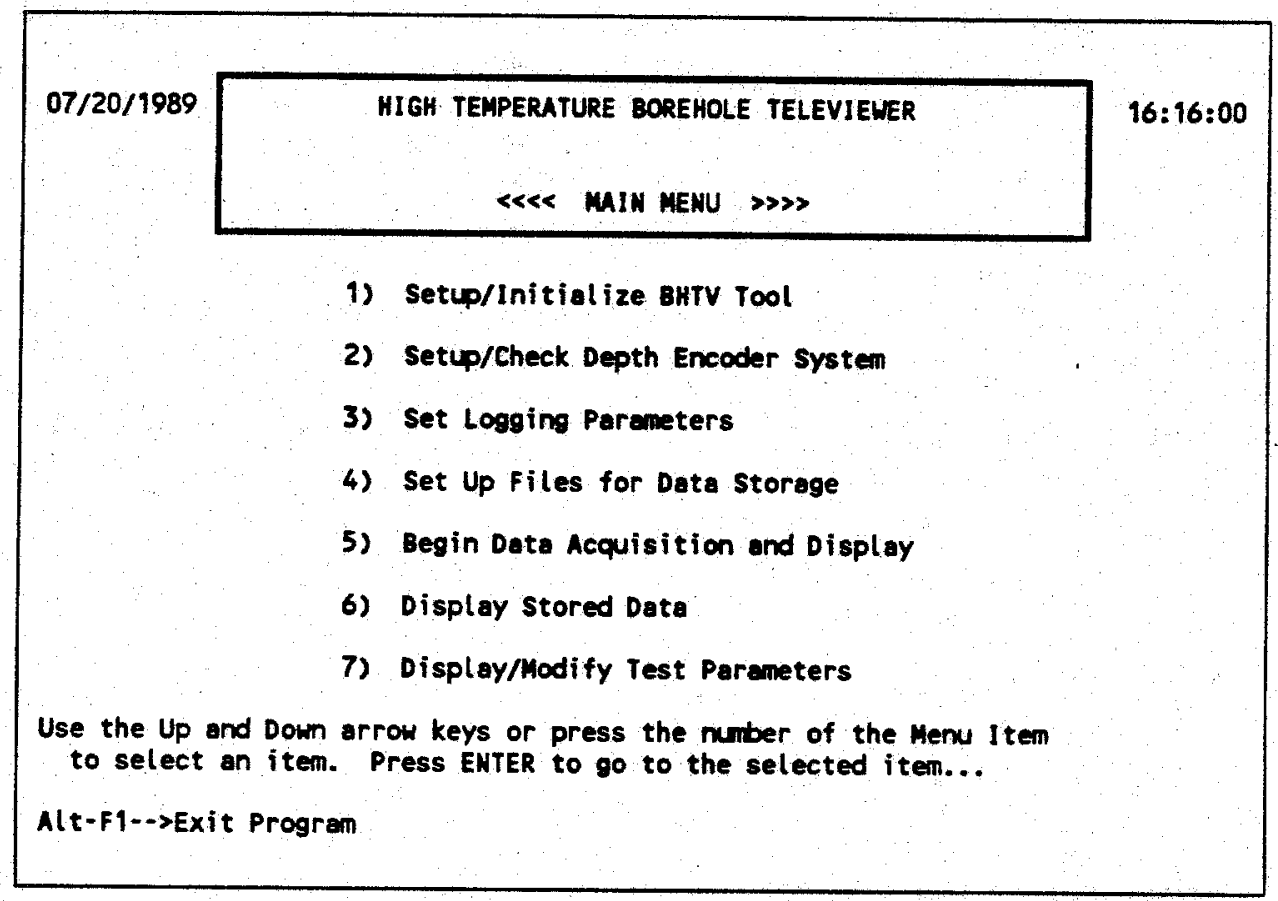

Figure II.2. CRT screen display for the Main Menu. This display illustrates the format used in the other menus. Each menu has a header which gives the menu name. On either side of the menu the current machine date and time are displayed. (Note: If either the date or time displayed in the menus is incorrect, the user should exit the program, returning to the operating system, and correct them. The machine date and time are stored in the data files during the data acquisition process.) Below the header is a list of menu selections. The current menu selection, which can be activated by pressing the Enter key, is shown highlighted. On some menus, an item selection message is displayed below the list of menu selections. Finally, the function key (or keys) that, when pressed, exit the menu, end the program, or perform some other operation are displayed at the bottom of the screen. 


\section{II.5.2. Depth Encoder Setup Menu}

The CRT screen display for the Depth Encoder Menu is shown in Figure II.3. The purpose of this menu is to setup and test the depth counter connected to the computer using the serial port COMI. The counter itself is a Gemini 2000 model which is connected to an optical encoder mechanically attached to the cable or the cable drum assembly. The counter has a nonvolatile memory which stores the last values of the Preset and Scale Factor. When the Depth Flag is True, the software interrogates the counter for the Preset and Scale Factor values. If the counter does not respond, the first error message shown in the error message section is displayed. The current menu item is highlighted and may be selected by pressing the Return or Enter key. To move between the menu items, the user may either select the number of the desired item or move between the items by using the up or down arrow keys. As shown in the example in Figure II.3, each menu item has a short descriptive message explaining the function of the highlighted menu selection. The functions of the four menu items in this menu are described below:

Menu Item: Default Value: Other Values: Function:

Menu Item: Default Value:

Other Values:

Function:

Menu Item:

Default Value:

Other Values:

Function:
Reset Counter

Not Applicable

Not Applicable

Resets the counter to the preset value stored in the counter.

\section{Scale Factor}

If Tool Flag is True then the scale factor stored in the counter is displayed. If False, a value of 1.0000 is displayed.

Allowed Range:

$-5.9999 \leq$ Scale Factor $\leq+5.9999$

When Tool Flag is True, this item displays the current scale factor stored in the counter. Pressing the ENTER key allows the user to store a new scale factor in the counter. When the new factor has been entered in the counter, the counter display will change according to the new factor. The counter should be reset to the previously stored preset value.

\section{Preset Value}

If Tool Flag is True then the preset value stored in the counter is displayed. If False, a value of 0.00 is displayed.

Allowed range : $-9999.99 \leq$ Preset Value $\leq+9999.99$ (when the counter is set to display 2 decimal places). When Tool Flag is True, this item displays the current preset value stored in the counter. Pressing the ENTER key allows the user to store a new preset value 


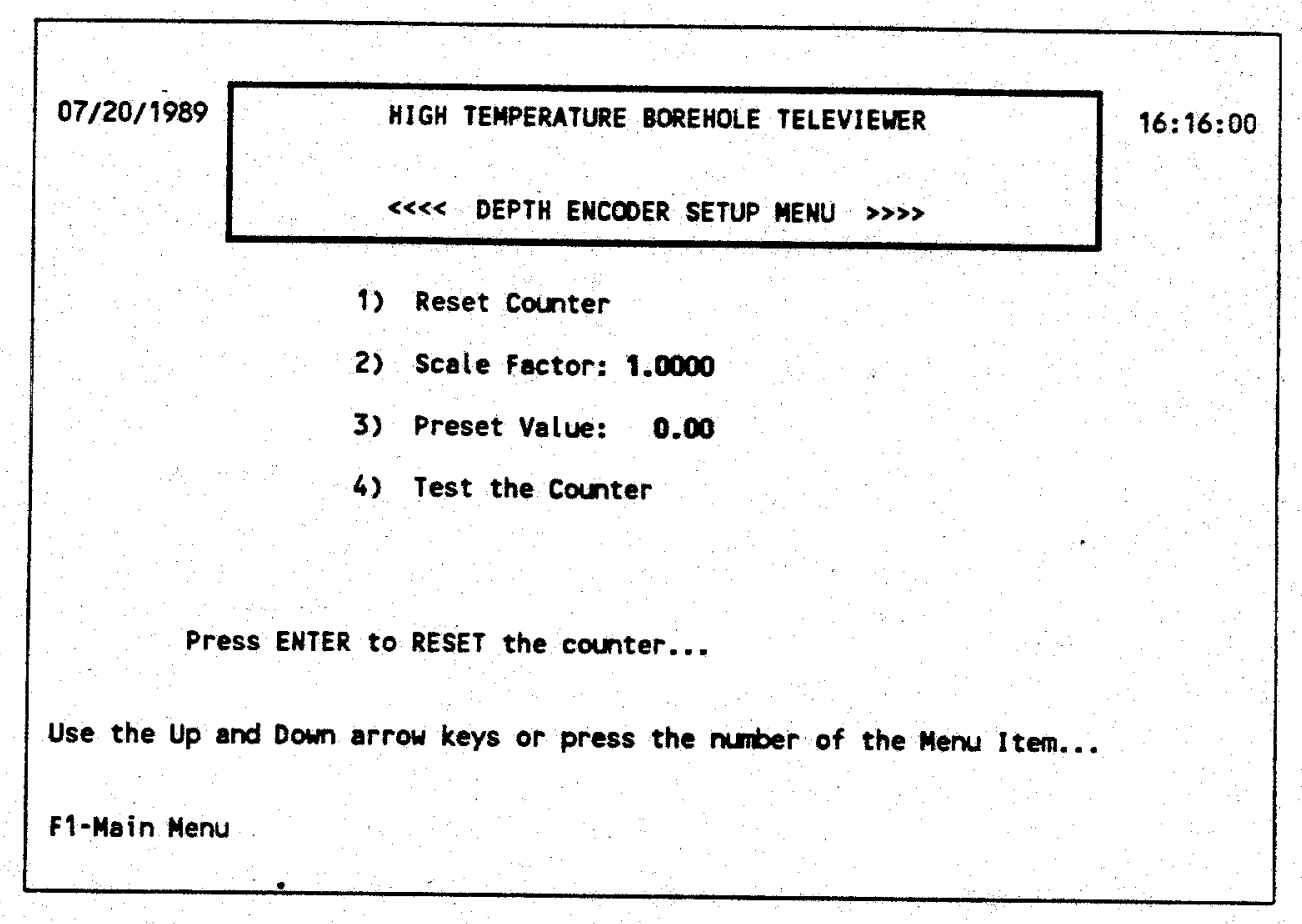

Figure II.3. Example of the default CRT screen display for the Depth Encoder Setup Menu shown when the Depth Flag variable is False.

\author{
in the counter. Resetting the counter sets the coun- \\ ter display to the new preset value. \\ Menu Item: \\ Default Value: \\ other Values: \\ Function: \\ Function key:

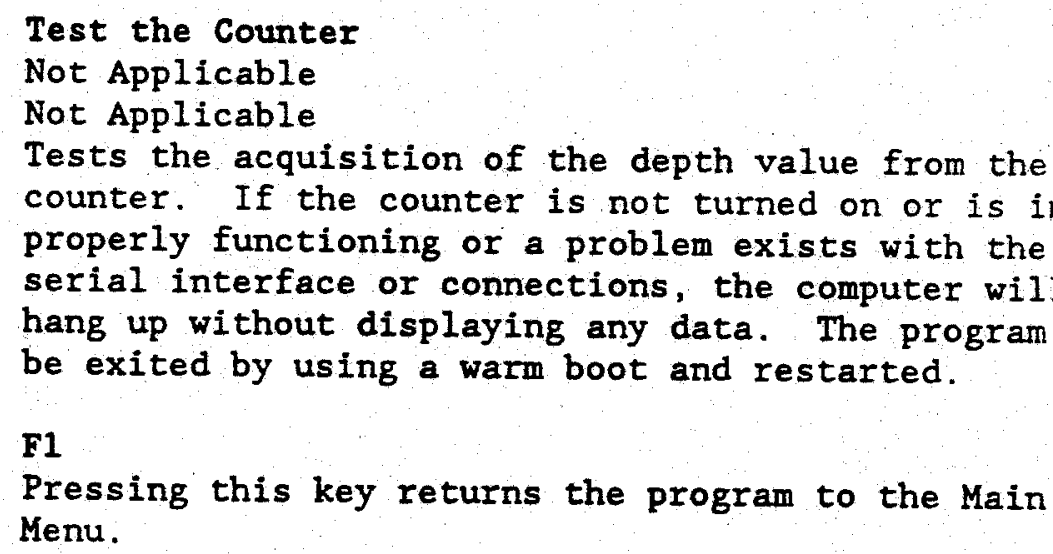
properly functioning or a problem exists with the be exited by using a warm boot and restarted.

$\mathbf{F 1}$ Pressing this key returns the program to the Main Menu. \\ counter. If the counter is not turned on or is im- \\ serial interface or connections, the computer will \\ hang up without displaying any data. The program must
}




\section{II.5.2.1 Error Messages}

In this menu, the software allows the user to enter new values for the Preset value and the Scale Factor. If the Depth Flag is False, no data entry is permitted. All error messages are displayed in the data entry window for a few seconds after which the software returns to the menu. The user must select the item again and properly enter the desired value. With the Depth Flag set to True and the counter turned on and connected to the computer, the following error messages may be displayed after the user has entered a change in one of the values:

Error Message: Problem:

Error Message:

Menu Item:

Problem:

Error Message:

Menu Item:

Problem:

Error Message: Menu Item:

Problem:

Error Message: Menu Item:

Problem:

Error Message: Menu Item: Problem:
Depth Counter not responding on Serial port! No response was obtained from the depth counter when the Depth Flag is True. The counter was not turned on, connected to the wrong port, or some other problem may exist. The software changes the value of the Depth Fleg to False.

Error in the input data...

All data input selections.

Incorrect data entry; for example, a letter rather than a numeral value may have been entered.

Scale Factor outside of range: $-5.9999<$ Factor $<=$ 5.9999

Scale Factor

The value entered is outside the allowed range of the Scale Factor for the counter.

Scale Factor not entered into counter...

Scale Factor

A timeout has occurred in checking that the new Scale Factor value was received by the counter. Previous experience has shown that the counter has indeed received the new Scale Factor but a problem occurred sending this data back to the computer.

Preset Value outside of range: $-10,000<$ Value $<10,000$ Preset Value The value entered is outside the allowed range of the Preset value for the counter.

Preset Value Factor not entered into counter... Preset Value

A timeout has occurred in checking that the new Preset Value was received by the counter. Previous experience has shown that the counter has indeed received the new Preset value but a problem occurred sending this data back to the computer. 


\section{II.5.3. Tool Setup Menu}

The CRT screen displayed for the Tool Setup Menu is shown in Figure II.4. This menu sets up the tool parameters (i.e., the gain, transducer frequency, and the heading reference) and checks the temperature acquisition from the tool. The Data Acquisition Menu, which is called from the Tool setup Menu, sets the ADC and software parameters for data acquisition from the tool and tests this data acquisition. The current menu item is highlighted and may be selected by pressing the Return or Enter key. To move between the menu items, the user may either select the number of the desired item or move between the items by using the up or down arrow keys. As shown in the example in Figure II.4, each menu item has a short descriptive message explaining the function of the highlighted menu selection. The following parameters can be changed in this menu:

\section{Menu Item: \\ Default Value: \\ Other Values: \\ Function:}

Menu Item: Default Value: Other Values: Function:

Menu Item: Default Value: Other Values: Function:

\author{
Tool Gain \\ $\mathrm{x} 1$ \\ $\mathrm{x} 10, \times 50$ \\ Sets the tool gain to the value displayed.
}

Transducer Frequency

High (1.3 $\mathrm{MHz}$ crystal)

Low $(400 \mathrm{kHz}$ crystal)

Sets the transducer frequency to the value displayed. The HT-BHTV tool has two transducers available for use. The HIGH setting selects the higher frequency transducer having a frequency of $1.3 \mathrm{MHz}$. This trans. ducer frequency is the preferred setting since the higher frequency provides more resolution allowing observation of finer details on the walls of the borehole. The Low setting, a frequency of $400 \mathrm{kHz}$, provides a low resolution view of the borehole.

\section{Heading Reference \\ Mark \\ Magnetometer}

Sets the Heading Reference to the value displayed. A value of Mark selects the internal tool mark. This is typically used when the tool is used inside casing or if the formation contains a high percentage of magnetic material. The Magnetometer setting uses the internal magnetometer so that the display may be referenced to magnetic north. 


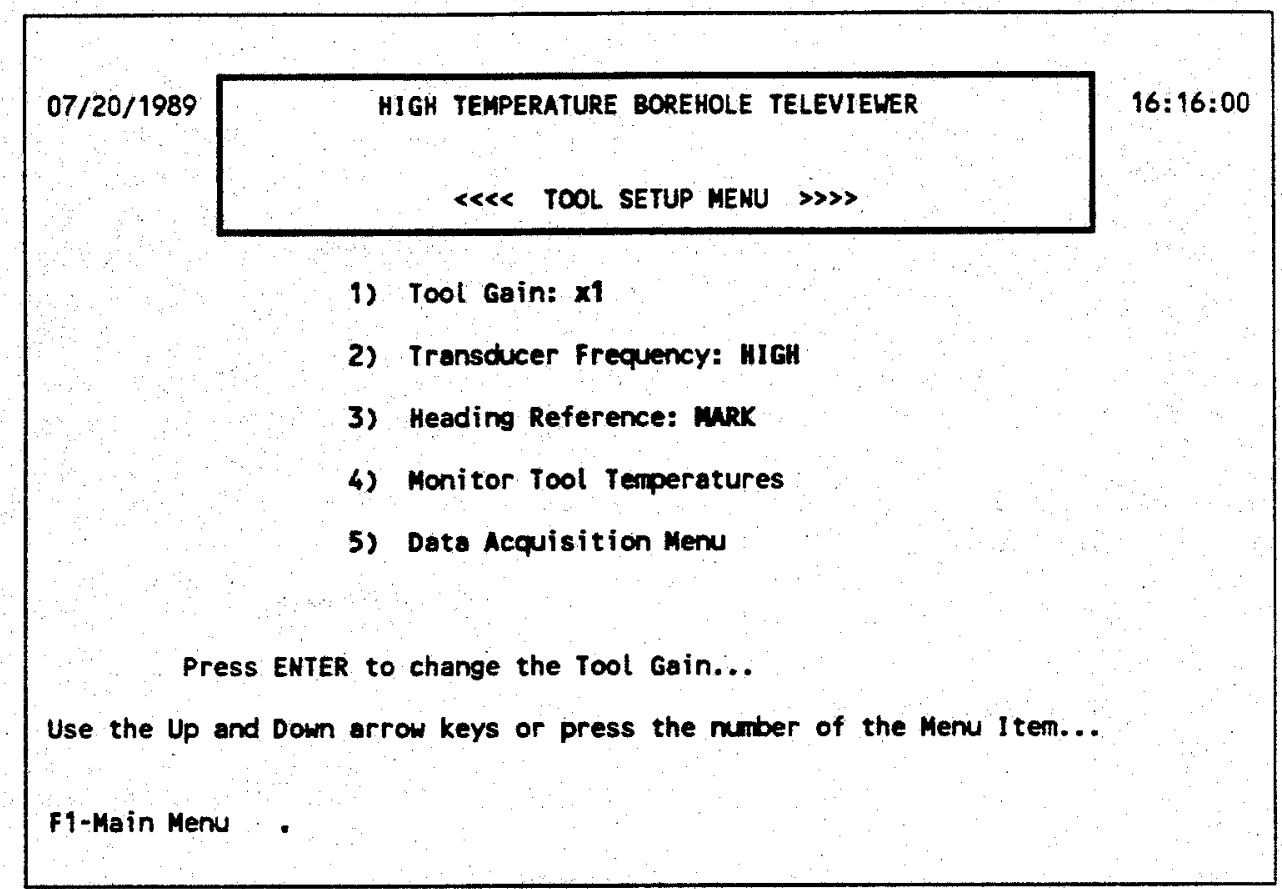

Figure II.4. An example of the CRT screen display for the Tool Setup Menu showing the default settings of the HT-BHTV tool parameters.

$\begin{array}{ll}\text { Menu Item: } & \text { Monitor Tool Temperatures } \\ \text { Default Value: } & \text { Not Applicable } \\ \text { Other Values: } & \text { Not Applicable } \\ \text { Function: } & \text { This item checks the serial connection to the tool and } \\ \text { the temperature sensors in the tool by monitoring the } \\ \text { available temperatures. Three temperatures are re- } \\ \text { turned by the tool. These are the heat sink, elec- } \\ \text { tronics, and the well temperature. An example of the } \\ \text { CRT display shown while the tool temperatures are } \\ \text { monitored is provided in Figure II. } 5 \text {. The heat sink } \\ \text { and electronics temperatures monitor the internal tool } \\ \text { temperature. The electronics in the tool has a maxi- } \\ \text { mum temperature limit of } 150^{\circ} \mathrm{C} \text {. The well temperature } \\ \text { gives the temperature of the well fluid surrounding } \\ \text { the tool. The mechanical section of the tool has a } \\ \text { maximum temperature limit of } 275^{\circ} \mathrm{C} \text {. }\end{array}$




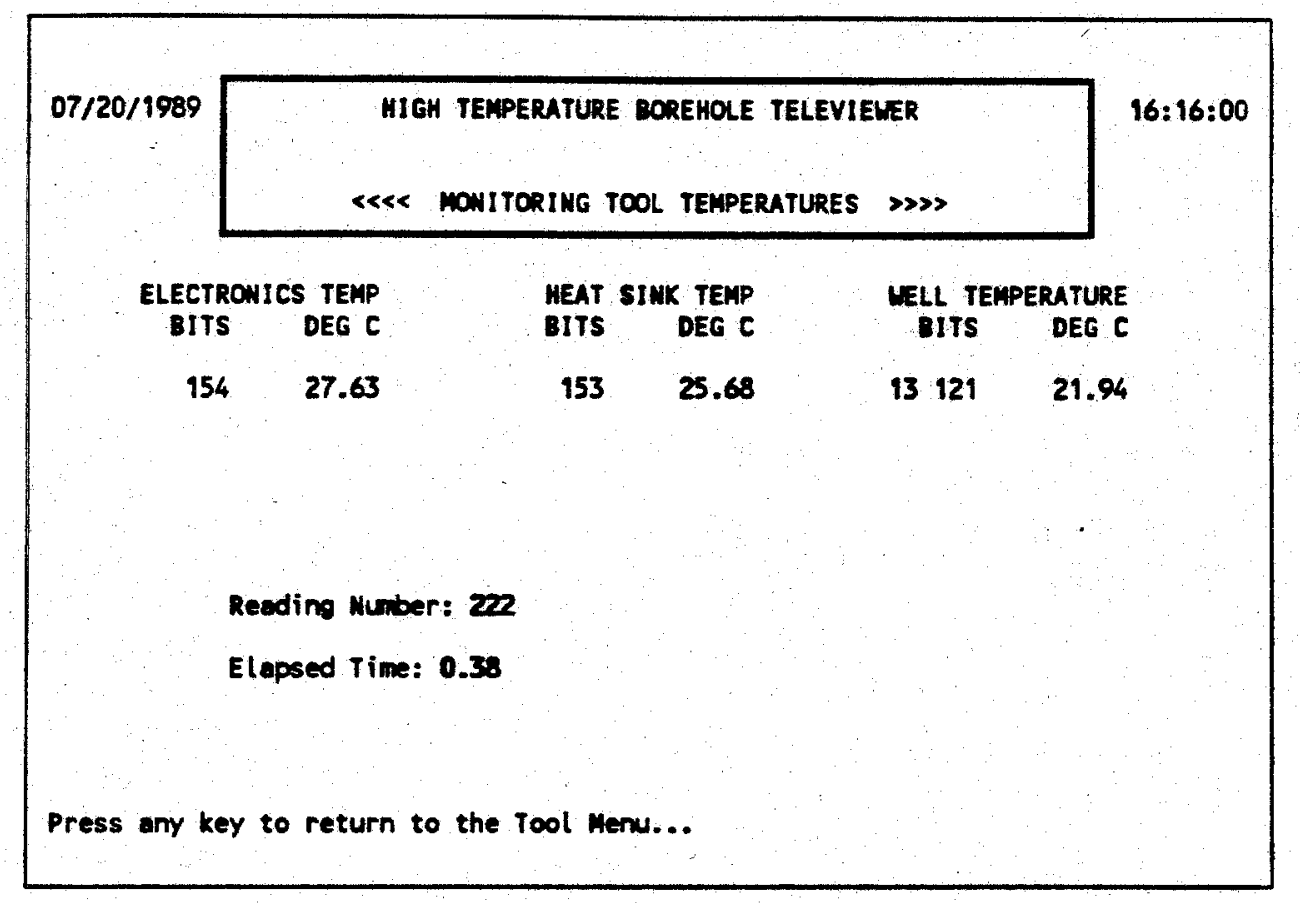

Figure II.5. An example of CRT screen displayed for monitoring the HT-BHTV temperatures. The three temperatures available from the tool are shown including the unaltered data (in bits) and the calculated temperature in ${ }^{\circ} \mathrm{C}$. The elapsed time shows the time required to obtain the three temperature values from the tool. This time typically has a value of .38 seconds.

\footnotetext{
Menu Item: Data Acquisition Kenu

Default Value: Not Applicable

Other Values: N Not Applicable

Function: This item calls the data acquisition menu which is explained in detail below.

Function key: $\quad$ F1

Pressing this key returns the program to the Main Menu.
}

\section{II.5.3.1 Error Kessages}

There are no error messages associated with this menu. However, if the computer is not properly connected to the HT-BHTV tool through the Surface Unit, the computer may hang up. 


\section{II.5.4, Data Acquisition Menu}

The CRT screen display for the Data Acquisition Menu is shown in Figure II.6. This menu allows the user to set up the ADC board in the computer and view the waveform acquired by this board. A complete description of this bcard and its operation is provided in section III. The current menu item is highlighted and may be selected by pressing the Return or Enter key. The user moves between the menu items with the up or down arrow keys. The functions of the menu items shown in Figure II. 6 are described below:

Menu Item:

Default Value:

Other Values:

Function:
Menu Item:

Default Value:

Other Values:

Function:

Menu Item:

Default Value:

Other Values:

Function:

\section{Digitizer Gain}

$\mathrm{x} 1$

$\times 2, \times 20, \times 200$.

Sets the gain of the digitizer board in the computer to the displayed value. The available gain values and the corresponding full scale voltage values are:

$\begin{array}{ll}\times 1 & \pm 10 \text { volts } \\ \times 2 & \pm 5 \text { volts } \\ \times 20 & \pm 500 \text { millivolts } \\ \times 200 & \pm 50 \text { millivolts }\end{array}$

Sync. Threshold

-2.441 volts

Allowed maximum range (dependent upon the Digitizer Gain Setting):

+10 volts $\geq$ sync. Threshold $\geq$ - 10 volts.

Sets the value of the sync pulse threshold value to the displayed number. The sync threshold value is used by the software to check for the presence of a sync pulse. It is suggested that the user run the Data Acquisition Test and Display the acquired waveform after changing this parameter to be sure that the new value can be used to properly find the sync pulses from the HT-BHTV tool. Figure II.7 illustrates the positions of the threshold and window values on a model waveform.

\section{Range Threshold}

0.977 volts

Allowed maximum range (dependent upon the Digitizer Gain Setting):

+10 volts $\geq$ Range Threshold $\geq-10$ volts.

Sets the alue of the range threshold value to the displaye number. The range threshold value is used by the software to check for the presence of a return signal from the side of the borehole. If the signal level is too low, then the data value will be 0 and 


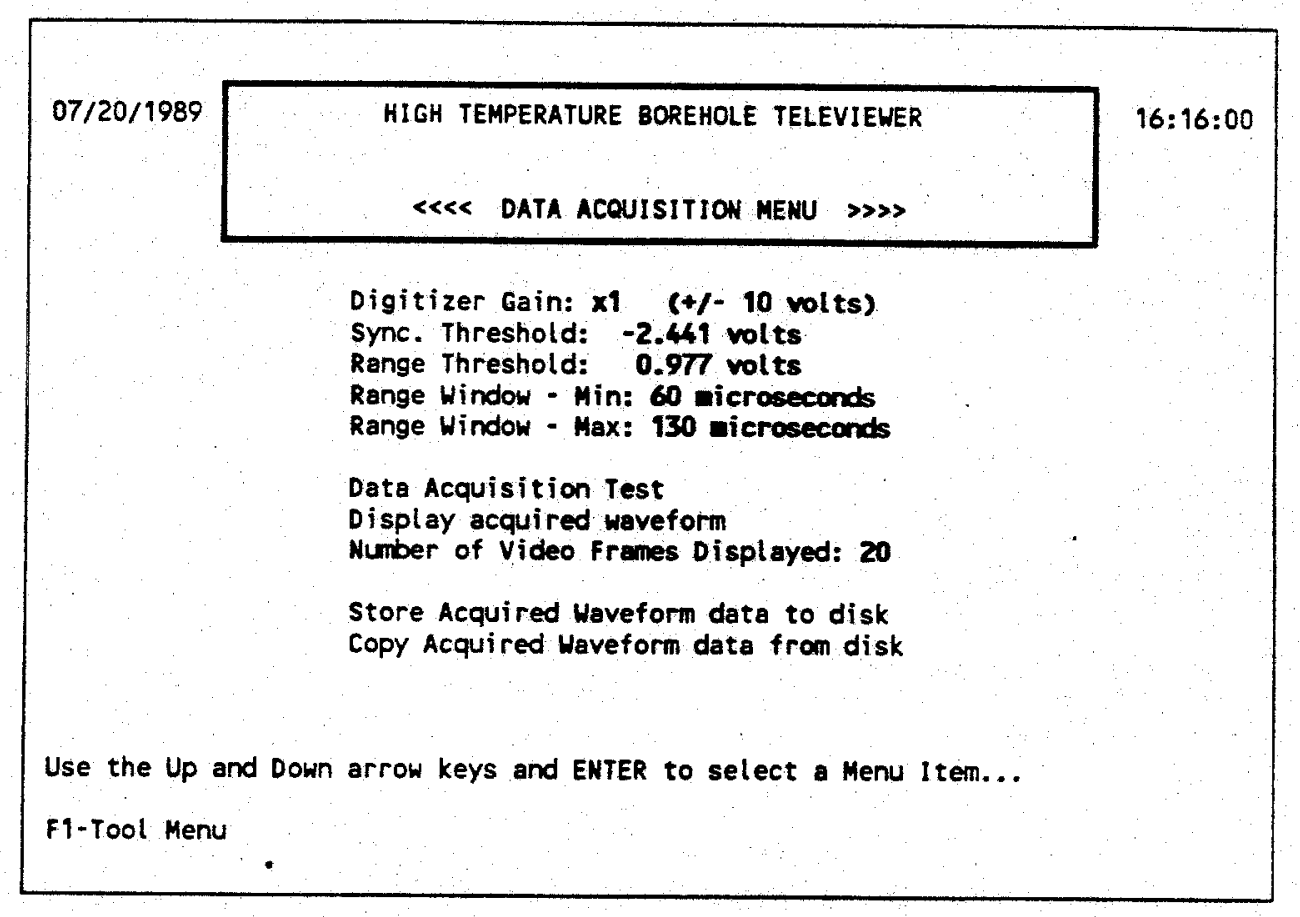

Figure II.6. An example of the CRT screen displayed for the Data Acquisition Menu using the default settings of the data acquisition parameters.

$\begin{array}{ll}\text { Menu Item: } & \text { Range Window - Min } \\ \text { Default Value: } & 60 \text { microseconds } \\ \text { Other Values: } & \text { Allowed Range: } \\ & 0 \text { < Range Window - Min < Range window - Max } \\ \text { Function: } & \text { Sets the minimum value of the range window to the } \\ & \text { displayed number. The range window is used by the } \\ & \text { software to check for the presence of a return signal } \\ \text { from the side of the borehole. If the signal level is }\end{array}$


Menu Item:

Default Value:

Other Values:

Function:

Menu Item:

Default Value:

Other Values:

Function: outside of the window defined by the minimum and the maximum window values, then the data value will be 0 and the software will display black on the screen. It is suggested that the user run the Data Acquisition Test and Display the acquired waveform after changing this parameter to be sure that the new value can be used properly to find the desired return signal from the tool. Figure II.7 shows how the program uses the value of this parameter to find the return signals from the waveform acquired from the HT-BHTV tool.

\section{Range Window - Max}

130 microseconds

Allowed Range:

Range Window - Min $<$ Range Window - Max $<500$ microseconds.

Sets the maximum value of the range window to the displayed number. The range window is used by the software to check for the presence of a return signal from the side of the borehole. If the signal level is outside of the window defined by the minimum and the maximum window values, then the data value will be 0 and the software will display black on the screen. It is suggested that the user run the Data Acquisition Test and Display the acquired waveform after changing this parameter to be sure that the new value can be used properly to find the desired return signal from tool. Figure II.7 shows how the program uses the value of this parameter to find the return signals from the waveform acquired from the HT-BHTV tool.

\section{Data Acquisition Test}

Not applicable.

Not Applicable.

This menu item tests the data acquisition by the ADC board from the HT-BHTV tool. During the data acquisition, the acquired waveform data is stored in a default file on the virtual disk set up in the RAM of the computer. The waveform data is constantly overwritten in this file as illustrated by the record number displayed on the screen during this test. On the CRT screen, the number of heading pulses and sync pulses found by the software are displayed. Also, the 


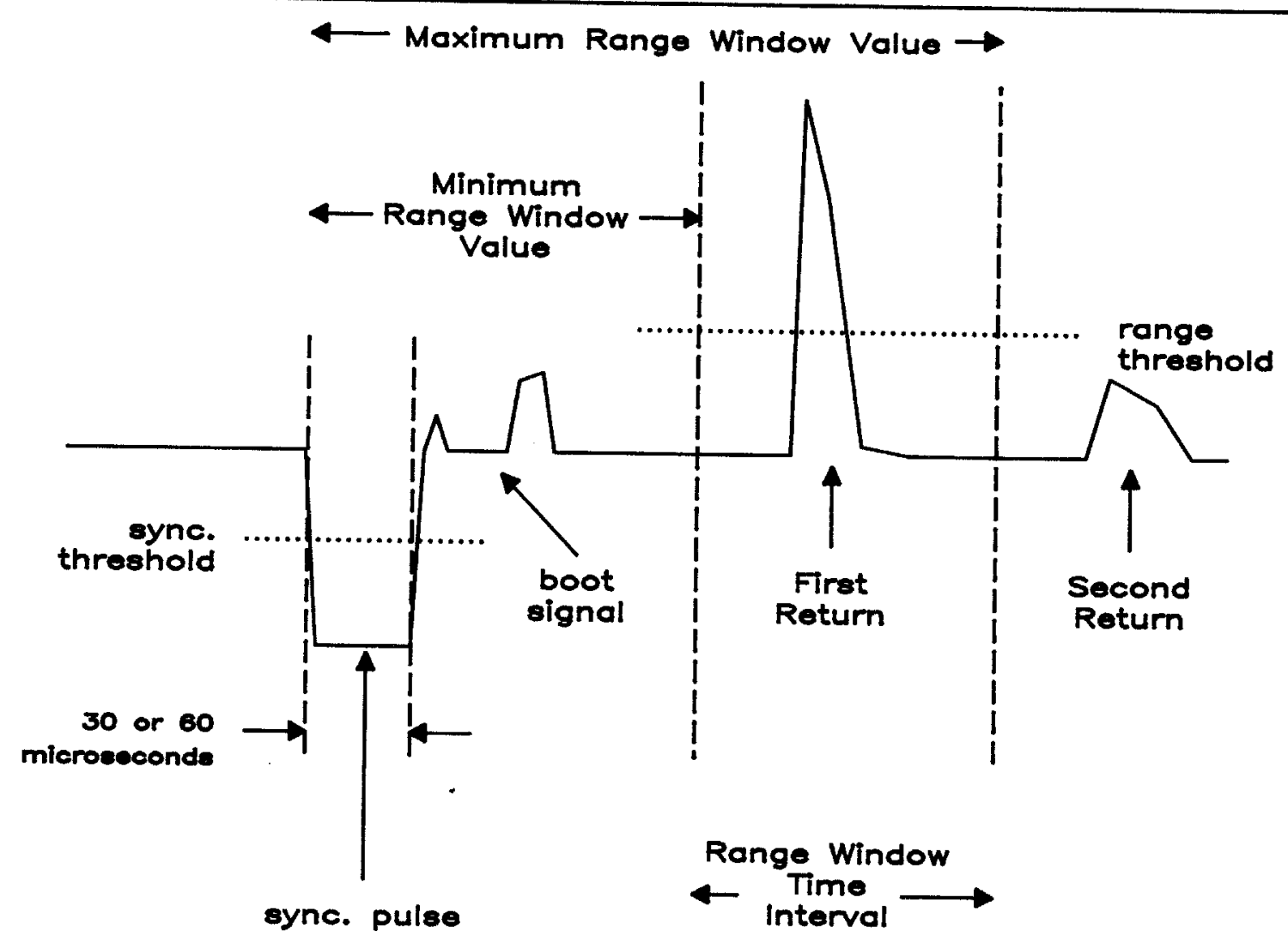

Figure II.7. An example of the positions of the sync threshold, range threshold, and the range window values on a model waveform acquired by the HT-BHTV tool from the ADC board. The sync threshold value is used to define a sync or heading pulse. Sync pulses have a width of $30 \mu \mathrm{s}$, whereas, a heading pulse has a width twice that of the sync pulse. The minimum and maximum values of the range window are measured from the negative slope of the sync pulse. The boot signal typically extends to about $60 \mu \mathrm{s}$; this tends to interfere with signals from small diameter boreholes. 
difference between two heading pulses is calculated and displayed. This difference depends upon the rotation rate of the tool. The optimum values for the heading pulse difference as a function of the tool rotational speeds are:

$\begin{array}{cc}\text { Tool Speed (rps) } & \text { Heading Difference } \\ 3 & 650 \\ 6 & 325 \\ 9 & 217\end{array}$

The actual value of the heading pulse difference is dependent upon many parameters including the total cable length, the present depth (and thus the amount of cable unwound), and the environment which the cable sees. For example, it is acceptable to have a difference value in the range 645 to 648 for a tool speed of 3 rps going through perhaps $4000 \mathrm{ft}$ of logging cable. If no sync pulses are counted by the program then the tool is not connected or it is not rotating or the sync threshold is not set to a suitable value. If sync pulses are counted but no heading pulses are counted then there may be a problem with the mark or magnetometer signal from the tool. The tool should be reset and the data acquisition tested again. The CRT screen that is displayed during the data acquisition test is shown in Figure II.8. The data displayed in here is described in more detail later in this section.

Menu Item:

Default Value:

Other Values:

Function:

\section{Display acquired waveform}

Not applicable.

Not Applicable.

This item displays the waveform currently stored in the virtual disk drive specified in the VDISK.TXT file. Examples of the waveform displayed on the CRT screen are shown in Figures II.9, II.10, II.11. By displaying the waveform, the user can check the settings of the sync and range threshold values and the range window so that the best values of these parameters may be selected. If the Hard Copy variable has been set to ON in the Logging/Data Display Setup Menu, then a copy of the displayed screen can be obtained by pressing the Ctl-PrtScr key. The software prints out a brief header consisting of the current date and time and the current values of the Data Acquisition variables (i.e., digitizer gain, syne and range threshold, and range window). The CRT screen shows the status of the printing operation by listing the percent of the 


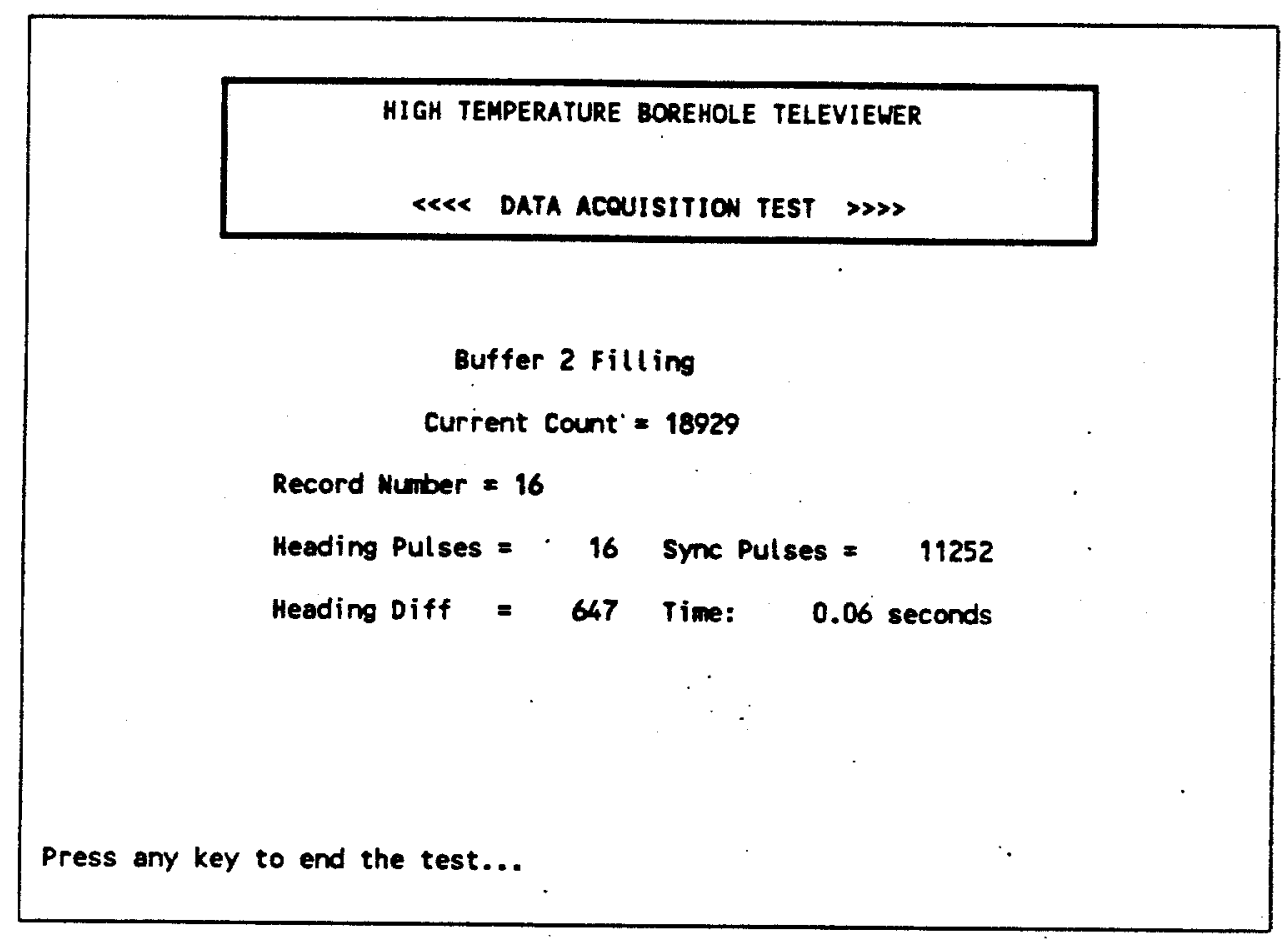

Figure II.8. An example of the CRT screen displayed when the Data Acquisition Test item is selected on the Data Acquisition Menu.

$\begin{array}{ll} & \begin{array}{l}\text { screen that has been printed. The entire printing } \\ \text { operation takes somewhat more than two minutes. }\end{array} \\ \text { Menu Item: } & \text { Number of video Frames Displayed } \\ \text { Default Value: } & 20 \\ \text { Other Values: } & \text { Allowed Range: } \\ & 1<- \text { Frames Displayed <- } 200 \\ \text { Function: } & \text { This item allows the user to set the number of video } \\ & \text { frames displayed when the waveform currently residing } \\ & \text { on the virtual disk is displayed. A video frame is } \\ & \text { defined as the time between sync pulses from the HT- } \\ & \text { BHT tool and is approximately equal to } 512 \text { microsec- } \\ & \text { onds. The software truncates this value to 500 micro- } \\ & \text { seconds to calculate the number of data points dis- } \\ \text { played. Figures II.9, II.10, and II.11 illustrate the } & \\ \text { waveform displayed for } 20,5, \text { and } 200 \text { video frames, } \\ \text { respectively. On the screen, the sync and Range } \\ \text { Threshold values are shown by horizontal colored }\end{array}$




\author{
Menu Item: \\ Default Value: \\ Other Values: \\ Function:
}

Menu I tem:

Default Value:

Other Values:

Function:

Function key: $\quad$ F1 lines. When 5 or less video frames are selected for display, the current settings of the Range Window are shown by two colored vertical lines.

Store Acquired Waveform data to disk

Not applicable.

Not Applicable.

This selection allows the user to store the current digitized waveform in a file in the BHTVDATA directory on the hard disk. The software uses the extension WAV for these files. An already existing file may not be overwritten. See the Error Messages section for a complete listing of the errors associated with this selection.

\section{Copy Acquired Waveform data from disk}

Not applicable.

Not Applicable.

This selection prompts the user for the name of an existing waveform file on the hard disk. If the file is found, it is copied to the virtual disk overwriting any waveform data stored there.

Pressing this key returns the program to the Tool Setup Menu.

\section{II.5.4.1 Error Messages}

In this menu, the software allows the user to enter new values for the sync threshold, range threshold, range window, and the number of video frames. All error messages are displayed in the data entry window for a few seconds after which the software returns to the menu. The user must select the item again and properly enter the desired value. The following error messages may be displayed after the user has entered a change in one of the values:

Error Message: Error in the input data...

Menu Item: All data input selections.

Problem: Incorrect data entry; for example, a letter rather than a numerical value may have been entered.

Error Message: You have exceeded the Digitizer voltage range!

Menu Item:

Problem: sync and Range Threshold values The value entered is outside the voltage range of the $A D C$ board at the specified Digitizer Gain. For example, with a Digitizer Gain of $x 1$, the full scale voltage range is $+/-10$ volts. Entering a value of 11 for this input will display this error message. 
HIGH TEMPERATURE BHTU WAUEFOAM DISPLAY

Record number: 7

Pulses: 1230

Press Ct1-Prtser for a Hard Copy...

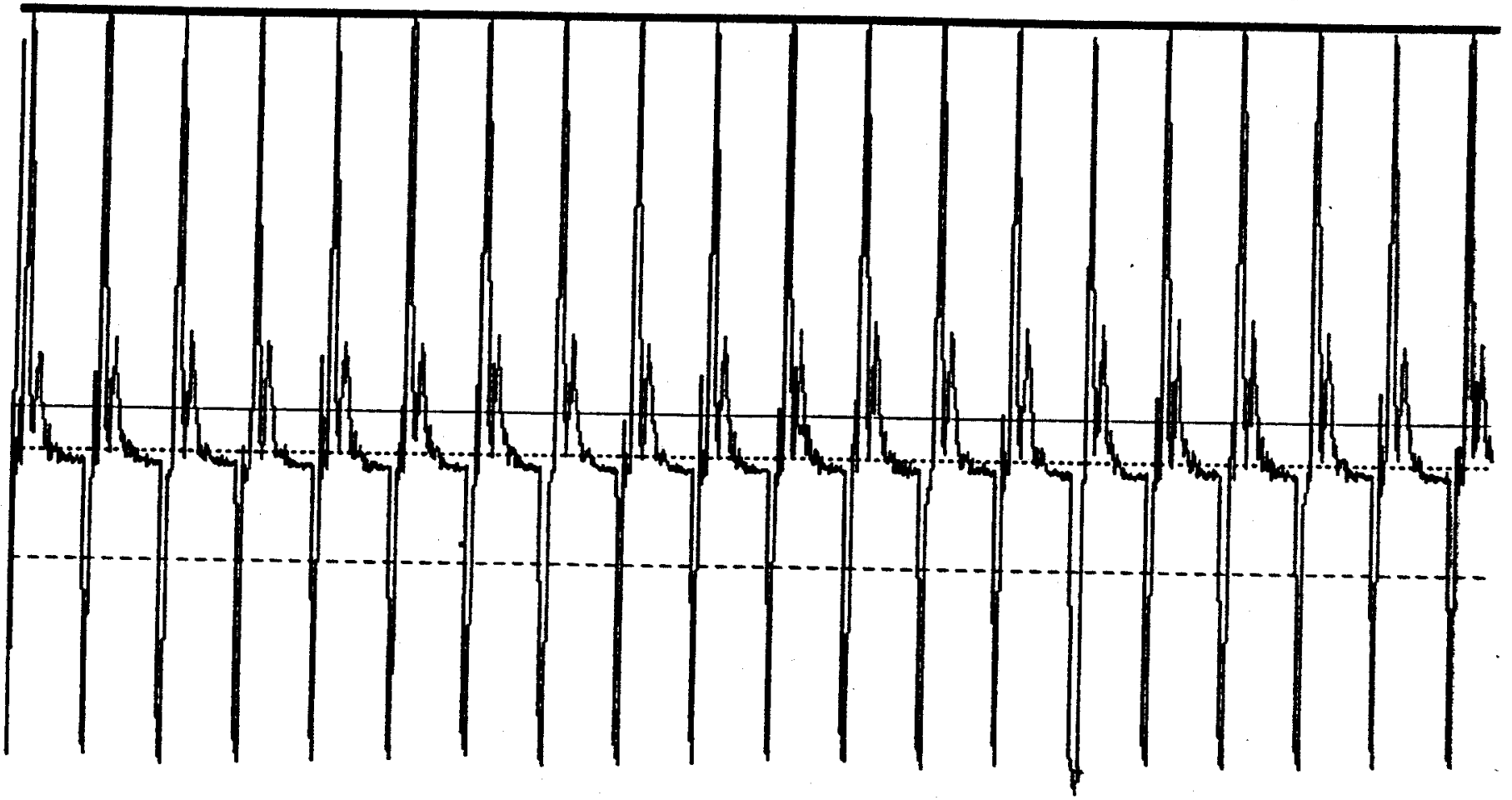

1225

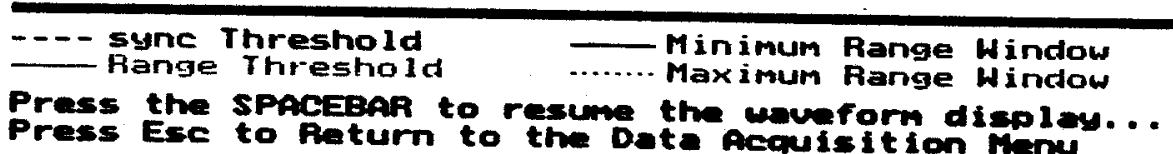

Figure II.9. An example of the CRT screen displayed when the Display acquired waveform item is selected on the Data Acquisition Menu. The default value of 20 video frames is used for the display. The display halts when a heading pulse has been located. The heading pulse is indicated by an arrow on the screen below which is shown the current sync pulse count. The dotted line in the center of the display indicates the zero voltage value. 
HIGH TEMPERATURE BHTU WAUEFOAM DISPLAY

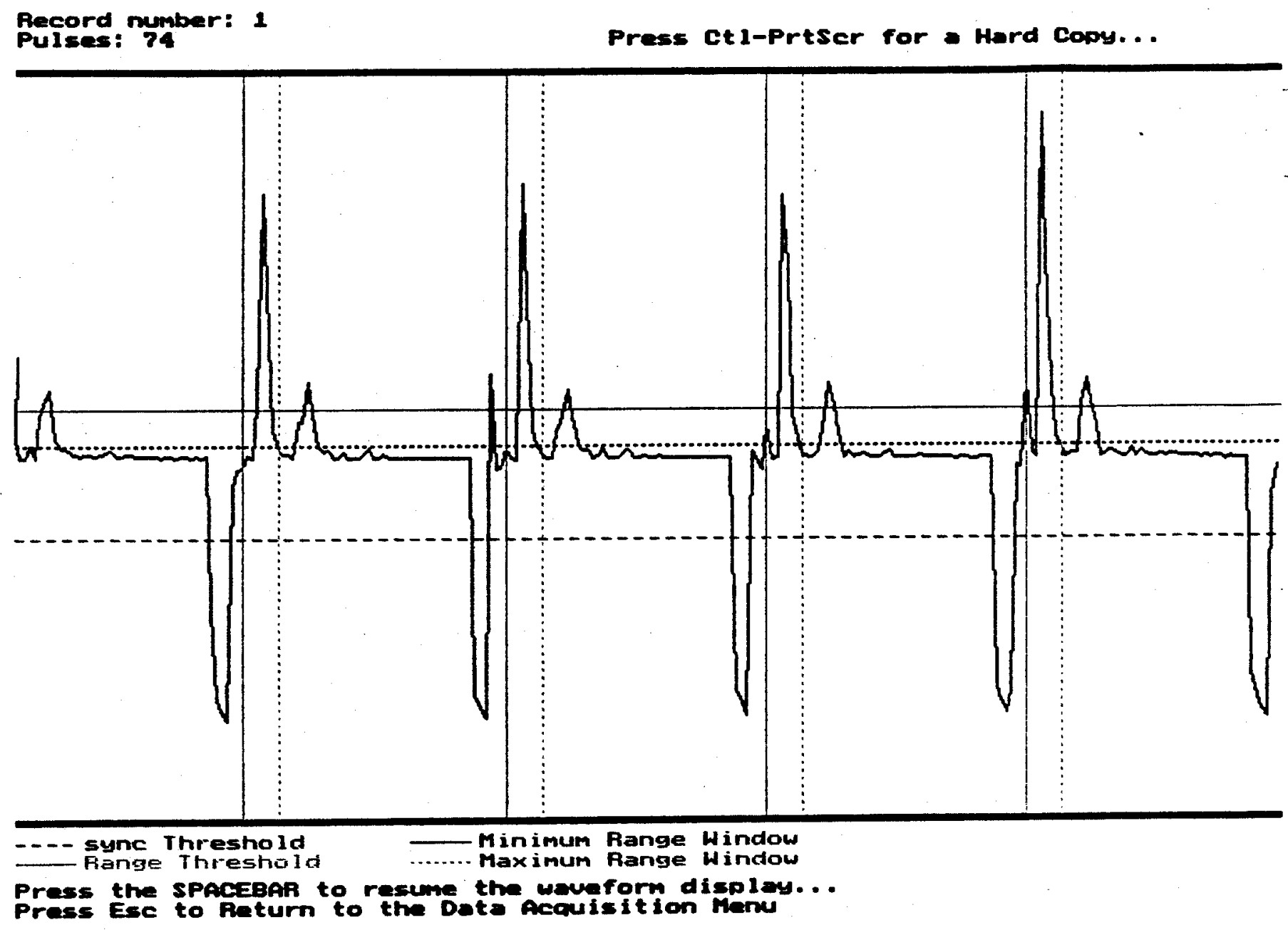

Figure II.10. An example of the CRT screen displayed when the Display acquired waveform item is selected on the Data Acquisition Menu. A value of 5 video frames is used for the display. The range time window is shown by the two vertical lines. This window is shown whenever 5 or less video frames are selected for display. 

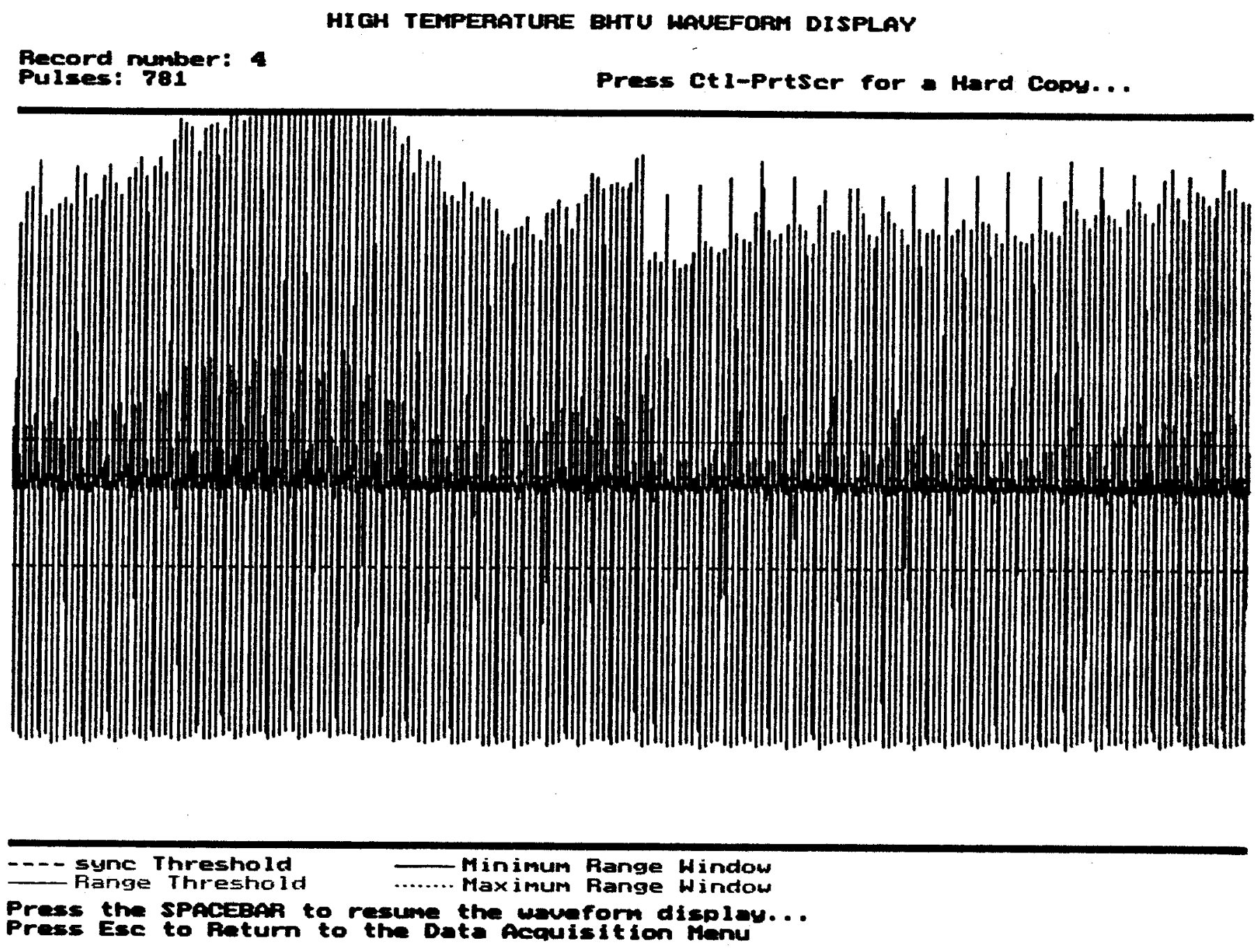

Figure II.I1. An example of the CRT screen displayed when the Display acquired waveform item is selected on the Data Acquisition Menu. A value of 200 video frames is used for the display. This display may be used to monitor the peak amplitude envelope of the returned signal. 
Error Message: Menu Item:

Problem:

Error Message:

Menu Item:

Problem:

Error Message:

Menu Item:

Problem:

Error Message:

Menu Item:

Problem:

Error Message:

Menu Item:

Problem:

Error Message:

Menu Item:

Problem:

Error Message:

Menu Item:

Problem:
Error in the Range Window value!

Range Window; both minimum and maximum values

The entered value for either the minimum or maximum value of the range window must be greater than 0 or less than 500 microseconds. In addition, if the minimum value exceeds the maximum value or the maximum value entered is less than the current minimum value, this error message is displayed.

Error in the number of video frames to display! Video frames to display

The value entered for the number of video frames displayed when the Display acquired waveform item is selected is outside the allowed range of 1 to 200 frames.

There is no waveform file on the virtual disk! Display Acquired Waveform

No file containing digitized waveform data is present on the virtual disk drive. A waveform must be acquired from the tool or a waveform file must be copied from the hard disk in order to display the data.

File Name cannot exceed 8 characters!

Store/Copy Acquired Waveform

The entered name for a file was more than eight characters. The File Name must follow the MS-DOS rules for file names.

A File Name must be entered! Store/Copy Acquired Waveform No characters were entered for the file name. The user pressed the Return or Enter key without entering any other characters. Pressing the Enter key at the File Name prompt allows the user to return to the Test Parameter/Setup File Menu without changing the values of the Setup parameters in memory.

No Waveform File named exists ! Copy Acquired Waveform The entered name for the Waveform File (displayed in the blank line shown above) was not found in the BHTVDATA directory on the hard disk.

The Waveform File named already exists! Store Acquired Waveform The entered name for the Waveform File (displayed in the blank line shown above) already exists in the BHTVDATA directory on the hard disk. A new name must 
be entered to store the waveform currently present on the virtual disk.

Error Message:

Menu Item:

Problem:

\section{Invalid Waveform File name!}

Store Acquired Wave form

The entered name for the Waveform File is not a valid DOS file name. A new name must be entered to store the current waveform in memory.

\section{II.5.5. Logging/Data Display Setup Menu}

The CRT screen display for Logging/Data Display Menu is shown in Figure II.12. This menu is subdivided into two sections. The first section, as indicated on the figure, contains the Logging Parameters. The Logging Parameter variables are primarily concerned with parameters set before a logging operation with the HT-BHTV tool. The second section contains the Data Display Parameters. These are user-controlled variables which define how the data, whether newly acquired or redisplayed from stored data, are displayed on the CRT screen. Some of the variables shown in this menu do not function in this version of the software, but they are included to show other data acquisition or display parameters which may be used in later versions of the software. Those parameters which do not function are. Indicated by the message Note: This parameter not avallable in the menu item descriptions provided below. The current menu item is highlighted and may be selected by pressing the Return or Enter key. The user moves between the menu items with the up or down arrow keys. The functions of the menu items shown in Figure II.12 are described
below:

\begin{abstract}
Menu Item: Default Value: Other Values: Function:
\end{abstract}

Menu Item: Default Value: Other Values: Function:

\section{Data Mode}

TEST

BHTV, FILE

This item selects the value of the Data Mode variable used by the program. These three data modes are described in more detail in Section II.4 on the modes of operation of the software.

\section{Data Acquisition Mode}

Data-Driven

Depth-Driven, From Tape

The three values of this variable define how the program acquires the data from the ADC board. In both the Data-Driven and the Depth-Driven acquisition mode, the program assumes that the HT-BHTV tool is connected and operating and thus the data is being obtained directly from the tool. In the Data-Driven mode, all the data from the tool (that is, every tool rotation) 


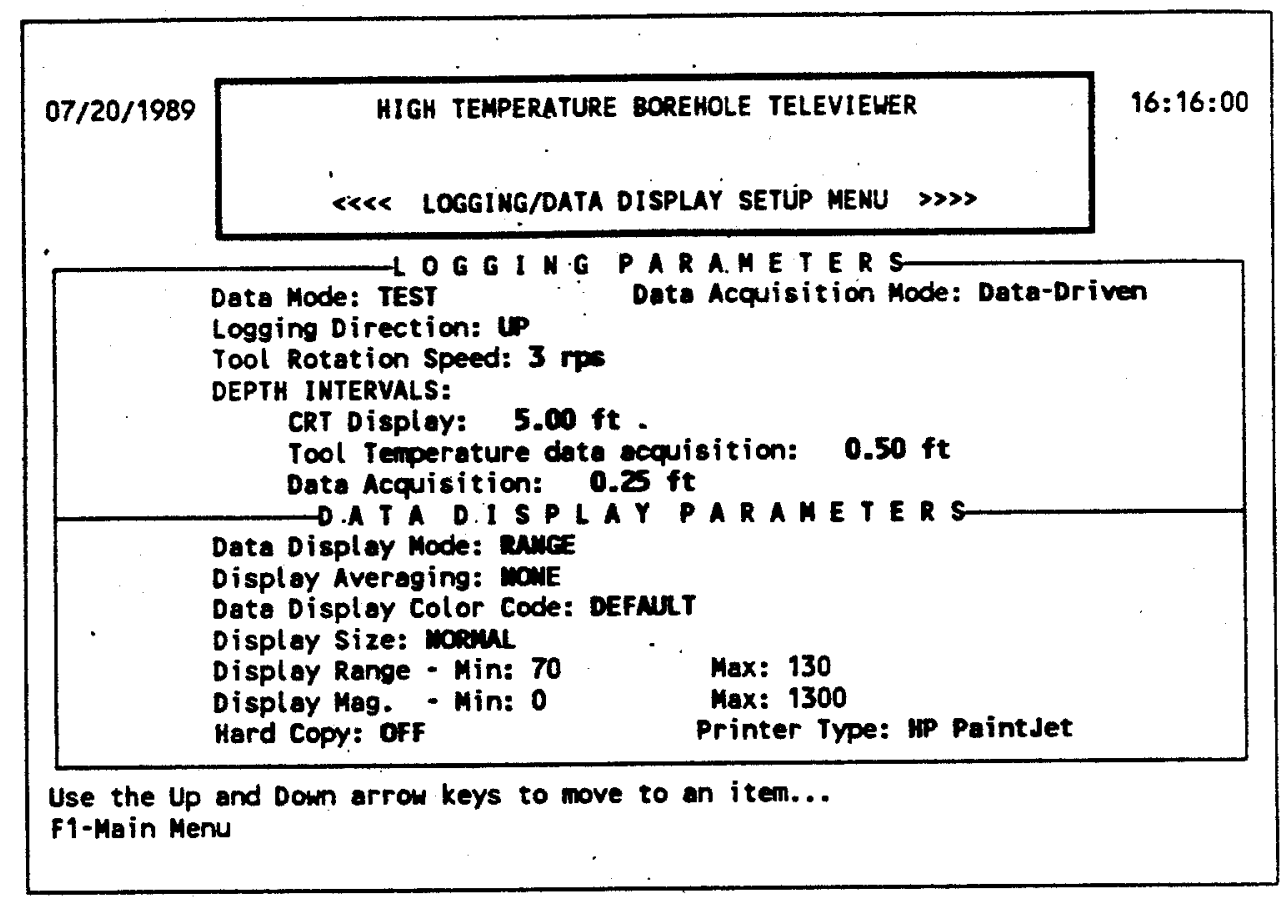

Figure II.12. An example of the CRT screen displayed for the Logging/Data Display Setup Menu with the default values of the parameters selected.

Item:

Default Value:

Other Values:

Function: is displayed on the CRT screen and stored if the Data Mode variable is set to BHTV. In the Depth-Driven data acquisition mode, all the data is digitized by the computer, as in the Data-driven mode, but the data is only displayed and/or stored when the depth value has been incremented to the value defined under the Data Acquisition Depth Interval. This mode may be used to reduce the amount of data displayed and stored when only a low resolution look at the borehole is desired. The From Tape mode is used when data previously stored on a video tape is replayed for digitization and display. Note: Both the Depth-Driven and From Tape data acquisition mode are not currently available.

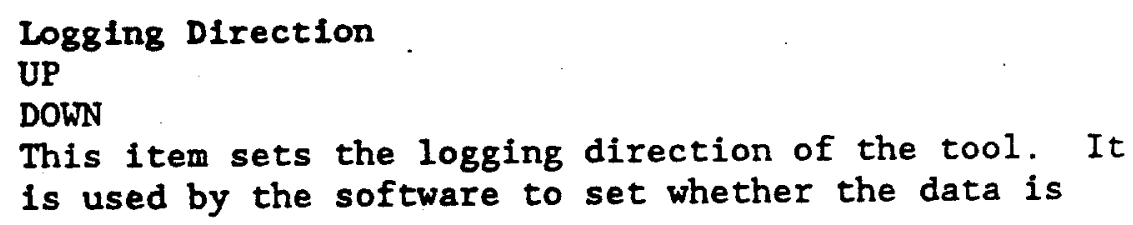
is used by the software to set whether the data is 
Menu Item:

Default Value:

Other Values:

Function: displayed first at the top of the screen (when logging down) or at the bottom of the screen (when logging up). This parameter is also used for the display of the depth annotation on the CRT screen.

\section{Tool Rotation Speed}

3 rps

6 rps, 9 rps

Sets the rotational speed of the tool in the software. This parameter is used by the software to set the number of pixels displayed on the CRT screen and the amount of decimation required of the original data: Section III describes the decimation of the data in more detail.

The following three items set the value of the specified depth intervals used in the software.

Menu Item:

Default Value:

Other Values:

Function:

Menu Item:

Default Value:

Other Values:

Function:

Menu Item:

Default Value:

Other Values:

Function:

Menu Item:

Default Value:

Other Values:

Function:

\section{CRT Display}

$5.00 \mathrm{ft}$

Allowed range $>0.01 \mathrm{ft}$

This parameter sets the depth increment used for the display of the depth annotation on the CRT screen.

For example, if the CRT Display depth interval is set at $5 \mathrm{ft}$ then the depth w111 be displayed at 100, 105, $110 \mathrm{ft}$ and so on assuming an initial depth of $100 \mathrm{ft}$ and logging down the borehole.

Tool Temperature data acquisition

$0.50 \mathrm{ft}$

Allowed range $>0.01 \mathrm{ft}$

This parameter sets the depth increment used for the acquisition of the temperature data from the tool.

Note: This parameter not avallable.

Data Acquisition

$0.25 \mathrm{ft}$

Allowed range $>0.01 \mathrm{ft}$

This parameter sets the depth increment used for

Depth-Driven data acquisition.

Note: This parameter not avallable.

\section{Data Display Mode}

RANGE

MAGNITUDE, RANGE/MAGNITUDE

This function sets the display mode on the CRT screen when data is being displayed. See Section II.6 for more information on this parameter. 
Menu Item: Default Value: Other Values: Function:

Menu Item: Default Value: Other Values: Function:

Menu Item: Default Value: Other Values: Function:

Menu Item: Default Value: Other Values:

Function:
Display Averaging

NONE

$\mathrm{x} 2, \mathrm{x} 4$

This parameter sets the amount of averaging performed by the software on the data displayed on the CRT screen. The default setting displays all the data without any averaging. The $\mathrm{x} 2$ or $\mathrm{x} 4$ setting averages either 2 or 4 lines (or records) of data and displays the averaged data line.

Note: This parameter not avallable.

\section{Data Display Color Code}

DEFAULT

None

The color palette used for the display of range and magnitude data may be modified when this parameter is selected. Sixteen colors are available on the CRT screen. The color code display and the default color settings are described in Section II.6 on the data display selection from the Main Menu.

Note: This parameter not available.

Display Size

NORMAL

EXPANDED

This parameter toggles between the NORMAL and the EXPANDED data display on the CRT screen. These two displays are described in Section II.6.

Display Range - Min

60 microseconds

Allowed Range:

$-10,000<-$ Minimum Display Range <- $+10,000$.

This menu item allows the user to preset the minimum value of the Display Range window for the data display. The values used here are in units of microseconds since they relate to the arrival time of the return signal from the borehole. The large range permitted $(t /-10,000)$ allows the user to change the color of the display to emphasize certain features or to reduce the color variation observed. This value, together with the maximum Display Range value, provides the user with a simple filtering operation on the displayed data. The values of these parameters only affect the display of the data; they have no influence on the way the data is found in the software or the value of the data stored to the hard disk. See Section II.6 for more information on the Range and Magnitude display parameters. 
Menu Item: Default Value: Other Values:

Function:

Menu Item: Default Value: Other Values:

Function:
Display Range - Max

130 microseconds

Allowed Range: $-10,000<-$ Minimum Display Range <- $+10,000$. This menu item allows the user to preset the maximum value of the Display Range window for the data display.

Display Mag. - Min

0

Allowed Range:

$-10,000<-$ Minimum Display Magnitude <- $+10,000$. This menu item allows the user to preset the minimum value of the Display Magnitude window for the data display. The magnitude data obtained from the ADC card is retained in its integer format. So, independent of the value of the digitizer gain, the magnitude data will be in the range of \pm 2048 . For example, with a digitizer gain of 1 , the $A D C$ board has a range of \pm 10 volts. A reading of +5 volts will have an integer value of +1024 . Changing the digitizer gain will change the range in volts of the $A D C$ but will not affect the range of the integer-valued data from the board. As with the Display Range window, the large range of values for the Display Magnitude window allows the user to optimize the color display for the application.

Item:

Default Value:

Other Values:

Function:

Menu Item: Default Value: Other Values: Function:
Display Mag. - Max

1000

Allowed Range:

- 10,000 - Minimum Display Magnitude <- 10,000. This menu item allows the user to preset the maximum value of the Display Magnitude window for the data display.

Hard Copy

OFF

ON

Setting this item to on allows the user to make hard copies of the CRT screen during the display of stored data or during data acquisition when the acquisition has been paused. The software checks whether a printer is connected and operating before it toggles this item to oN. If no printer is found, this item remains OFF. 


$\begin{array}{ll}\text { Menu Item: } & \text { Printer Type } \\ \text { Default Value: } & \text { HP PaintJet } \\ \text { Other Values: } & \text { None } \\ \text { Function: } & \text { Only the Hewlett Packard PaintJet Color printer is } \\ & \text { currently supported by the software. This printer } \\ & \text { provides a color hard copy of the CRT screen when data } \\ & \text { is displayed. Refer to Section III. for more informa- } \\ & \text { tion on the operation and the programing of this } \\ \text { printer. }\end{array}$

Function key: $\quad$ F1 Pressing this key returns the program to the Main Menu.

\section{II.5.5.1 Error Messages}

In this menu, the software allows the user to enter new values for the three depth interval increments and the minimum and maximum values of the Display Range and the Display Magnitude. All error messages are displayed in the data entry window for a few seconds after which the software returns to the menu. The user must select the item again and properly enter the desired value. The following error messages may be displayed after the user has entered a change in one of the values:

Error Message: Menu Item:

Problem:

Error Message: Menu Item: Problem:

Error Message: Menu Item: Problem:

\section{Error Message:}

Menu Item:

Problem:
Error in the input data... All data input selections. Incorrect data entry; for example, a letter rather than a numeral value may have been entered.

\section{Data value must be greater then zero.}

All Depth Intervals

The entered value of the depth interval must be a positive number. The software only deals in positive numbers for the depth. Logging up or down a well is specified by the Logging Direction variable in this menu.

Range Display value must be $>-10,000$ or $<+10,000$. Both the minimum and maximum Range Display items. The software only permits the Range Display values in the specified range. The entered value is outside of this range.

Minimum value of the Range Display cannot exceed or equal the maximum value. Minimum Range Display item The entered value was larger than the current maximum value of the Range Display interval. 
Error Message: Maximum value of the Range Display cannot be less than the minimum value.

Menu Item:

Problem:

Maximum Range Display item

The entered value was less than the current minimum value of the Range Display interval.

Error Message: Magnitude Display value must be $>-10,000$ or $<=$

Menu Item: $+10,000$.

Problem:

Both the minimum and maximum Magnitude Display items. The software only permits the Magnitude Display values in the specified range. The entered value is outside of this range.

Error Message: Minimum value of the Magnitude Display cannot be >the maximum value.

Menu Item:

Problem:

Minimum Magnitude Display item

The entered value was larger than the current maximum value of the Magnitude Display interval.

Error Message: Maximum value of the Magnitude Display cannot be <the minimum value.

Menu Item:

Maximum Magnitude Display item

Problem:

The entered value was less than the current minimum value of the Magnitude Display interval. 
II.5.6. BHTV File Menu

The BHTV File Menu has a different format than the other menus described. In the menus described previously, the user changed the values of the parameters in the menu to the values desired for a particular operation; for example, the display of previously stored data requires different settings for the parameters than the settings required for data acquisition from the HT-BHTV tool. In the File Menu, additional information is displayed in the menu depending on the type of file currently assigned. When no file has been assigned by the user, the CRT screen display for the File Menu is as shown in Figure II.13. There are two types of files defined by the HT-BHTV software. These are called NEW or OLD files. NEW files are used to store data from the HT-BHTV tool (or if the Tool Flag variable is False, simulated data, constructed by the software, will be stored in the file). Only NEW files may be used to store "new" data, that is, no data may be appended to an existing file containing previously stored data. old files are those files containing data stored from an earlier operation of the software (again, the data may be either from the tool or simulated data from the test). The software automatically labels a file as either NEW or OLD. When the user selects the File Name item in the menu and types in the name of a file, the software checks whether a file of that name exists on the hard disk. If the file exists, it is labeled OLD and the information stored about the file is read from the file. (Note: For further information concerning the data files used by the software refer to section III.) If a file of the name entered by the user does not exist, then the file is labeled NEW and the CRT screen shown in Figure II.14 is displayed. An example of the CRT screen displayed for an OLD file is shown in Figure II.15. For the menu items shown on the bottom of the screen, the highlighted menu items may be selected by pressing the Return or Enter key. The user moves between the menu items with up or down arrow keys. The menu items selected by the user will be described first. The additional information displayed by the menu will be discussed following the discussion of the menu items. The user should refer to the CRT screen displays shown in Figures II.13, II.14, and II.15.

\section{User-Selected Menu Items}

Menu Item: Default Value: Other Values: Function:

\section{File Name}

NONE

User-selected file name.

Selecting this item displays a small window on the CRT screen which prompts the user for the name of a file. only eight character names without extensions are permitted for the file name. The software provides its own extensions for the files as explained in section III. After a file name is entered the software checks the BHTVDATA subdirectory for a file of that name. If one is found with that name, it is labeled an oud file. If a file of the selected name 


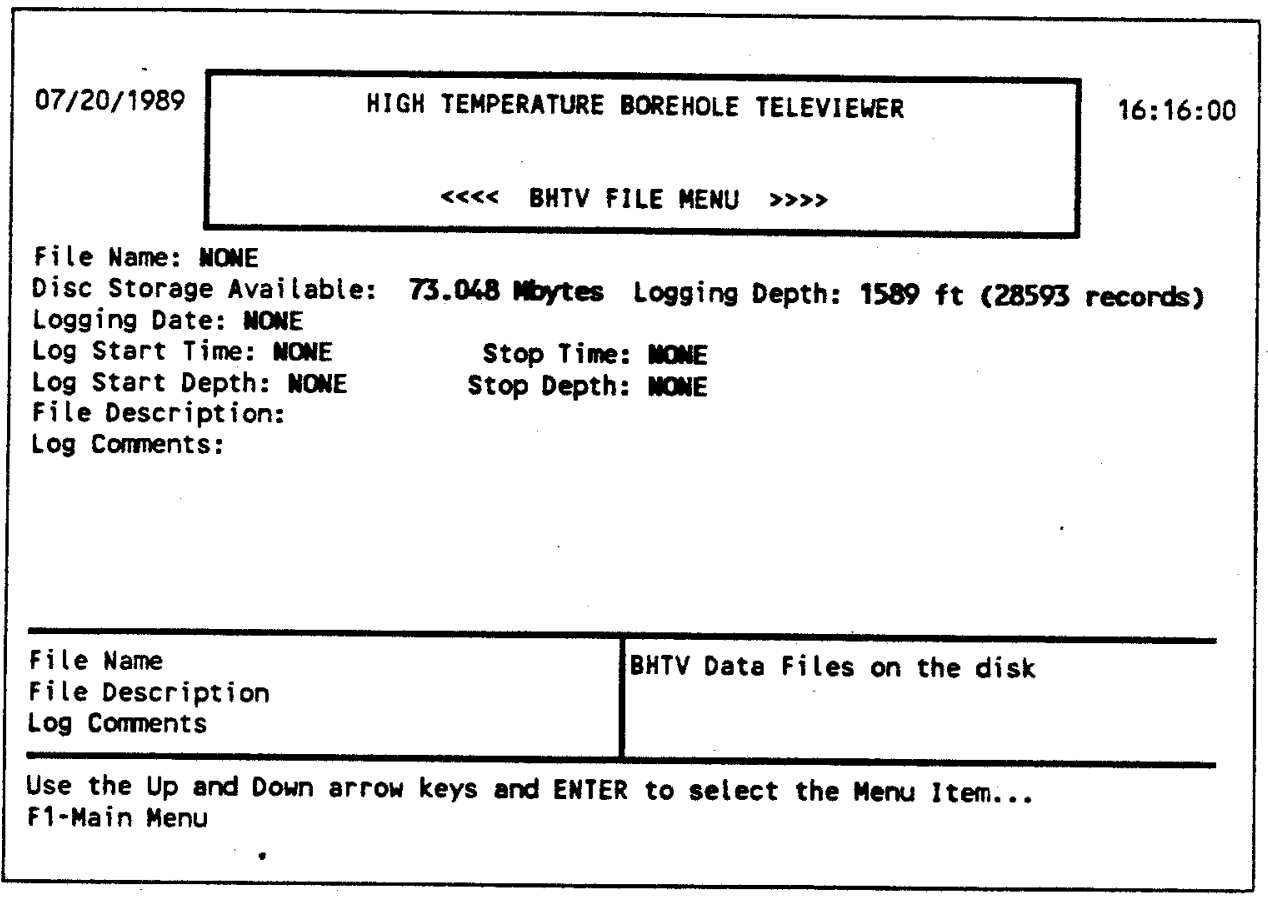

Figure II.13. An example of the CRT screen displayed for the BHTV File Menu when no file has been assigned.

does not exist, the file is a NEW file and the software prepares the appropriate data files on the hard disk.

Menu Item:

File Description

Default Value: Not applicable

Other Values: Not applicable

Function:

Selecting this item displays a small window on the CRT screen which prompts the user for a description of the file. For example, the user may choose to include the well logged and other pertinent information in this description. The description is displayed by the software when the directory of data files on the hard disk is selected. See BHTV Data Files on the disk below. The description is limited to 60 characters.

Menu Item: Log Comments

Default Value: Not applicable

Other Values: Not applicable

Function:

Selecting this item displays a small window on the CRT screen which prompts the user for comments to be 


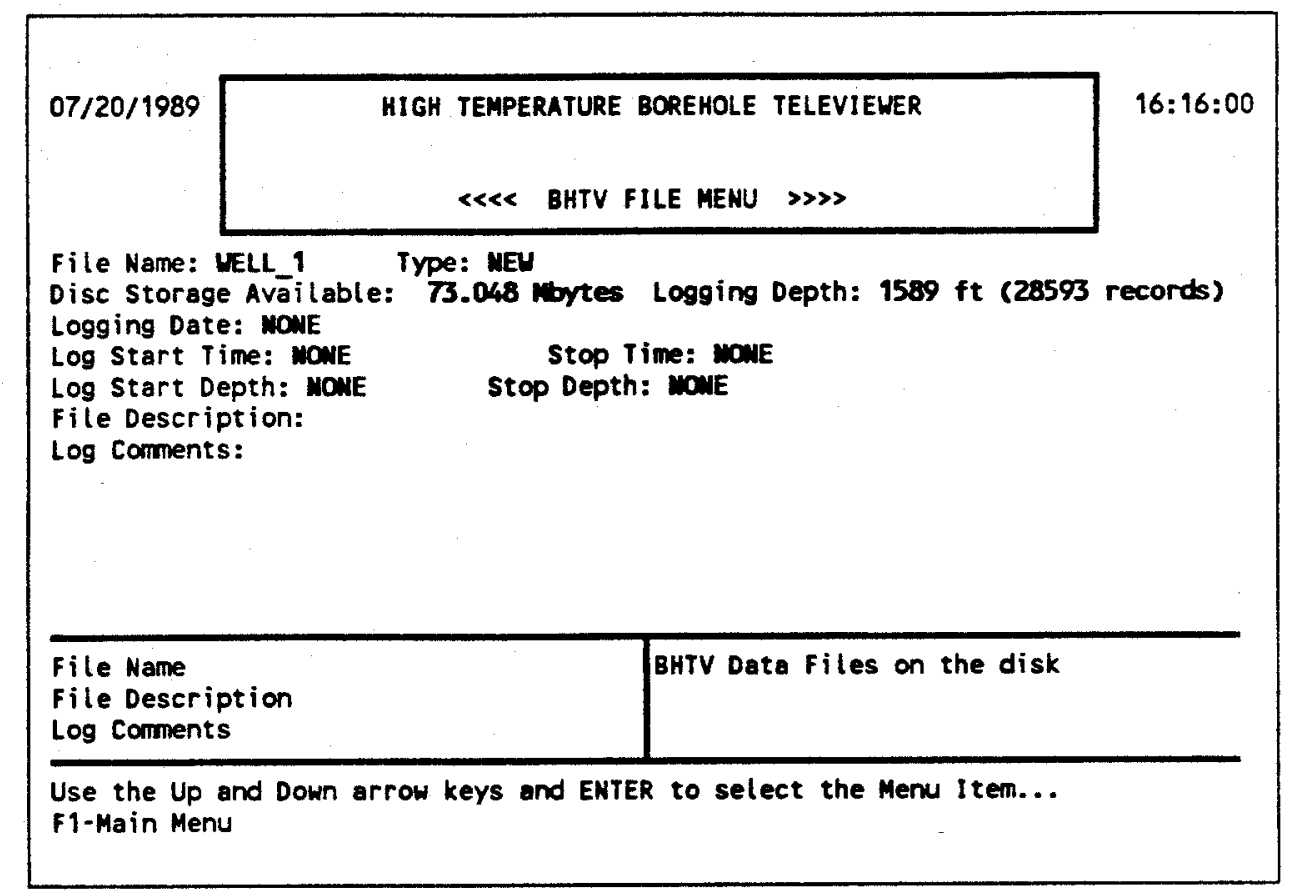

Figure II.14. An example of the CRT screen displayed for the BHTV File Menu when a NEW file is selected.

Menu Item: Default Value: Other Values: Function:

stored with the data in this file. Five 78-character lines of comments may be added by the user for each file. When this item is selected, the software cycles through each of the comment lines. Information may be appended to but not deleted from a previously entered comment. Pressing the Enter key concludes the input for the specified comment line.

BHTV Data Files on the disk

Not applicable

Not applicable

When this item is selected, the program searches the BHTVDATA directory for all HT-BHTV data files (refer to Section III). After the search, all the files found are displayed, up to a maximum value of 100 files, in a window as shown in the example of Figure II.16. In the display, the number of data files found is shown and each individual file is listed by its eight character name, the logging date, and the usersupplied file description. Fifteen files are displayed at a time. The software directs the user to 


\begin{tabular}{|c|c|c|}
\hline \multicolumn{2}{|c|}{ 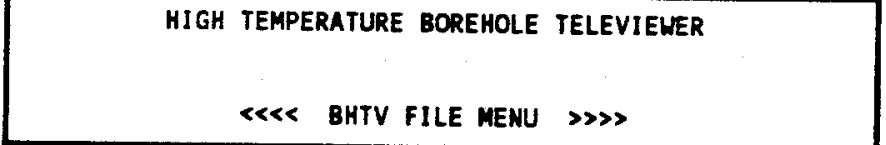 } & \multirow[b]{2}{*}{$\begin{array}{l}\text { records) } \\
0.43 \mathrm{hrs} \\
587.77 \mathrm{ft}\end{array}$} \\
\hline $\begin{array}{l}\text { File Name: WeLL_ } \quad \text { Type: OW } \\
\text { Disc Storage Available: } 73.048 \text { mbrtes } \\
\text { Logging Date: 06/08/1989 } \\
\text { Log Start Time: 14:47:05.27 Stop Time: } \\
\text { Log Start Depth: } 81.59 \text { ft Stop Depth: } \\
\text { File Description: } \\
\text { log Corments: } \\
\text { Coment } 1 \\
\text { Comment } 2 \\
\text { Comment } 3 \\
\text { Comiment } 4 \\
\text { Comment } 5\end{array}$ & $\begin{array}{l}\text { File Size: } 3907 \text { records } \\
\text { Logging Depth: } 1589 \mathrm{ft} \text { (28593 } \\
\text { 15:12:40.16 Elapsed Time: } \\
\quad 666.36 \mathrm{ft} \text { Total Depth: }\end{array}$ & \\
\hline $\begin{array}{l}\text { File Name } \\
\text { File Description } \\
\text { Log Comments }\end{array}$ & $\begin{array}{l}\text { BHTV Data files on the disk } \\
\text { Copy BHTV files to Tape }\end{array}$ & \\
\hline $\begin{array}{l}\text { Use the Up and Down arrow keys and ENTER } \\
\text { F1-Main Menu }\end{array}$ & to select the Menu Item... & \\
\hline
\end{tabular}

Figure II.15. An example of the CRT screen displayed for the BHTV File Menu when a OLD file is selected.

press a key to continue the file listing or to return to the BHTV File Menu if the last screen is displayed.

\section{Additional Information Displayed in the Menu}

Menu Item: Type

Default Value: Dependent on the file named by the user.

Other Values: NEW, OLD

Function:

NEW files are used to store data from a logging operation. OLD files contain data previously stored from the tool (or simulated data constructed by the software). The data in these files may be viewed on the CRT screen but no additional data may appended to these files. A complete description of the data files produced by the HT-BHTV program is provided in Section III. 


\section{HT-BHTV DATA FILES}

Number of Data Files on the disk: 3

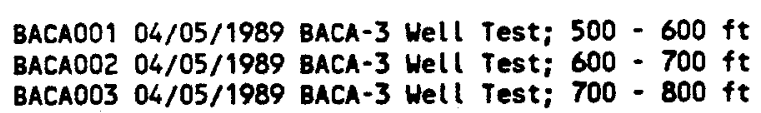

Press any key to return to the BHTV file Menu...

Figure II.16. An example of the CRT screen displayed for the listing of HTBHTV files on the hard disk which are available for display.

Menu Item: Default Value: Other Values: Function:

Menu Item: Default Value: other Values: Function:
File size

Displayed only for an OLD file.

Not applicable

The file size is the total number of records or horizontal lines which may be displayed on the CRT screen for the indicated file. For example, in Figure II.15, the display shows that this file contains $3907 \mathrm{re}$ cords. Since each record corresponds to a display line and 460 lines may be displayed on the CRT screen in the NORMAL display size mode, then this file contains the equivalent of $8.5 \mathrm{CRT}$ screens of HT-BHTV data.

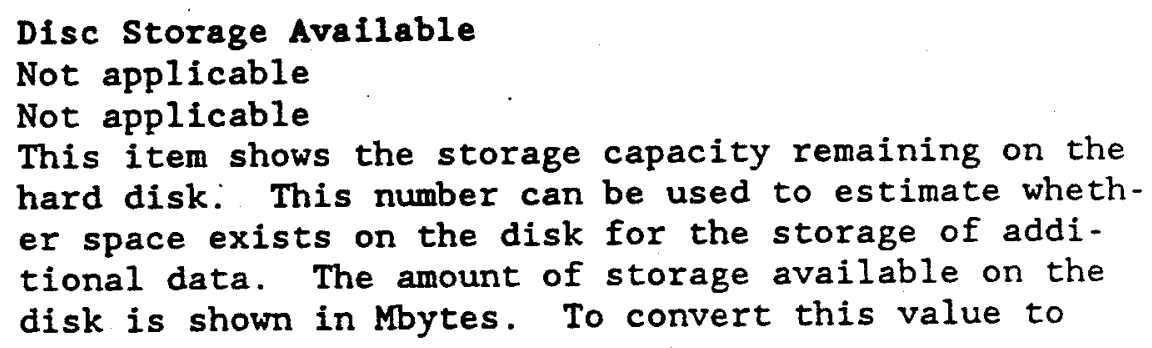
hard disk: This number can be used to estimate whether space exists on the disk for the storage of additional data. The amount of storage available on the disk is shown in Mbytes. To convert this value to 
Menu Item: Default Value: Other Values: Function:
Menu Item:

Default Value: Other Values:

Function:

Menu Item:

Default Value:

Other Values:

Function: bytes, multiply the displayed value by $1,024,000$. (Note that about 1.175 Mbytes of disk storage is required for each CRT screen in the NORMAL display size mode. The depth displayed on the screen will depend on the logging rate and the Data Acquisition Mode selected in the Logging/Data Display Setup Menu. For example, with a logging rate of $5 \mathrm{ft} / \mathrm{min}$, about $12.8 \mathrm{ft}$ of data may be displayed on the screen in the NORMAL display size mode.) If only a small amount of space is available, it is advisable to archive some of the HT-BHTV data on the disk to tape. See Section II.7 for more details about this procedure.

\section{Logging Depth}

Not applicable

Not applicable

This item displays two pieces of information related to the empty storage capacity on the hard disk. The number of records (or lines) of data that may be stored on the system is computed from the amount of storage available (see above) and the size in bytes of a data record in the digitized data files (those files with a .BTV extension; see Section III for more information on the data file structure used by the HT-BHTV software). The computed record number is used to estimate the depth (in $f t$ ) which may be logged at a logging rate of $10 \mathrm{ft} / \mathrm{min}$. The number displayed here may be easily converted to a logging depth at any other logging rate. For example, at a logging rate of $5 \mathrm{ft} / \mathrm{min}$, the estimated depth that may be logged can be found by multiplying the displayed depth by 0.5 .

\section{Logging Date}

NONE for a NEW file.

The date the data was acquired/stored for an OLD file. This item displays the date on which the data contained in the specified oLd file was obtained and stored.

\section{Log Start Time}

NONE for a NEW file.

The time at which the logging operation was started for an OLd file.

This item displays the starting time of the logging operation for the data stored in the specified OLD file. 
Menu Item: Log Stop Time

Default Value: NONE for a NEW file.

Other Values: The time at which the logging operation was stopped for an OLD file.

Function:

This item displays the stopping time of the logging operation for the data stored in the specified OLD file.

Menu Item: Elapsed Time

Default Value: Not displayed for a NEW file.

Other Values:

Function:

Elapsed logging time in hours for an OLD file.

This item displays the result of the calculation of

the total logging time from the start and Stop times of the data acquisition stored in the specified OLD file.

Menu Item:

Log Start Depth

Default Value: NONE for a NEW file.

Other Values: The depth at which the logging operation was started for an oud file.

Function:

This item displays the starting depth in feet of the logging operation for the data stored in the specified OLD file.

Menu Item: Log Stop Depth

Default Value: NONE for a NEW file.

Other Values:

Function:

The depth in feet at which the logging operation was stopped for an OLd file.

This item displays the depth at which data acquisition for a logging operation was stopped.

Menu Item: Total Depth

Default Value: Not displayed for a NEW file.

Other Values: Total depth logged in feet for an oLd file.

Function:

This item displays the difference between the starting and stopping depth for the data acquisition from the HT-BHTV tool during a logging operation.

Function key: F1 Pressing this key returns the program to the Main Menu. 


\section{II.5.6.1 Error Messages}

In this menu, the software allows the user to enter a new File Name for either data acquisition or display of previously acquired data. All error messages are displayed in the data entry window for a few seconds after which the software returns to the menu. The user must select the item again and properly enter the desired value. The following error messages may be displayed after the user has entered a change in one of the values:

Error Message:

Menu Item:

Problem:

Error Message: Menu Item:

Problem:

Error Message: Menu Item:

Problem:
File Name cannot exceed 8 characters! File Name

The entered name for a file was more than eight characters. The File Name must follow the MS-DOS rules for file names.
A File Name must be entered! File Name
No characters were entered for the file name. The user pressed the Return or Enter key without entering any other characters. Pressing the Enter key at the File Name prompt allows the user to return to the BHTV Pile Menu without changing the file already opened.

\section{Invalid File Name!}

File Name

An incorrect File Name was entered. Most likely the name included some invalid characters. The file names must conform to acceptable MS-DOS names.

\section{II.5.7. File Display Menu}

The initial or default CRT screen displayed for the File Display menu is shown in Figure II.17. This menu allows the user to selectively view the data acquired and stored from the HT-BHTV tool. The format of this menu is similar to the BHTV File Menu. In this menu, additional information pertaining to the selected file is displayed to aid the user in choosing an appropriate depth or record number interval to display. Two other figures provide examples of the CRT display when either the depth or record number interval is selected. Figure II.18 shows an example of the display when the user selects a depth interval range. Figure II.19 is an example of the screen when the record number interval is selected. For the menu items shown on the bottom portion of the screen, the highlighted menu item may be selected by pressing the Return or Enter key. The user moves between the menu items with up or down arrow keys. The user-selected menu items will be discussed first followed by a brief summary of the additional information displayed on the screen. This additional information is identical to the information shown in the BHTV File Menu which was described in Section II.5.6. 


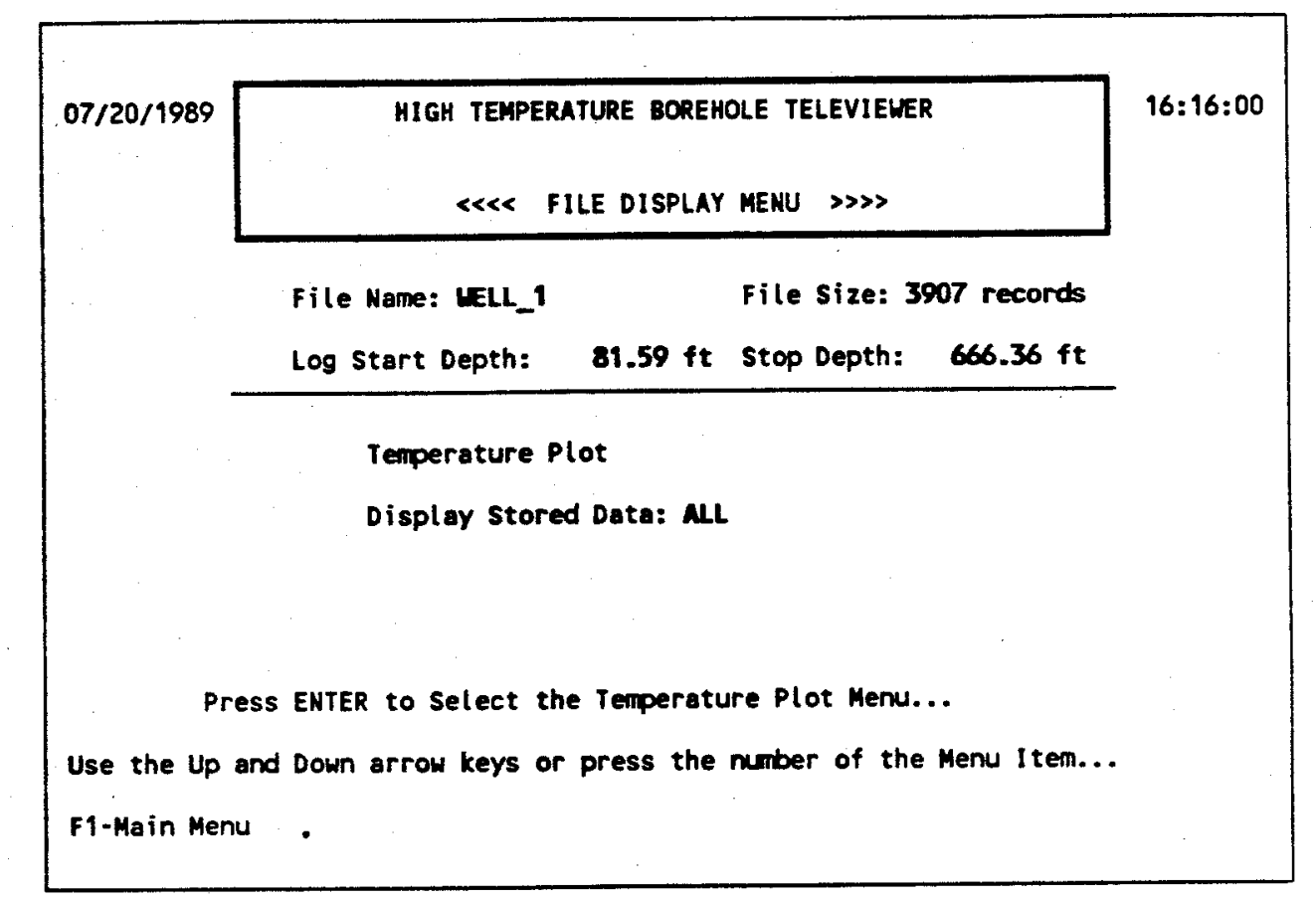

Figure II.17. An example of the CRT screen displayed for the File Display Menu for the initial or default display.

\section{User-Selected Menu Items}

Menu Item: Temperature Plot

Default Value: Not applicable

Other Values: Not applicable

Function:

This item allows the user to display the temperature data acquired from the tool stored in the specified file.

Note: This menu item is not presently available.

Menu Item:

Default Value:

Other Values:

Function:
Display Stored Data

ALL

PARTIAL

This item allows the user to select the manner in which the stored data will be displayed. In the default ALI selection, the data will be displayed beginning at record number 0 (which is the first record stored in the file) to the last record number of the file. The PARTIAL selection allows the user to choose to display only a portion of the data stored in the 


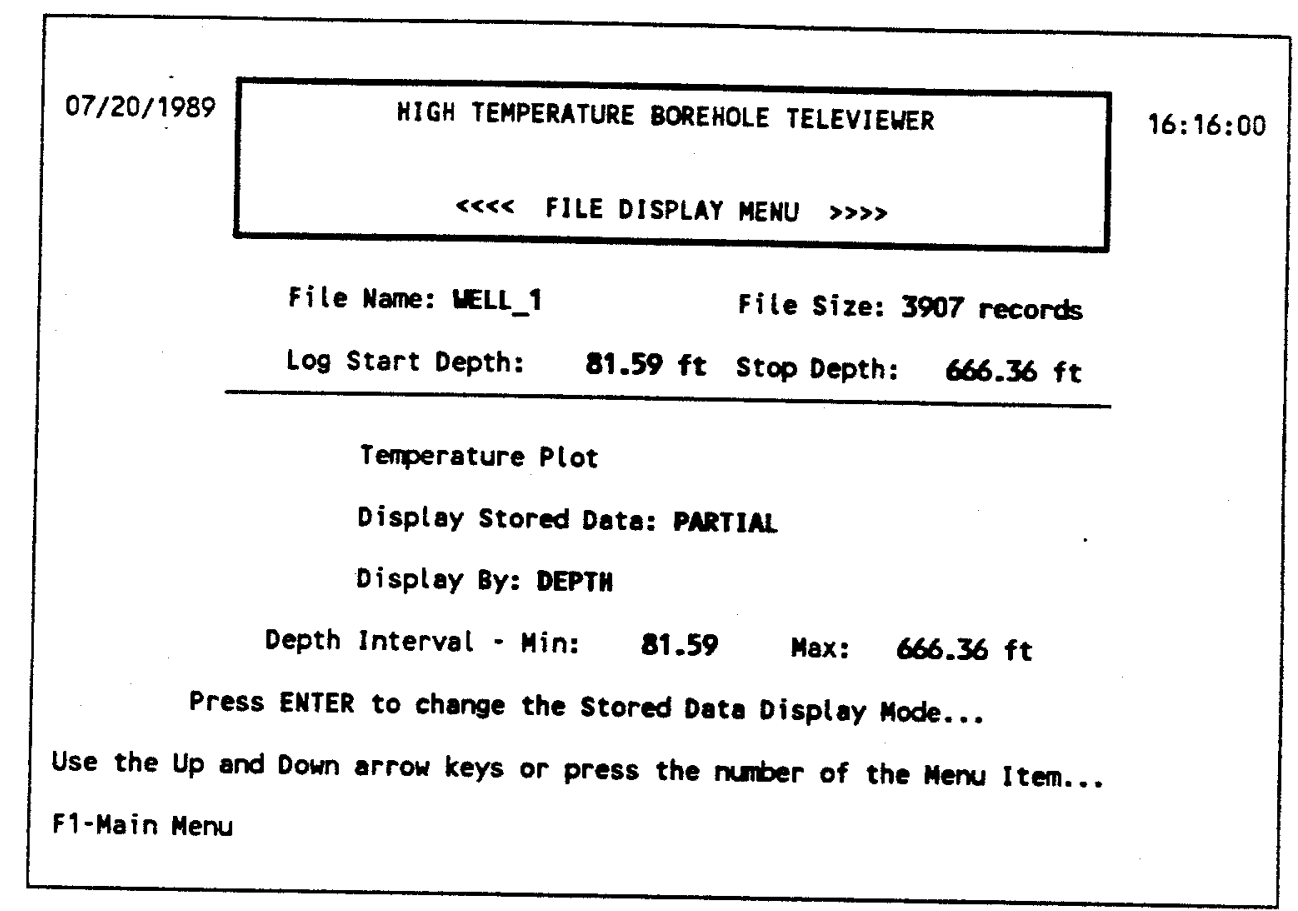

Figure II.18. An example of the CRT screen displayed for the File Display Menu for the Depth Interval Display.

\begin{tabular}{|c|c|}
\hline & $\begin{array}{l}\text { specified file. The user may select to display the } \\
\text { data by either the depth or record number interval. } \\
\text { These are selected by the following menu item. }\end{array}$ \\
\hline $\begin{array}{l}\text { Menu Item: } \\
\text { Default Value: } \\
\text { Other Values: }\end{array}$ & $\begin{array}{l}\text { Display By } \\
\text { DEPTH } \\
\text { RECORD NUMBER }\end{array}$ \\
\hline Function: & $\begin{array}{l}\text { This item is only displayed on the CRT screen when the } \\
\text { user selects the PARTIAL selection of the Display } \\
\text { Stored Data item described above. Two selections are } \\
\text { available in this menu item. The default select of } \\
\text { DEPTH allows the user to specify a depth interval to } \\
\text { display. RECORD NUMBR directs the software to dis- } \\
\text { play the data according to the record number interval } \\
\text { specified in the menu item below. }\end{array}$ \\
\hline $\begin{array}{l}\text { Menu Item: } \\
\text { Default Value: }\end{array}$ & $\begin{array}{l}\text { Depth Interval } \\
\text { Minimum and maximum logged depths contained in the } \\
\text { specified file. } \\
\text { User-specified } \\
\text { When the Display By menu item is set to DEPTH, this }\end{array}$ \\
\hline
\end{tabular}




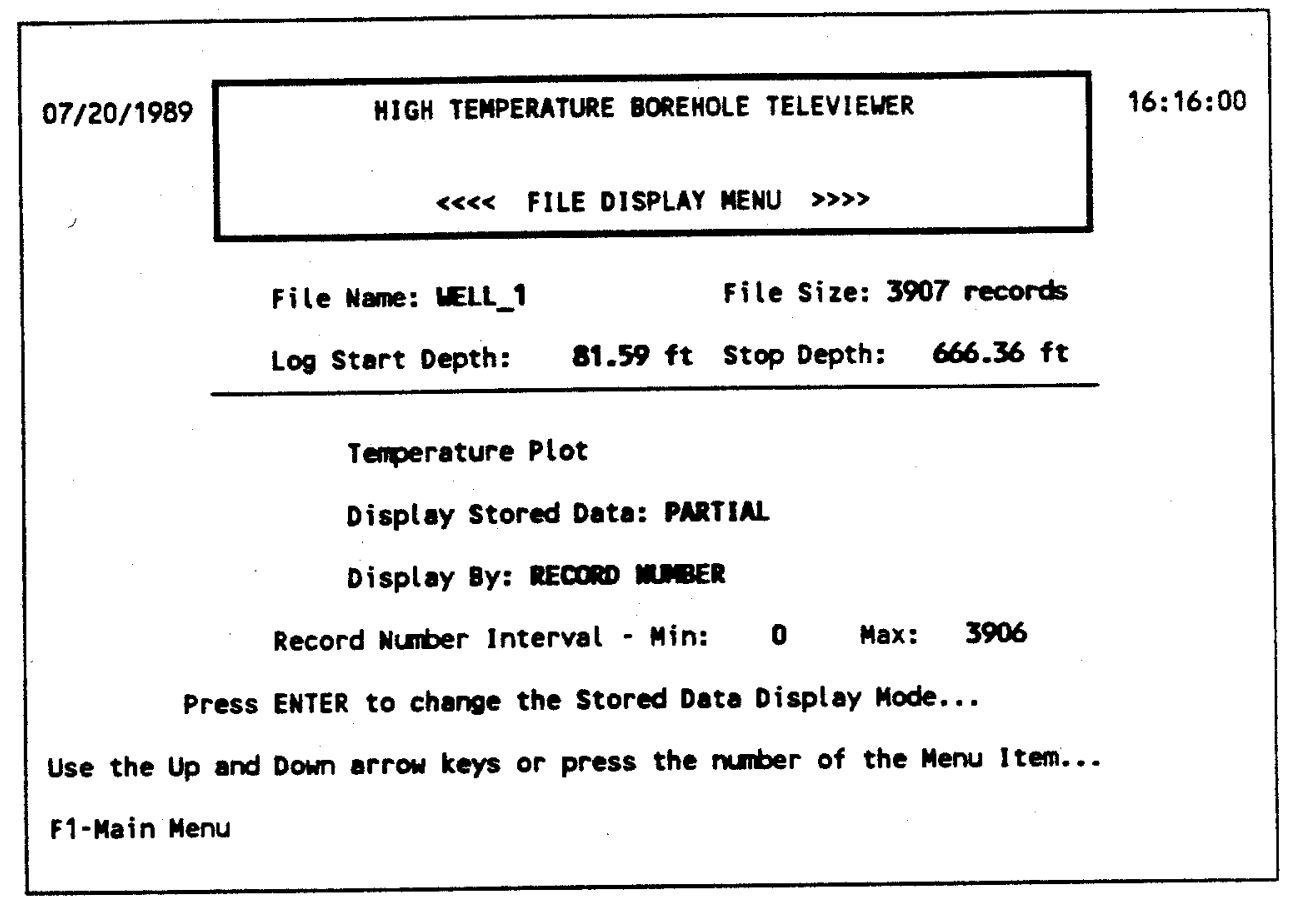

Figure II.19. An example of the CRT screen displayed for the File Display Menu for the Record Number Interval display.

menu item is shown on the CRT screen. Selecting this item by pressing the Return or Enter key allows the user to specify the depth range which should be displayed from the specified file. The software only permits a depth interval which is within the logging depths contained in the file. The user enters the minimum depth value followed by the maximum depth value. These values are the true minimum and maximum depths desired by the user irrespective of the logging direction of the data in the file. The software will display the data properly depending upon the logging direction. An example of the CRT screen display for this option is shown in Figure II.18.

Menu Item:

Record Number Interval

Default Value: Record number range from 0 to the last record in the Other Value: User-specified Function: When the Display By menu item is set to RECORD NUMBER, this menu item is shown on the CRT screen. Selecting this item by pressing the Return or Enter key allows 
the user to specify the record number range which should be displayed from the specified file. of course, the user is limited to the record numbers available in the file. Any record number selection outside of this range produces an error message by the software. An example of the CRT screen display for this option is shown in Figure II.19.

\title{
Additional Information Displayed in the Menu
}

\author{
Display Item: File Name \\ Function: User-selected file name. \\ Display Item: File Size \\ Function: \\ The file size is the total number of records or hori- \\ zontal lines which may be displayed on the CRT screen \\ for the indicated file. The file size shows the total \\ records in the specified file. Since the file begins \\ at record number 0 , the last record in the file is \\ equal to File Size - 1. \\ Display Item: Log Start Depth \\ Function: The depth at which the logging operation was started \\ for the specified file. \\ Display Item: $\quad$ Log Stop Depth \\ Function: The depth at which the logging operation was stopped \\ for the specified file.
}

Function key: F1

Pressing this key returns the program to the Main Menu.

\section{II.5.7.1 Error Messages}

In this menu, the software allows the user to enter new Depth or Record Number intervals for displaying only a portion of the data contained in a file. Before entering this menu, the user must have opened a file for data display in the BHTV File Menu. If no OLD file was opened, the software displays the first error message shown below and returns to the Main Menu. All error messages are displayed in the data entry window for a few seconds after which the software returns to the menu. The user must select the item again and properly enter the desired value. The following error messages may be displayed after the user has entered a change in one of the values: 
Error Message: Problem:

Error Message: Menu Item:

Problem:

Error Message: Menu Item:

Problem:

Error Message:

Menu Item:

Problem:

Error Message:

Menu Item:

Problem:

Error Message:

Menu Item:

Problem:

\section{Error Message:}

Menu Item:

Problem:

Error Message:

Menu Item:

Problem:
A previously existing File must be opened... An OLD file must be opened from the BHTV File Menu prior to entry into this menu.

Error in the Input data... All data input selections. Incorrect data entry; for example, a letter rather than a numerical value may have been entered.

Data value must be a positive number. Depth Interval and Record Number Interval The user entered a negative number for one of the interval values.

The value entered is less than the Minimum depth in the file...

Depth Interval

The value entered was less than the minimum depth in the specified file.

The value entered is greater than the Maximum depth in the file...

Depth Interval

The value entered was greater than the maximum depth in the specified file.

The value entered is less than the Minimum depth previously entered...

Maximum value of the Depth Interval

The maximum value of the Depth Interval entered was less than the minimum value just entered. The user must properly enter a minimum and maximum value for the Depth Interval which will be displayed from the specified file.

The value entered is greater than the Maximum record no. In the file

Record Number Interval

The value entered was greater than the maximum record number of the specified file.

The value entered is less than the Minimum record no. previously entered...

Maximum value of the Record Number Interval

The maximum value of the Record Number Interval entered was less than the minimum value just entered. The user must properly enter a minimum and maximum value for the Record Number Interval which will be displayed from the specified file. 


\section{II.5.8. Test Parameter/Setup File Menu}

This menu sets the user-controlled software flags used in the software. Section II. 3 discusses the use of these flags. The CRT screen display for this menu is shown in Figure II.20. The current menu item is highlighted and may be selected by pressing the Return or Enter key. To move between the menu items, the user may either select the number of the desired item or move between the items by using the up or down arrow keys. As shown in the example in Figure II.20, each menu item has a short descriptive message explaining the function of the highlighted menu selection.

$\begin{array}{ll}\text { Menu Item: } & \text { Tool Flag } \\ \text { Default Value: } & \text { False } \\ \text { Other Values: } & \text { True } \\ \text { Function: } & \text { The Tool Flag should be set to True when the HT-BHTV } \\ & \text { tool is connected to the computer system and the user } \\ & \text { wishes to acquire temperature and/or acoustic data } \\ & \text { from the tool. Also, this flag must be True if the } \\ & \text { ADC board will be used to digitize the data stored on } \\ \text { a video tape. }\end{array}$

Menu Item: Depth Flag

Default Value: False

Other Values: True

Function: The Depth Flag must be True to acquire the depth information from the depth counter. With this flag set to false, the software calculates its own depth beginning at a value of $22000 \mathrm{ft}$ and incrementing (or decrementing, depending upon the value of the Logging Direction variable) this depth by $0.0556 \mathrm{ft}$ for each line of data displayed on the CRT screen. This incremental value simulates a logging rate of $10 \mathrm{ft} / \mathrm{min}$.

Menu Item: Temperature Flag

Default Value: False

Other Values: True

Function:

The Temperature Flag variable must be True for the software to acquire and display temperature data. If the Tool Flag is True, the software will acquire the temperature data from the HT-BHTV tool and display the converted temperatures on the CRT screen. Note: The serial interface on the computer must be connected to the interface on the HT-BHTV surface unit so that the software may obtain the data from the tool. If the Tool Flag is False and the Temperature Flag is True, the software will display simulated temperature values. When the Temperature Flag is False, no temperature information is acquired or displayed. 


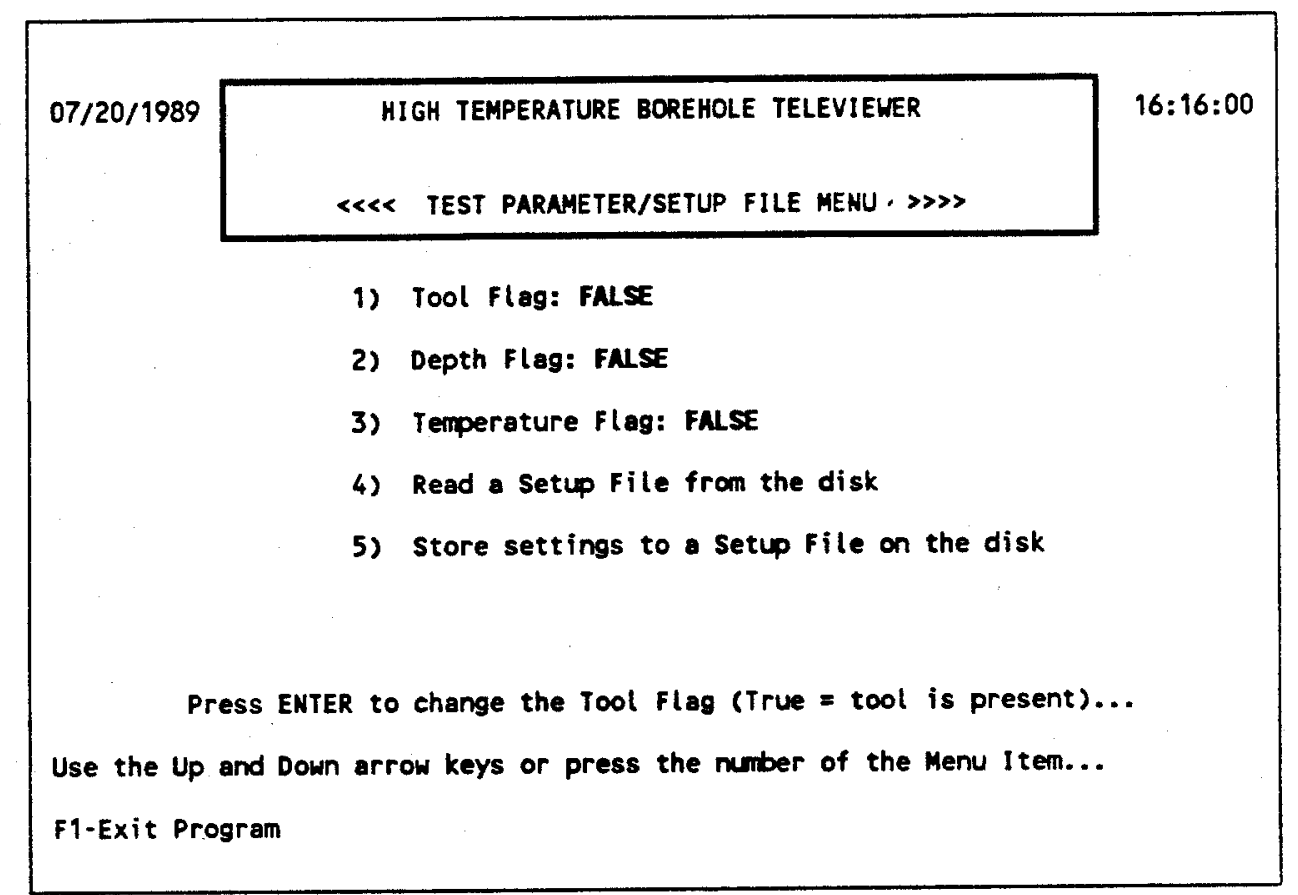

Figure II.20. An example of the CRT screen displayed for the Test Parameter/ Setup File Menu using the default settings of the flag variables.

Menu Item: Default Value: Other Values: Function:
Read a Setup File from the disk

Not Applicable

Not Applicable

Selecting this item displays a small window on the CRT screen which prompts the user for the name of the desired Setup File. Setup files are stored in the BHTVDATA directory with the extension .SET. As in the BHTV File Menu, the software adds the correct extension to the Setup file. The user must enter a valid eight character name for the file. No extension should be added by the user. The software will check the disk for a Setup File of the specified name. If the file is found, the setup data contained in the file will be read by the program. If no file is found, an error message is displayed. The Setup File stores the Tool Control parameters and the values of the Display Window which were selected when the file was originally stored. The following parameters are contained in the Setup File: 
Digitizer Gain

sync Threshold

Range Threshold

Range Window (min. and max. values)

Range Display Window (min. and max. values)

Magnitude Display Window (min. and max. values)

Menu Item: Store settings to a Setup File on the disk

Default Value: Not Applicable

Other Values: Not Applicable

Function:

Selecting this item displays a small window on the CRT screen which prompts the user for the name of the Setup File. The current values of the variables listed above will be stored in the Setup File. The software checks the disk to determine if a Setup File of the specified name already exists. If it does, an error message is displayed. Setup files may not be overwitten by the program. If no file of the usersupplied name is found on the disk, the software stores the information in the file and returns to the Test Parameter/Setup File Menu.

Function key: F1

Pressing this key returns the program to the Main Menu. 


\section{II.5.8.1 Error Messages}

In this menu, the software allows the user to enter a Setup File Name to store current settings to the disk or to change the setup settings to those contained in the specified file. All error messages are displayed in the data entry window for a few seconds after which the software returns to the menu. The user must select the item again and properly enter the desired value. The following error messages may be displayed after the user has entered a Setup File name:

Error Message: Menu Item: Problem:

Error Message: Menu Item: Problem:

Error Message: Menu Item: Problem:

Error Message: Menu Item: Problem:

Error Message: Menu Item: Problem:
File Name cannot exceed 8 characters! Store/Read Setup File The entered name for a file was more than eight characters. The File Name must follow the MS-DOS rules for file names.

A File Name must be entered! Store/Read Setup File No characters were entered for the file name. The user pressed the Return or Enter key without entering any other characters. Pressing the Enter key at the File Name prompt allows the user to return to the Test Parameter/Setup File Menu without changing the values of the Setup parameters in memory.

No Setup File named exists! Read Setup File The entered name for the Setup File (displayed in the blank line shown above) was not found in the BHTVDATA directory on the hard disk.

The Setup file named already exists! Store Setup File The entered name for the Setup File (displayed in the blank line shown above) already exists in the BHTVDATA directory on the hard disk. A new name must be entered to store the current settings of the Setup parameters.

\section{Invalid Setup File name!} Store Setup File The entered name for the Setup File is not a valid DOS file name. A new name must be entered to store the current settings of the Setup parameters. 


\section{II.6. Data Acquisition and Display}

The Data Display and Acquisition selection in the Main Menu is really the heart of the HT-BHTV software. This portion of the program displays data acquired from the tool, stored in a file, or simulated data calculated by the software. The actual function that this section of the code performs is dependent on the settings of the user-controlled software flags and the operational mode of the software selected by the user. The values of these variables and the resultant operation of the software is summarized in Table II.3 below.

Note: The current version of the software cannot acquire both the acoustic BHTV data and the temperature from the tool at the same time because of time constraints in the software. Consult Section III for further information on the method of data acquisition from the tool. The operations shown in Table II.3 in which the temperature $\mathrm{flag}$ is set to True do not, in fact, acquire temperature data from the tool. These operations were included in the table for completeness. Further versions of this software could include the temperature acquisition operation. Section V discusses possible software modifications and advancements. The temperature may be acquired from the tool using a separate computer system and special software. This option is dis. cussed more fully in Section II.8.

The three user-controlled software flags in the table, the Tool, Depth, and Temperature flag variables, are discussed in section II.3. The mode of operation variable, which has three possible values - TEST, BHTV, and FILE, is discussed in Section II.4. In the table, two adjectives are used which described the type of operation performed. The adjective simulated means that the software is providing the values for the data. Acquired means that the software is obtaining the values for the data from either the HT-BHTV tool or the depth counter. The last line of Table II. 3 gives the operation when the FILE mode of operation is selected. Note that this mode ignores the values of the software flag or else sets the value to False.

When the Data Acquisition/Display item is selected from the Main Menu, the software will display either of two screens on the CRT. When either the TEST or the BHTV mode was selected in the Logging/Data Display Setup Menu, the CRT screen shown in Figure II.21 is displayed. If the FILE mode has been selected then the CRT screen shown in Figure II.22 is displayed. The message displayed on the screen depends upon the File Display option selected in the File Display Menu. If the entire file is to be viewed, then the display shows the message as in Figure II.21: ENTIRE FILE. If only a portion of the file was selected then the display shows the message SELECTED DEPTH INTERVAL if the depth interval option was selected in the File Display Menu or SELECTED RECORD NUMBERS if the record number option was selected. If the depth interval option was selected, the software does a fast binary search to find the record numbers it must display for the depth interval selected. During this 


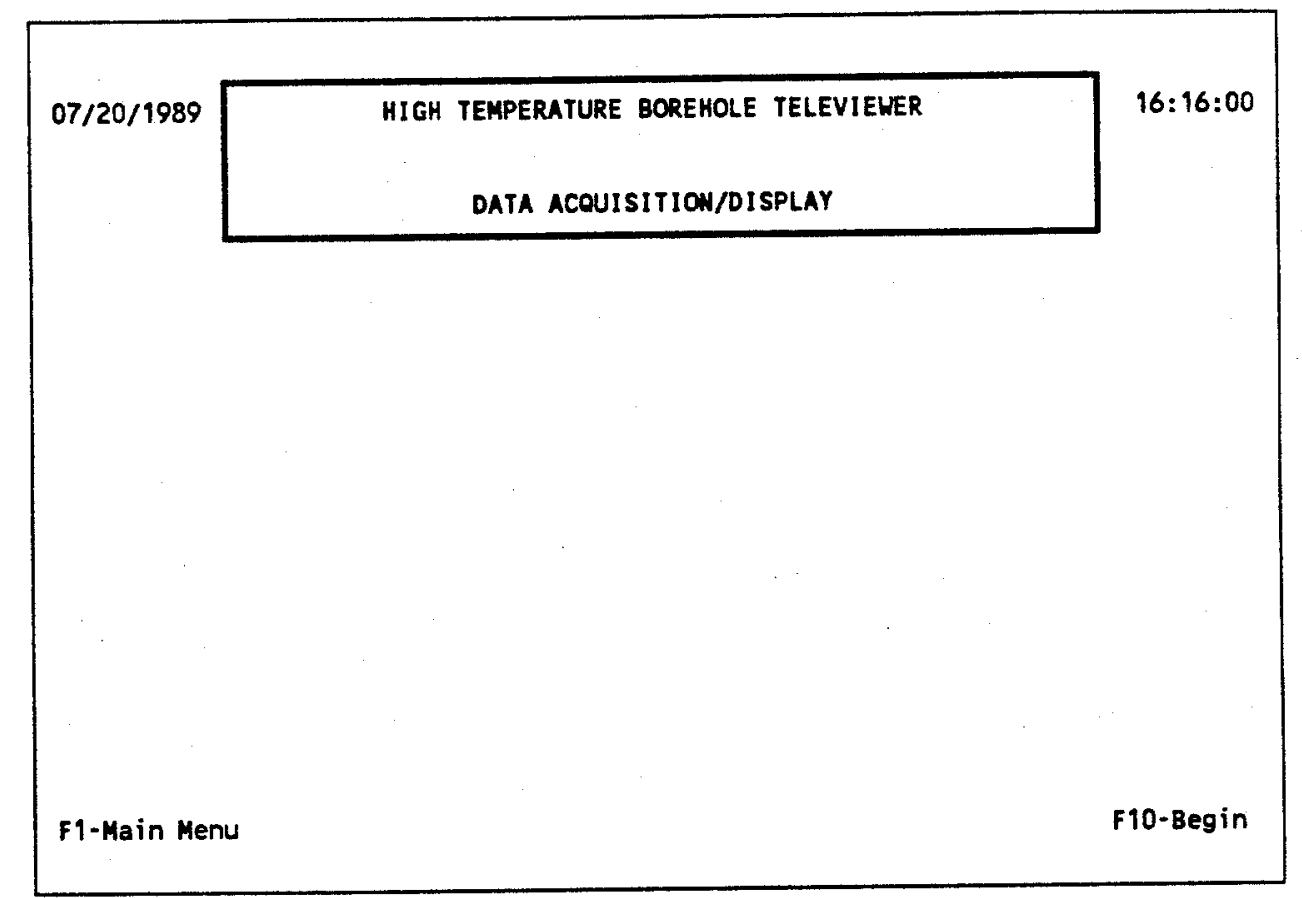

Figure II.21. An example of the CRT screen displayed when the Data Acquisition/Display option is selected in the Main Menu. This example shows the display when the Data Mode variable in the Logging/ Data Display Setup Menu is set to either TEST or BHTV.

search, which should take only a few seconds, the CRT screen will display the message

Searching for records. Please wait....

The two function keys displayed on the CRT screen have the following function:

Function key: $\quad$ F1 Pressing this key returns the program to the Main Menu.

Function key: $\quad$ F10 Pressing this key directs the software to begin the Data Acquisition and Display operation. The functions performed by the software will depend on the values of the Tool Flag and Data Mode variables. 


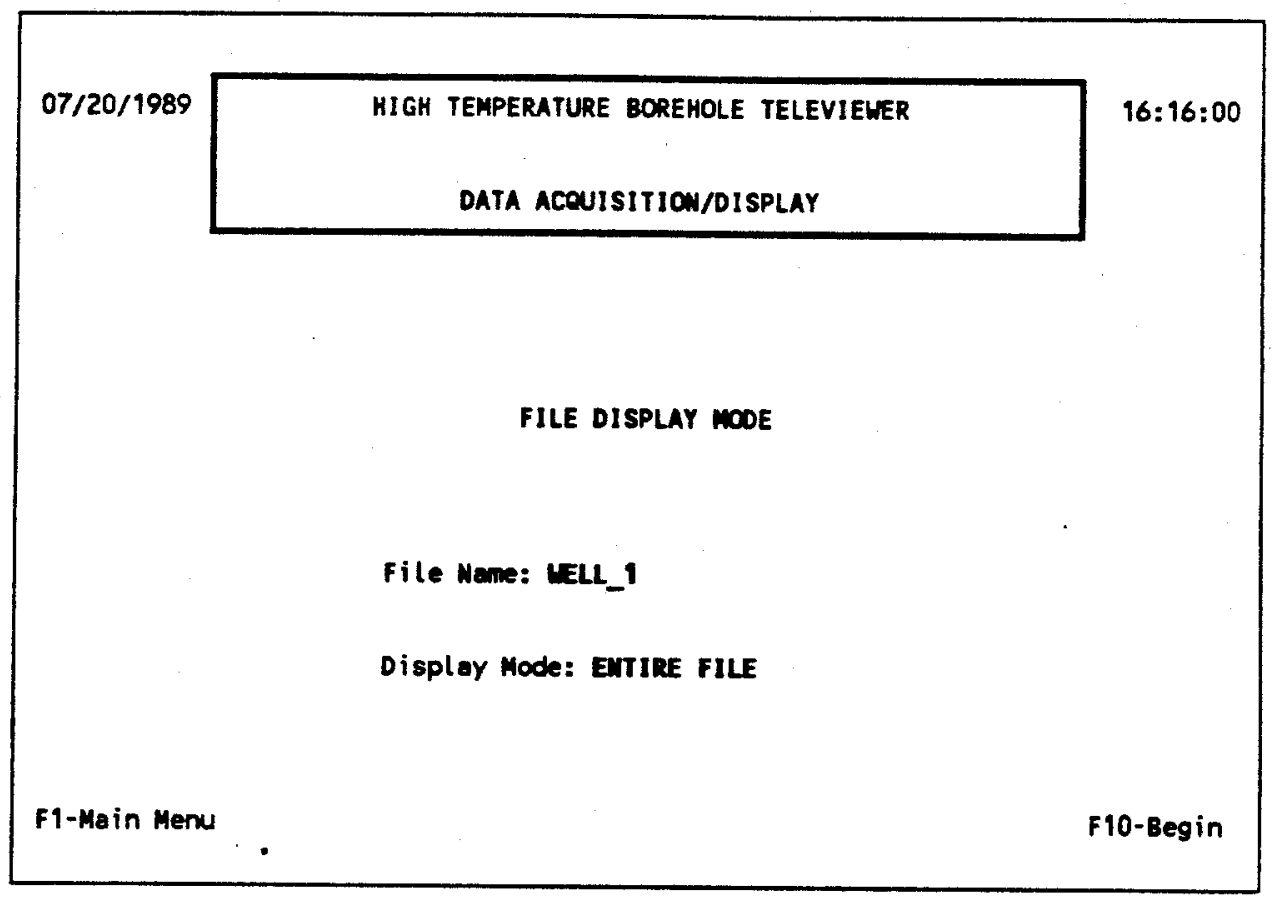

Figure II.22. An example of the CRT screen displayed when the Data Acquisition/Display option is selected in the Main Menu and the Data Mode variable in the Logging / Data Display Setup Menu is set to FILE. This example shows the display when the entire file is to be viewed.

\section{II.6.1. Error Messages}

When the Data Acquisition/Display option is selected from the Main menu, the software checks certain conditions and will either display an error message and return to the Main Menu or, in certain situations, transfer the user to the BHTV File Menu. The checks performed by the software pertain to the settings of the Data Mode variable and the type of file currently assigned by the software. If Data Mode is set to FILE and no file is assigned, no error message is displayed but the software routes the user to the BHTV File Menu. If Data Mode was set to FILE and a NEW file was assigned in the BHTV File Menu, the following error message is displayed:

Cannot access a NEW file in the FILE data mode...

and the software returns to the Main Menu. If the BHTV Data Mode was selected and a NEW file was not opened in the BHTV File Menu, then the software displays no error message but routes the user to the BHTV File Menu. However, if 
Table II.3. Summary of the possible settings of the user-controlled software flag and operational mode variables and the resultant operation of the software.

\begin{tabular}{|c|c|c|c|c|}
\hline $\begin{array}{l}\text { Tool } \\
\text { Flog }\end{array}$ & $\begin{array}{l}\text { Depth } \\
\text { Flag }\end{array}$ & $\begin{array}{l}\text { Temp. } \\
\text { flag }\end{array}$ & $\begin{array}{l}\text { Dote } \\
\text { Mode }\end{array}$ & Operation \\
\hline False & Folse & False & TEST & Simulated Tool and Depth date displayed \\
\hline False & False & False & BHTV & Simulated Tool and Depth data displayed and stored in user-specified file \\
\hline False & False & True & TEST & Simulated Tool, Depth and Temperature data displayed \\
\hline False & False & True & BHTV & $\begin{array}{l}\text { Simulated Tool, Depth and Temperature data displayed and stored in } \\
\text { the user-specified fite }\end{array}$ \\
\hline False & True & False & TEST & Simulated Tool data and Acquired Depth displayed \\
\hline False & True & False & BHTV & $\begin{array}{l}\text { Simulated Tool data and Acquired Depth displayed and stored in } \\
\text { the user-specified file }\end{array}$ \\
\hline False & True & True & TEST & Simulated Tool and Tenperature data and Acquired Depth displayed \\
\hline Fatse & True & True & BHTV & $\begin{array}{l}\text { simulated Tool and Temperature data and Acquired Depth displayed and stored } \\
\text { in the user-specified file }\end{array}$ \\
\hline True & False & Folse & TEST & Acquired Tool date and simulated Depth displayed \\
\hline True & False & False & BHTV & $\begin{array}{l}\text { Acquired Tool data and simulated Depth displayed and stored in } \\
\text { the user-specified file }\end{array}$ \\
\hline True & False & True & TEST & Acquired Tool and Temperature data and simulated depth displayed \\
\hline True & False & True & BHTV & $\begin{array}{l}\text { Acquired Tool and Tenperature data and simulated depth displayed and stored } \\
\text { in the user-specified file }\end{array}$ \\
\hline True & True & False & TEST & Acquired Tool and Depth date displayed \\
\hline True & True & False & BHTV & Acquired Tool and Depth data displayed and stored in the user-specified file \\
\hline True & True & True & TEST & Acquired Tool, Depth and Temperature data displayed \\
\hline True & True & True & BHTV & $\begin{array}{l}\text { Acquired Tool, Depth and Temperature data displayed and stored in } \\
\text { the user-specified file }\end{array}$ \\
\hline$\cdots$ & $\cdots$ & $\cdots$ & FILE & Dete stored in user-specified file displayed \\
\hline
\end{tabular}

the BHTV Data Mode was selected and an OLD file was opened in the BHTV File Menu, then the software displays the following error message:

Cannot access an OLD file in the BHTV data mode...

and the software returns to the Main Menu. In summary, in either the BHTV or the FILE Data Modes, it is necessary that a file have been opened in the BHTV File Menu. The software does not allow the user to append data to an existing file, hence, in the BHTV mode only a file of type NEW is permitted. Conversely, a NEW file, by definition, does not have any data stored in it yet so only a file of type OID is allowed when the Data Mode variable is set to FILE. 


\section{II.6.2. Description of the CRT Screen for Data Display}

Once the Data Acquisition/Display operation is selected by pressing the F10 key, as shown in Figure II.21 or II.22, then the software enters the graphics mode on the CRT screen and begins the operations defined by the current values of the Data Mode and the Flag variables as shown in Table II. 3 . An example of the Data Display screen shown on the CRT is given in Figure II.23 for the NORMAL Display size mode and in Figure II.24 for the EXPANDED Display Size mode. Eight areas of the display are indicated by numbers on the two figures. Some examples of the actual display may be found in Section IV. The eight display areas and their corresponding identification are summarized in Table II.4.

Table II.4. Listing of the eight display sections of the CRT graphics Data Display. Refer to Figures II.23 and II.24 for the positions of these areas on the screen.

\begin{tabular}{c|l}
\hline Area No. & \multicolumn{1}{|c}{ Identification } \\
\hline 1 & Data Display Area \\
2 & Depth Annotation Area \\
3 & Status Display Area \\
4 & Special Key Display Area \\
5 & Range/Magnitude Color Code Area \\
6 & Display Scale Iine \\
7 & Menu Display Line \\
8 & Message Display Line \\
\hline
\end{tabular}

The information displayed in these areas is described below.

\section{II.6.2.1. Data Display Area}

The Data Display Area graphically shows the data obtained from a file, simulated data calculated by the software, or data acquired by the ADC board following the calculation by the software. The meaning of the colors displayed on the screen are given in the Range/Magnitude Color Code Area. The range information is the arrival time of the return signal having units of microseconds. The magnitude data is the maximum amplitude value of the return signal given in the integer values obtained from the ADC board. The full scale range of this display is \pm 2048 corresponding to the selected gain setting on the ADC board. For example, a digitizer gain setting of $x 1$ gives a full scale range of \pm 10 volts. The left side of the Data Display corresponds to the Heading Reference indicator from the tool. It is magnetic north when the magnetometer is used and the mark position on the tool for the Mark reference. See Section III for more detailed information on the data display. 


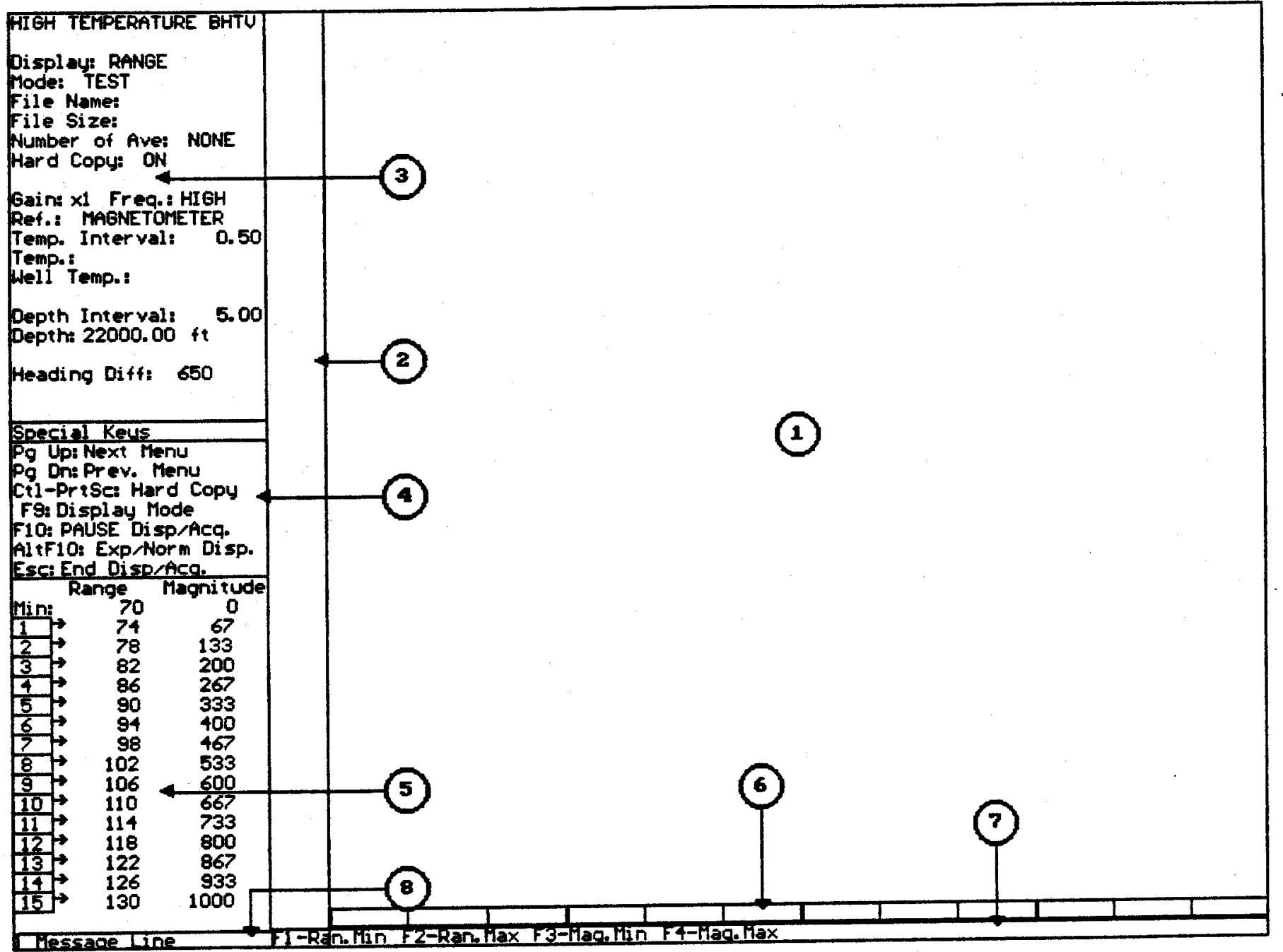
Figure II.23. The Data Display CRT screen for the NORMAL Display Size mode.
The numbered areas of the display are explained in the text. 


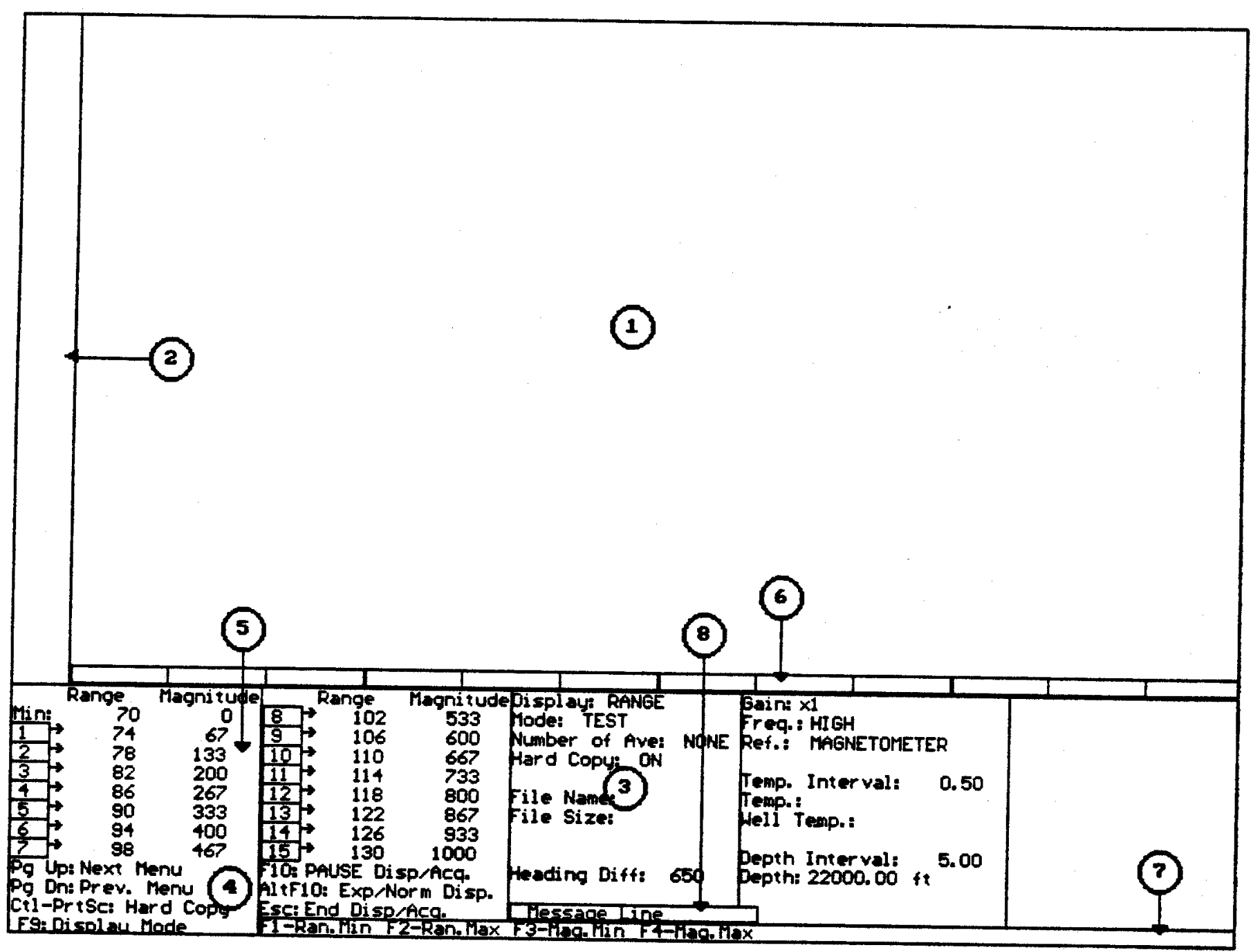

Figure II.24. The Data Display CRT screen for the EXPANDED Display Size mode. The numbered areas of the display are explained in the text. 


\section{II.6.2.2. Depth Annotation Area}

In this area of the display, the current depth at which the data was obtained is shown. The depth is displayed according to the current value of the Depth Interval which is set in the Logging/Data Display Setup Menu. The value of the depth displayed in this area is truncated since no decimal places are displayed. As noted previously, if the Depth Flag is True, the depth displayed is that acquired from the depth counter. When the Depth Flag is False, the software calculates a depth from an initial depth of 22,000 feet.

\section{II.6.2.3. Status Display Area}

The Status Display Area provides the user with the current settings of some of the important display and tool variables as well as with an update of the depth or the status of the current file if applicable. All the items shown in this display area are described below.

Display Item: Function:

Display Item: Function:

Display Item: Function:

Display Item: Function:
Display In this display item, the current value of the Data Mode variable is displayed. Possible values for this variable are: TEST, BHTV, and FILE. See Section II.5.5 for more information.

\section{Mode}

The current value the Data Display Mode variable is shown in this item. The possible values for this variable are: RANGE, MAGNITUDE, and RANGE/MAGNITUDE.

File Name

In the BHTV Data Mode, the file in which all the acquired data are being stored is displayed here. In the FILE Data Mode, the name of the file from which the displayed data are taken is shown. In the TEST Data Mode, nothing is shown for this display item.

\section{File Size}

In the BHTV Data Mode, two values are displayed for the size of the file. The first or leftmost value, shows the record of the virtual disk file in which the most recent displayed line of data was stored. The second value shows the total number of records contained in the data file on the hard disk. As explained more fully in Section III, the software stores the acquired data in a data file on the virtual disk. drive labeled E:. This memory area (which is set up when the computer is turned on) contains approximately 11 ibytes of capacity. This is enough to store 3900 
HT-BHTV data records. Hence, the first record value in this display item shows the current record count in the virtual disk file. When this count reaches 3900 records, the software will pause the data collection operation to transfer the data from the virtual disk memory to the hard disk in the BHTVDATA directory. It requires slightly more than 2 minutes to complete this transfer. During the transfer operation, since no data acquisition is occurring, the tool should be stopped in the hole. It is the user's responsibility to watch this display and stop the tool in the hole when the data transfer process begins. The second number will provide the user with an indication of the total number of records which will be stored in the file on the hard disk. The software will allow a maximum value of 15,600 records or 4 complete transfers of the virtual disk file. This is in excess of 40 Mbytes of data storage.

Display Item: Function:

Display Item: Function:

Display Item:

Function:

Display Item: Function:

Display Item: Function:
Number of Ave

The current number of averages performed on the data is shown here. At present, no averaging of the data is permitted.

Hard Copy

The current setting of the Hard Copy variable is shown here. Note that this variable must be set to oN to obtain a hard copy printout of the data display. The value of this variable may be changed in the Logging/ Data Display Setup Menu (Section II.5.5) or from one of the Data Display Menus described below.

Gain

The current Tool Gain value is displayed here. This value may be changed in the Tool Setup Menu (Section II.5.3).

Freq

The current Tool Transducer Frequency value is dis played here. This value may be changed in the Tool Setup Menu (Section II.5.3).

Ref

The current Tool Heading Reference value is displayed here. This value may be changed in the Tool Setup Menu (Section II.5.3). 
Display Item:

Function:

Display Item:

Function:

Display Item: Function:

Display Item: Function:

Display Item: Function:

Display Item: Function:
Temp. Interva1

The current setting of the Tool Temperature data acquisition depth interval is displayed here. See Section II.5.5 for more information on this variable.

Temp.

If the Temperature Flag is True, then the heat sink and the electronics temperatures are displayed here. With the Tool rlag set to False, the software will calculate temperatures to place here. When the Tool Flag is True, the temperatures acquired from the HTBHTV Tool are displayed. Temperatures are displayed in units of degrees $C$.

We11 Temp.

If the Temperature Flag is True, then the well temperature is displayed here. With the Tool Flag set to False, the software will calculate a temperature to place here. When the Tool Flag is True, the well temperature acquired from the HT-BHTV Tool is displayed. The temperature is displayed in units of degrees $C$.

Depth Interval The current value of the depth increment used for the depth annotation on the data display is shown. This value is set in the Logging/Data Display Setup Menu (Section II.5.5).

\section{Depth}

The current depth reading is displayed in this item. If the Depth Flag is False then the depth displayed will be the simulated depth calculated by the software beginning at a depth value of 22,000 feet. When the Depth Flag is True, the depth displayed here is that obtained from the depth counter.

Heading Difference

This display item is only present when the HT-BHTV Tool is acquiring data from the ADC board either in the TEST or BHTV Data Mode. This item shows the difference in sync pulses between the last and current heading pulse found by the software. It is a useful monitor of the performance of both the tool and the software. See Section II.5.4 on the Data Acquisition Menu and Section III for more information on the heading pulse difference. 


\section{II.6.2.4. Special Key Display Area}

In this display area, the defined function of certain keys are listed. These special keys (their operation remains the same no matter which menu is currently shown on the CRT screen - see section II.6.2.7 below) and their function are:

Special Key: Function:

Special Key: Function:

Special Key: Function:

Special Key: Function:

Special Key: Function:
$P_{g}$ Up

Pressing this key changes the menu shown on the Menu Display Line (see Section II.6.2.7).

Pg Dn Pressing this key changes the menu shown on the Menu Display Line (see Section II.6.2.7).

Ct1-PrtSer

Pressing this key will direct the software to produce a hard copy of the CRT screen currently displayed. The Hard Copy variable must have already been set to ON either in the Logging/Data Display Setup Menu or through one of the menus displayed in the menu line on this display. In the FILE Data Mode, the user may select a hard copy when the display is updating or when the display has been paused by pressing the F10 special key. In the other two Data Modes, the display must have been paused to obtain a hard copy of this display. The software prints out some information prior to the screen dump. The information printed is shown in Table II.5 for the FILE Data Mode. In the TEST Data Mode, only the current data and time, and the digitizer board parameters are printed. In the BHTV Data Mode, the name of the file and the File Description line are printed in addition to those mentioned for the TEST mode.

F9

Pressing the F9 key changes the value of the Data Display Mode variable. The software toggles through the three available settings of this mode. When the display mode is changed, the data display immediately changes to the current setting of this variable.

F10

Pressing this key pauses the display and data acquisition process. A message is flashed in the Message Line area informing the user that the display has paused. Pressing any key will resume the operation of the software. 
Table II.5. The information displayed when a screen dump is requested of the software. The information shown here is an example of the information displayed in the FILE Data Mode.

\section{HIGH TEPERATRE BHTV}

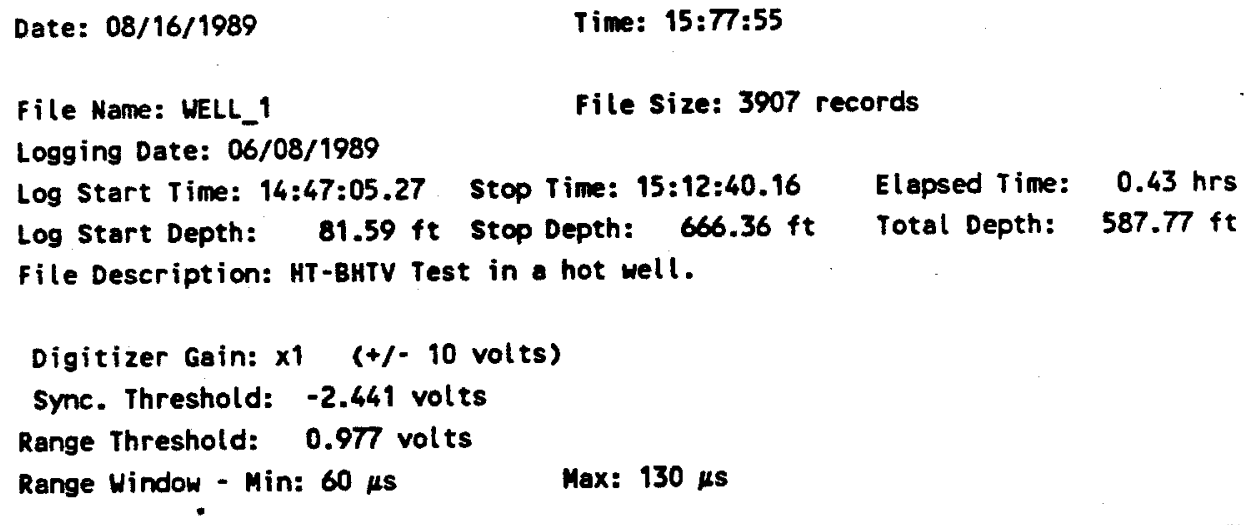

Special Key: Function:

Special Key: Function:

\section{AltF10}

This special key changes the size of the display area. In the NORMAL Display Size Mode, pressing this key changes the display to the EXPANDED Display Size Mode. The CRT screen is cleared, the new screen is set up, and the data is displayed in the new size.

\section{Esc}

Pressing the Escape key directs the software to exit the Data Acquisition/Display operation. In the FILE Data Mode, the software pauses the display. Pressing any key at this point will return the user to the Main Menu. In the BHTV Data Mode, the software first transfers the data from the virtual disk file to the hard disk. When this operation is complete, the software enters the BHTV File Menu. The user can now add any additional comments to the five lines of comments permitted for each file or add more information to the File Description line. Note that the software has now labeled the data file as an OLD file rather then a NEW file. The user may now review the data stored in this file, or open another file for additional data storage. No further data may be added to the data file just completed. In the TEST Data Mode, the user is returned to the Main Menu. 


\section{II.6.2.5. Range/Magnitude Color Code Area}

The Range/Magnitude Color Code area displays the colors on the data display and the resultant value of the Range or Magnitude. The Display Window defined by the Range or Magnitude minimum and maximum values is divided by the fifteen available colors. Black is used for the cases when the data falls outside the data acquisition or the display window. On the display, the value of the Range or the Magnitude shown next to the displayed color defines the end of the interval for that color. All data values which fall in that interval will be displayed in that color. The default color table used in the software is summarized in Table II.6.

Table II.6. The default color table used in the HT-BHTV software. The number of the color refers to the default color palette used in Turbo Pascal Version 4.0. Note that color number 0 is black which is used for data outside of the data acquisition or the display windows.

\begin{tabular}{cl}
\hline Color No. & Color \\
\hline 1 & Blue \\
2 & Green \\
3 & Cyan \\
4 & Red \\
5 & Magenta \\
6 & Brown \\
7 & Light Gray \\
8 & Dark Gray \\
9 & Light Blue \\
10 & Light Green \\
11 & Light Cyan \\
12 & Light Red \\
13 & Light Magenta \\
14 & Yellow \\
15 & White \\
\hline
\end{tabular}

\section{II.6.2.6. Display Scale Line}

The Scale shown in this area gives an approximate indication of the relative position of the data shown on screen. The left side of the screen is the mark indication or magnetic north depending upon whether the mark or the magnetometer is used in the tool as the heading reference. The lines on the scale are at separations of 30 degrees for either the Range or Magnitude display mode or at 60 degrees for the Range/Magnitude display mode. 


\section{II.6.2.7. Menu Display Line}

There are two menus which appear on the Menu Display Line in the data display. When each menu is displayed, the function keys displayed in the menu are programmed to provide the listed operation. The menus are toggled by using either the $\mathrm{Pg}$ Up or the $\mathrm{Pg}$ Dn keys. The first menu allows the user to change the values of the Range and Magnitude display windows. The second menu defines two function keys which permit the user to change the value of the Hard Copy variable and to clear the data display. The operation of the function keys defined in the two menus are described below.

\section{Menu 1}

\section{Function key: \\ Name: \\ Operation:}

$$
\begin{array}{r}
\text { Function key: } \\
\text { Name: } \\
\text { Operation: }
\end{array}
$$

Function key:
Name:
Operation:

Function key:

Name:

Operation:
F1

Ran. Min.

Allows the user to enter a new value for the minimum value of the Range display window.

F2

Ran. Max.

Allows the user to enter a new value for the maximum value of the Range display window.

\section{F3}

Mag. Min.

Allows the user to enter a new value for the minimum value of the Magnitude display window.

\section{F4}

Mag. Min.

Allows the user to enter a new value for the maximum value of the Magnitude display window.

\section{Menu 2}

\author{
Function key: $\quad$ F6 \\ Name: Clear Disp. \\ Operation: Clears the Data Display Area.
}

Function key: $\quad$ F7

Name: Hard Copy

Operation: Toggles the Hard Copy variable. The variable can only be set to on when the printer is properly connected.

\section{II.6.2.8. Message Display Line}

The Message Display Line is used to display messages, e.g., when the display has been paused, or for a data input area, as for the Range and Magnitude display windows in Menu 1 described above. 


\section{II.7. Archiving the data to Tape}

It is good practice to archive all data taken in the field to tape so that a copy of the data is available if some problem develops with the hard disk. Additionally, the large capacity hard disk on this computer system (available storage of 300 Megabytes) can quickly fill up during a logging operation making it necessary to archive some data to make room for additional acquired data. The computer system comes equipped with an internal 135Megabyte tape drive. The SY-TOS tape operating system is provided with this drive to backup, verify, and restore televiewer data files. The user should consult the manual for this system [6] for the proper operating procedure. Note: Experience with this tape system and software has shown that the computer must be turned off and back on before using the tape system. if the computer system was used to acquire televiewer data from the HT-BHTV tool.

\section{II.8. Temperature Acquisition Program}

Because of the rather severe time limitations in the system for data acquisition, display, and storage during a logging operation, the software is not capable of acquiring, temperature data. Since temperature data is considered important, especially as a tool diagnostic (cf. Section IV), a separate program is provided, for use on another computer system, to acquire and store the temperature data from the tool. This program may be started by typing BHTV_DEG at the C> prompt. The program asks for the name of a file in which to store the data. Once the program is started, temperatures are acquired at a $500 \mathrm{~ms}$ interval. The resultant file will contain the time and temperatures but no depth information. This file may be correlated with the tool data file (.BTV extension) to add the proper depth to the temperature data. 


\section{TECHNICAL DESCRIPTION OF SOFTWARE}

The HT-BHTV software was written in Turbo Pascal Version 4.0 [7,8,9,10, 11]. Included in the software package for this tool is additional software for the operation of the Metrabyte Data Acquisition Board for the computer. Turbo Pascal Version 4.0 allows a programming construct called a unit. Each unit is a self-contained program consisting of a set of procedures and functions. Selected procedures and functions in the unit may be called by another program or unit if these procedures are first defined in the interface section of the unit. Another section of the unit, called the implementation section, contains all the procedures and functions required by the unit but not accessible by other programs or units. The use of the unit in this language allows the programmer the flexibility to separate the operations of the software into these separate sections which can be compiled and debugged independently from other parts of the code. The HT-BHTV software has used the unit concept to build modular program sections for the separate menus and operations of the program.

There are 41 files contained in the HT-BHTV software package. Of these, two files, a source listing and an executable binary, are for the main program. Two are text files specifying the path name for the BHTVDATA directory and the virtual disk. Three are files associated with the Metrabyte Data Acquisition board. One file is an Include File for a unit. There are three batch files for starting the program or initializing the data acquisition system. The separate temperature acquisition program is contained in an executable binary and source listing file. The remaining 26 files comprise the bulk of the software. These are the 13 units in the software. Each unit has a source listing file using the extension. PAS and a precompiled unit file with the extension. TPU. These files are summarized in Table III.I.

A schematic diagram of the hardware and connections for the HT-BHTV tool and the computer system is shown in Figure III.1. The hardware requirements of this system are summarized in Appendix A. In this section, technical information regarding the operation of some parts of the HT-BHTV software is presented. In particular, the software interface with the depth counter, televiewer, ADC board, and printer are discussed. Certain important aspects of the software, including the file format and data display, are also discussed.

\section{III.1. Tool Parameters}

Control commands are sent and temperature data are received from the HT-BHTV tool through the Surface Unit over a 300 bps RS-232 serial line connected to the COM2 port on the computer. The serial interface is configured for 300 baud, no parity, 2 stop bits, and 8 data bits. Table III.2 summarizes some useful information on IBM PC compatible serial ports. Commands are sent to the tool by a coded byte ( 8 bits) sent over the serial line. Note that only a single byte is sent. No end-of-line terminators, such as a line feed 
Table III.1. Listing of the HT-BHTV software files. The units or programs shown below also require the following Turbo Pascal standard units: Dos, Crt, Graph, and Printer; and the following graphics files: EGAVGA.BGI and LITT.CHR. In the table, the heading labeled Note contains numbers with the following definition:

1 - Unit containing a menu and associated procedures;

2 - Unit containing data acquisition/display procedures;

3 - Unit containing misc. utility procedures.

\begin{tabular}{|c|c|c|c|c|}
\hline Unit Nane & File Name & File Ext. & Note & Function \\
\hline BHTV_MAIN & BHTVMAIN & EXE/PAS & $\cdot$ & Main program. \\
\hline Tool_Status & TOOLSTAT & TPU/PAS & 1 & Tool Setup Menu + associated procedures \\
\hline DigitizeBHTV & DIGBHTV & TPU/PAS & 1 & Data Acquisition Menu \\
\hline Depthcounter & DEPTHENC & TPU/PAS & 1 & Depth Encoder Setup Merus + associated procedures \\
\hline LoggingSetup & LOGSETUP & TPU/PAS & 1 & Logging/Data Display Setup Menu + associated procedures \\
\hline Datafiles & DATAFILE & TPU/PAS & 1 & BHTV File Menu + associated procedures \\
\hline Filedisplay & FILEDISP & TPU/PAS & 1 & File Display Menu + associated procectures \\
\hline TestParameters & TESTPARM & TPU/PAS & 1 & Test Paraneter/file Setup Menu \\
\hline Date_Acq_Display & DATA_ACO & TPU/PAS & 2 & Data Acquisition from tool using $A D C$ board \\
\hline NA & DATADISP & PAS & 2 & Include file for the DATA_ACO unit; data display procedures \\
\hline BHTV_data & BHTVDATA & TPU/PAS & 2 & Procedures for calculation of simulated tool data \\
\hline PrintData & PRNTDATA & TPU/PAS & 2 & Procedures for printing the CRT on color printer \\
\hline TextWindow & HINDOW & TPU/PAS & 3 & Windowing procudures; used for data input + error messages \\
\hline FileCopy & FILECOPY & TPU/PAS & 3 & Procudure for copying files; used to copy waveform data \\
\hline UtilitiesLibrary & UTIL_LIB & TPU/PAS & 3 & Misc. string, CRT screen, and keyboard procedures \\
\hline DASZOEXT & DAS2OEXT & TPU & 2 & Metrabyte-supplied unit \\
\hline tp $4 \mathrm{~d} 20$ & TP4D20 & TPU & 2 & Metrabyte-supplied unit; date acquisition procedures \\
\hline NA & DAS2O_O & OBJ & $\cdot$ & Object file with assembly language procs. for ADC board \\
\hline NA & BHTVPATH & $T X T$ & - & Text file containing path name for BHTVDATA directory \\
\hline MA & VOISK & $T \times T$ & - & Text file containing path name of virtual disk \\
\hline MA & HTBHTV & BAT & $\cdot$ & Batch file for starting ит-BHTV program \\
\hline NA & BHTVINIT & BAT/EXE/PAS & - & Batch, binary, source file for initial. system for ADC board \\
\hline NA & BHTV_DEG & BAT/EXE/PAS & - & Batch, binary, source file for temperature acq. progran \\
\hline
\end{tabular}




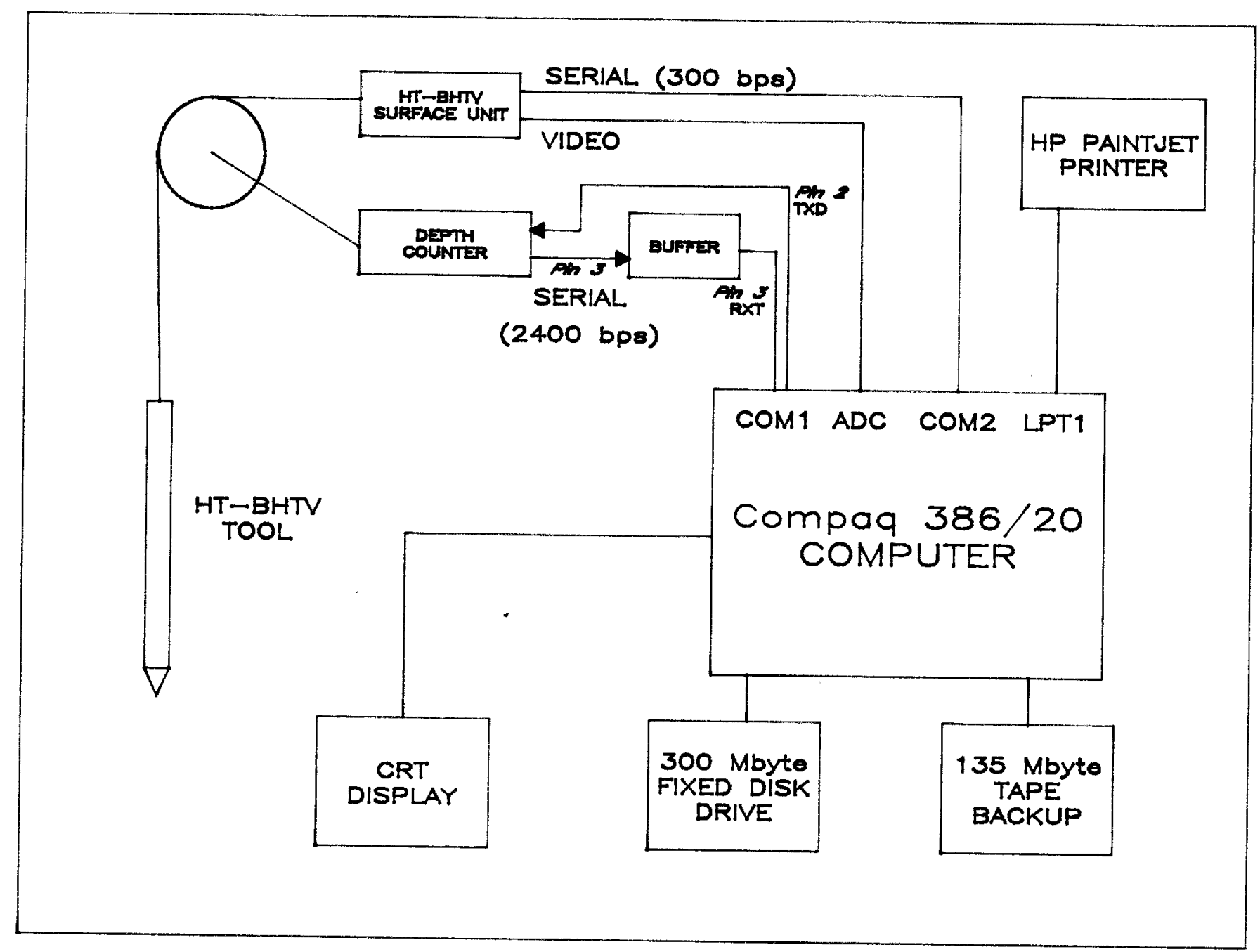

Figure III.1. Schematic diagram of the interconnection of the hardware required for the HT-BHTV system at the surface. A special serial connection is required for the depth counter system. The TXD line is for transmitted data, DTE to DCE; the RXT line is for received data, DCE to DTE. For the counter-to-buffer connection, the following pins on the serial line are tied together: pin 5 (CTS), pin 6 (DSR), pin 8 (DCD), and pin 20 (DTR). 
Table III.2. Summary of some useful addresses for the INS8250 UART used on IBM PC compatible computers [12] (Note: Compaq computers use a National Semiconductor NS16450 Asynchronous Communication Element; both of these uarts use the same addresses). The addresses listed below are given in hexadecimal units.

\begin{tabular}{l|l|l}
\hline Register & $\begin{array}{c}\text { Address } \\
\text { com1/COM2 }\end{array}$ & \multicolumn{1}{|c}{ Description } \\
\hline Receive Buffer & $\$ 3 F 8 / \$ 2 F 8$ & $\begin{array}{l}\text { Read only register containing most recently received } \\
\text { byte from the computer. }\end{array}$ \\
\hline Line Status & $\$ 3 F 0 / \$ 2 F 0$ & $\begin{array}{l}\text { Information on the status of the data transfer. Bit } 0 \\
\text { indicates that data is ready to be received. }\end{array}$ \\
\hline Modem Control & $\$ 3 F C / \$ 2 F C$ & $\begin{array}{l}\text { Bit 0: Data Terminat ready; computer is ready to } \\
\text { commicate with the device. } \\
\text { Bit 1: Request to Send (RTS). }\end{array}$ \\
\hline
\end{tabular}

and/or carriage return, are sent to the tool. Sending such additional data to the tool causes unforeseen results and could result in the tool locking up. Table III. 3 summarizes the commands and the byte patterns used.

The tool sends to the computer the requested temperature information as either one or two bytes. The electronics and the heat sink temperature have a resolution of 8 bits while the well fluid temperature has a resolution of 12 bits. Hence, the tool requires two commands to return the complete well temperature. Each of the commands returns one byte of this temperature. Following the return of the temperature information, the software calculates the temperature in degrees Celsius using the following equation for the electronics and heat sink temperatures:

$$
\text { Temperature in }{ }^{\circ} \mathrm{C}=1.953125 \text { * byte }-273.15 \text {; }
$$

and the equation below for the conversion of the well fluid temperature data:

$$
\text { Temperature in }{ }^{\circ} \mathrm{C}=\mathrm{k}_{0}+\mathrm{k}_{1} *_{n}+k_{2} *^{2}+k_{3} n^{3}+k_{4} *^{4}+k_{5} *^{5} \text {, }
$$

where

$$
\begin{aligned}
& n=(\text { High byte) } \star 256+\text { Low byte } \\
& k_{0}=288.1888 ; \\
& k_{1}=-0.1480216 ; \\
& k_{2}=3.767929 \times 10^{-5} \\
& k_{3}=-7.876804 \times 10^{-9} \\
& k_{4}=1.064097 \times 10^{-12} \\
& k_{5}=-6.423687 \times 10^{-17}
\end{aligned}
$$


Table III.3. Command byte sent to the HT-BHTV tool by the computer. The letter $\mathrm{x}$ denotes bit positions that are not used and ignored by the tool. The letter $b$ denotes bit positions defined by the current setting of another function. For example, the command byte for the low transducer frequency must contain the current setting of the heading reference in bit position 1 . Note that only the gain commands have bit 7 set to 0 ; all other tool commands require that bit 7 have a value of 1 .

\begin{tabular}{|c|c|c|c|c|c|c|}
\hline Function & 7 & & & & & $\begin{array}{l}\text { Byte } \\
210\end{array}$ \\
\hline $\begin{array}{l}\text { Gain - xl } \\
\text { Gain - x10 } \\
\text { Gain - x50 } \\
\text { Freq. - High } \\
\text { Freq. - Low } \\
\text { Heading - Mag. } \\
\text { Heading - Mark } \\
\text { Temp. - Sink } \\
\text { Temp. - Elect. } \\
\text { Temp. -Well-Low } \\
\text { Temp. -Well-High }\end{array}$ & $\begin{array}{l}0 \\
0 \\
0 \\
1 \\
1 \\
1 \\
1 \\
1 \\
1 \\
1 \\
1\end{array}$ & $\begin{array}{l}\mathbf{x} \\
\mathbf{x} \\
\mathbf{x} \\
\mathbf{x} \\
\mathbf{x} \\
\mathbf{x} \\
\mathbf{x} \\
\mathbf{x} \\
\mathbf{x} \\
\mathbf{x} \\
\mathbf{x}\end{array}$ & $\begin{array}{l}\mathbf{x} \\
\mathbf{x} \\
\mathbf{x} \\
\mathbf{x} \\
\mathbf{x} \\
\mathbf{x} \\
\mathbf{x} \\
\mathbf{x} \\
\mathbf{x} \\
\mathbf{x} \\
\mathbf{x}\end{array}$ & $\begin{array}{l}\mathbf{x} \\
\mathbf{x} \\
\mathbf{x} \\
0 \\
0 \\
0 \\
0 \\
1 \\
1 \\
0 \\
0\end{array}$ & $\begin{array}{l}\mathbf{x} \\
\mathbf{x} \\
\mathbf{x} \\
0 \\
0 \\
0 \\
0 \\
0 \\
0 \\
1 \\
1\end{array}$ & $\begin{array}{lll}x & 0 & 0 \\
x & 1 & 0 \\
x & 1 & 1 \\
0 & b & c \\
0 & b & 1 \\
0 & 0 & b \\
0 & 1 & b \\
0 & b & b \\
1 & b & b \\
0 & b & b \\
1 & b & b\end{array}$ \\
\hline
\end{tabular}

The term byte refers to the decimal representation of the data byte returned by the tool.

\section{III.2. Depth Counter}

The HT-BHTV software is designed to operate with a Red Lion Controls Gemini 2000 Counter which in turn is connected to a Red Lion Controls Rotary Pulse Generator model RGPC-46-1-0500 (500 pulses per revolution) optical encoder attached to the cable or the cable drum axle. The counter is connected to the computer at the COM 1 port over a 2400 bps RS-232 serial 1 ine through a Red Lion Controls Model GCM232 Serial Converter Module. Because of time constraints in the software and the approximately $100 \mathrm{~ms}$ internal conversion time of the counter, the serial line to the computer from the counter is configured as shown in Figure III.1. The output from the counter is fed into a serial buffer while the input to the counter from the computer bypasses this buffer. This allows the computer to send the request depth command to the counter and the resultant depth from the counter is stored in the buffer until the computer requests this stored depth. As indicated above, there is a $100 \mathrm{~ms}$ delay from the time the computer sends the command for the depth to the 
counter and the time the computer receives the depth from the counter. During data acquisition, the acoustic transducer in the tool is rotating at a rate of $333 \mathrm{~ms} /$ rotation. During this time, the software must acquire the digitized data, perform the necessary calculations, display and store the data. The system cannot afford a delay of $100 \mathrm{~ms}$ while waiting for the depth data from the counter. For this reason, the buffer was set up to hold this data until the computer requests it. The serial interface is configured for 2400 baud, 1 start bit, 1 odd parity bit, 1 stop bit, and 7 data bits. The commands sent to the counter and the format of the data returned by the counter are summarized in Table III.4.

Table III.4. Summary of Depth Counter commands. The asterisk, *, is the command delimiter for commands sent to the counter. The depth preset value and the depth value itself depend on the number of decimal places set in the counter. Possible values are 0,1 , and 2. The formats shown in the table assume that 2 decimal places have been selected. The number of decimal places shown on the counter cannot be changed by software but only by the front panel controls of the counter. See the manual for the counter for further information. NA indicates places where a response is not applicable. The letter $b$ refers to numerical values returned or sent to the counter.

\begin{tabular}{l|c|l}
\hline Command & Data Format & Type of Command \\
\hline$R^{*}$ & NA & Counter reset \\
$T C^{*}$ & $\pm b b b b . b b$ & Counter transmits depth to conputer \\
$T^{*}$ & $\pm b . b b b b$ & Counter transmits scale factor to computer \\
$T B^{*}$ & bbbb.bb & Counter transmits preset value to computer \\
VBbbbb.bb* & NA & Computer sends new preset value to the counter \\
VO $\pm b . b b b b^{*}$ & NA & Computer sends new scale factor to the counter \\
\hline
\end{tabular}

\section{III.3. Data File Format}

The HT-BHTV software stores selected data from its operation into one of six file types all of which are stored in the BHTVDATA subdirectory on the hard disk. Each of the files created by the program are typed or randomaccess files. There are four files storing data and information during a logging operation. Waveform data and setup information each have a single file associated with them.

\section{III.3.1. Televiewer Data Files}

The four files which result from a logging operation are denoted by the particular extension assigned by the software. The information stored in each record of these four files is summarized in Table III.5. 
Table III.5. Summary of information contained in each individual record of the four televiewer data files.

\begin{tabular}{|c|c|c|c|}
\hline File Ext. & Record Element Name & Record Eiement Type & Record Size \\
\hline BTV & $\begin{array}{l}\text { Depth } \\
\text { Time } \\
\text { Range } \\
\text { Magni tude }\end{array}$ & $\begin{array}{l}\text { real } \\
\text { string [11] } \\
\text { array }[1 . .650] \text { of integer } \\
\text { array [1..650] of integer }\end{array}$ & 2616 bytes \\
\hline 100 & $\begin{array}{l}\text { Date } \\
\text { Startiime } \\
\text { Stopt ime } \\
\text { StartDepth } \\
\text { StopDepth } \\
\text { Description } \\
\text { Comments }\end{array}$ & $\begin{array}{l}\text { string }[10] \\
\text { string }[11] \\
\text { string }[11] \\
\text { real } \\
\text { real } \\
\text { string }[60] \\
\text { array }[1 . .5] \text { of string [78] }\end{array}$ & 499 bytes \\
\hline DEG & $\begin{array}{l}\text { Depth } \\
\text { Time } \\
\text { Helllow } \\
\text { Wellinigh } \\
\text { ElectTemp } \\
\text { SinkTemp }\end{array}$ & $\begin{array}{l}\text { real } \\
\text { string[11] } \\
\text { byte } \\
\text { byte } \\
\text { byte } \\
\text { byte }\end{array}$ & 20 bytes \\
\hline CTL & $\begin{array}{l}\text { Depth } \\
\text { Time } \\
\text { Gain } \\
\text { Freq } \\
\text { Ref } \\
\text { OigitizerGain } \\
\text { symcThreshold } \\
\text { RangeThreshold } \\
\text { RangeWindowin in } \\
\text { Rangeldindowlax }\end{array}$ & $\begin{array}{l}\text { real } \\
\text { string }[11] \\
\times 1, \times 10, \times 50 \\
\text { High, Low } \\
\text { Magnetometer, Mark } \\
\times 1, \times 2, \times 20, \times 200 \\
\text { integer } \\
\text { integer } \\
\text { integer } \\
\text { integer }\end{array}$ & 28 bytes \\
\hline
\end{tabular}

Files with the . BTV extension contain the time, depth, and the data arrays in each separate record. There are two data arrays stored in each record. One array contains the magnitude or amplitude data extracted from the digitized waveforms obtained from the tool. The other array contains the range or time interval data. Section III.4 discusses the method used by the software to construct these data arrays from the digitized waveform. Each array contains 650 elements (which is approximately equal to the number of tool pulses during a single rotation of the transducers at a rate of 3 rps) stored in integer format. Each record in this file corresponds to a single horizontal line of data displayed on the CRT screen.

Files with the .DEG extension contain the temperature data acquired from the tool during a logging run. Each record corresponds to a separate temperature acquisition from the tool. If a second computer system was used for this data acquisition (cf. Section II.8), no depth information is stored in this file. However, the stored data acquisition times in the .BTV and .DEG files 
may be correlated and the correct depths can be added to the .DEG file. This exercise is left to the user.

Files with the .LOG extension contain information from the logging run. These files consist of a single record unlike the. BTV and. DEG files. The information in this file is entered and displayed in the BHTV File Menu.

Finally, files with the .CTL extension contain information on the data acquisition setup used for the tool and the ADC board. This file also consists of a single record.

\section{III.3.2. Waveform Data Files}

Digitized waveforms, acquired using the Data Acquisition Menu (cf. Section II.5.4), are stored in waveform data files in the BHTVDATA directory with the file extension. WAV. These are large files containing 640,000 bytes of data. The data are stored in an integer format, hence, 320,000 data samples are stored in each file. Since there are roughly 51 data samples for each video frame, these files store the equivalent of 6,274 video frames or about 9.6 rotations of the televiewer transducers. No additional information is stored in these files.

\section{III.3.3. Data Acquisition Setup Files}

The Data Acquisition Setup Files store data pertinent to data acquisition from the tool and the display of the data on the CRT screen. Section II.5.8 on the Test Parameter/Setup File Menu discusses the operation of storing and reading the information contained in these files. The files contain a single record having a size of 36 bytes. The names of the individual components of the data record and their data type are summarized in Table III. 6.

Table III.6. Summary of information contained in the Setup Files stored and read by the Test Parameter/Setup File Menu.

\begin{tabular}{l|l}
\hline Record Element Name & Record Element Type \\
\hline DigitizerGain & $\times 1, \times 2, \times 20, \times 200$ \\
syncThreshold & integer \\
RangeThreshold & integer \\
RangewindowMin & integer \\
RangewindowMax & integer \\
RangeMin & integer \\
RangeMax & integer \\
MagMin & integer \\
MagMax & integer \\
\hline
\end{tabular}




\section{III.4. Data Acquisition Using the Internal ADC Board}

The HT-BHTV software uses a Metrabyte Corp. model DAS-20 High Performance Analog and Digital Interface Board having 12 bit resolution and a maximum conversion rate of 100,000 samples/second to digitize the waveform returned from the televiewer [15]. This analog-to-digital converter board (ADC) operates in a background mode writing the digitized data to computer memory using a Direct Memory Access (DMA) channel [14]. The software uses the following three procedures from the tp4d20 unit [16]:

GetDMABuffer: allocates memory on the Turbo Pascal heap and returns a pointer to the starting address of the buffer; buffer size set to 64,000 bytes.

DAS20Mode0: initializes the DAS-20 system; sets interrupt level to 7 and the DMA level to 1 .

d20Ainsc: scans the analog input channels (channels 0 and 1 are used) and stores the result in the DMA buffer; set to continuous operation; takes 32,000 samples at a rate of 100,000 samples per second.

The DMA channel is limited to 64 kbytes or 32 kbytes of data samples. Because of this limitation, the software uses the concept of a double buffer to access the data stored in RAM from the ADC board. Two buffers, contiguous in memory, set to a size of 32,000 bytes or 16,000 data samples, are defined by the software. (Both the DATA_ACQ and DIGBHTV units employ this concept.) As the $A D C$ board writes to one buffer, the software is checking (or, in the case of the DIGBHTV unit, storing to virtual disk) the data in the other buffer.

The ADC board digitizes the televiewer data at a rate of 100,000 samples per second which yields a time resolution of $10 \mu \mathrm{s}$. A better time resolution than this value is really desired for the range or arrival time. However, the bus used on the IBM compatible systems tends to limit the maximum digitizing rate due to the limitation on data transfer through a DMA channel. To improve the time resolution of the system, the software uses a linear interpolation scheme to provide time intervals less than $10 \mu \mathrm{s}$. In this scheme, the data samples on either side of the sync and range threshold values (cf. Figure II.7) are used, together with the threshold values, to calculate a time with a resolution of $1 \mu \mathrm{s}$. In this technique, the principle assumption is that the data signal can be approximated as a linear response over the $10 \mu \mathrm{s}$ interval defined by the two points which bound the threshold values. Tests using this interpolation scheme have shown an improvement in the time resolution of the range information. However, future improvements to this system should include the incorporation of a faster digitizing board to reduce any potential error in the interpolation method used in the software. 
The magnitude or amplitude data is found using a relatively simple method. The software determines the maximum value of the first 4 data samples which exceed the Range Threshold level (cf. Figure II.7). This maximum value is then stored as the amplitude value. No interpolation is used to improve the amplitude resolution here because, unlike the case for the range value, a linear approximation is very likely not valid. Some knowledge of the signal shape is required to give a reasonable interpolated value. However, any calculation using an estimated signal shape may require too much time for the system and cause a loss of the heading pulse signal.

If the return signal from the wall of the borehole falls below the value of the range threshold level or falls outside of the range window time interval (cf. Figure II.7), the software will store a value of 0 for both the range and magnitude data. A value of 0 is displayed as no color or black on both the CRT screen and the hard copy display. The user must adjust either the range threshold value or the limits of the range window if a signal is de-

The data for both the range and magnitude arrays are stored in integer format (integers require 2 bytes or 16 bits; the ADC board used for the digitization has an amplitude resolution of 12 bits). The range information is stored in units of microseconds with a resolution of $1 \mu \mathrm{s}$. The magnitude data are stored as integer values in the range of \pm 2048 . The data are modified from the bit-shifted form received from the $A D C$ board [15]. Storing the data in this format means that the setting of the gain on the board is not used. The actual voltage value depends on this gain setting. See Section II.5.4 for the voltage ranges corresponding to the different gain settings.

Occasionally, some operation in the computer, either I/O related or computational, will require a slightly longer time to complete. When this happens, the Heading Difference display on the CRT screen will show a value substantially different than the normal difference value displayed. This "loss of synchronization" in the software will cause perhaps 1 or 2 data lines on the CRT screen to be displaced from the other data lines shown. With the double buffer used for the calculations, the data should be quickly "synchro. nized" again. However, if this problem becomes quite regular, this means that the Range Window Time Interval is probably too long and should be shortened.

\section{III.5. Data Display}

The graphics display in the VGA mode used in this software has 640 horizontal and 480 vertical pixels. The actual display area for the data (see Figures II.23 and II.24) is less than this because of the additional information shown on the CRT screen. In the NORMAL display mode, the data display area consists of 480 horizontal and 460 vertical pixels. In the EXPANDED display mode, the data display area consists of 610 horizontal and 340 verti. cal pixels. When both the range and magnitude data are displayed simultaneously, the number of horizontal pixels for each is reduced to 238 for the 
NORMAL display mode and to 303 for the EXPANDED display mode. (Note: this discussion assumes that the tool rotational speed is set to $3 \mathrm{rps}$; the other tool rotational speeds will have correspondingly different numbers of horizontal pixels.) The range and magnitude data arrays each contain 650 elements. obviously, these data must be reduced in some manner to permit a display of less than all the data. This is accomplished using a linear decimation algorithm [13]. This algorithm deletes samples and does a linear interpolation to provide values between data samples as required. These new samples are checked to see if they fall outside the range window time interval in the case of the range data. Those samples which are outside this window are assigned a value of 0 .

Following the data decimation, the data are checked to determine in which color interval they fall. The color intervals are displayed on the CRT screen and can be adjusted by changing the values of the Range or Magnitude display windows. Any change to these limits causes the software to display the new color intervals. Once the appropriate color interval is found, the pixel corresponding to the decimated data sample is assigned the color of that interval. This display has 16 possible colors (see Table II.6) which may be used with the color black reserved for the case when the data value falls outside of the Range Display or the Data Display windows.

\section{III.6. Hard Copy Output of CRT Screen}

A color hard copy of the CRT screen (for both the televiewer Range/ Magnitude display and the digitized waveform data display) is obtained using a Hewlett Packard PaintJet printer. This printer has a palette of 330 colors and a resolution $90 \mathrm{dpi}$. The printer is connected to the computer using a standard parallel interface. The complete screen dump to the printer requires slightly more than two minutes.

When a hard copy of the CRT screen is requested, the software reads the color of each pixel on the screen ( a total of 307,200 pixels for the VGA graphics mode) beginning at the top left and proceeding horizontally across the screen. The color of each pixel is converted to the appropriate printer color using the conversion table shown in Table III.7. The data are converted to characters which are sent to the printer. Each one-byte character defines the color of eight pixels. For the 16 colors listed in the table, four passes are required to define the correct color to the printer. 
Table III.7. Conversion table used in the software to convert the CRT screen color to a PaintJet printer color. The Row, Column heading in the table refers to the row and column numbers on the printer's color spectrum [17].

\begin{tabular}{l|c|c}
\hline CRT Screen Color & $\begin{array}{c}\text { PaintJet Palette } \\
\text { Index Number }\end{array}$ & Row, Column \\
\hline Black & 0 & 33,7 \\
Blue & 4 & 31,3 \\
Green & 2 & 17,2 \\
Cyan & 6 & 29,1 \\
Red & 1 & 11,8 \\
Magenta & 5 & 9,7 \\
Brown & 9 & 13,10 \\
Light Gray & 11 & 33,9 \\
Dark Gray & 10 & 33,8 \\
Light Blue & 13 & 29,3 \\
Light Green & 14 & 16,2 \\
Light Cyan & 8 & 29,4 \\
Light Red & 12 & 11,1 \\
Light Magenta & 7 & 9,10 \\
Yellow & 3 & 15,4 \\
White & 15 & 33,10 \\
\hline
\end{tabular}




\section{FIELD TESTS OF THE HT-BHTV TOOL}

Two field tests were made to test the HT-BHTV system. While these tests were to check the performance of the software, electronics, and the mechanical section of the tool, this section will stress the execution of the software in a field environment. The first test was conducted during the week of April 3 , 1989 in the Baca-3 well located in the Valles Caldera in northern New Mexico. The second test of the system was conducted in two Unocal Geothermal wells located in the Salton Sea known Geothermal Area in southern California during the week of June 5, 1989. The performance of the tool, paying particular regard to the software, is described for these two tests. Results are presented from the test in the Salton Sea area.

\section{IV.1. Baca-3 Well Test}

The Baca-3 well presented a relatively benign environment in which to test the HT-BHTV system. The maximum temperature encountered by the tool was about $155^{\circ} \mathrm{C}$. Table IV.1 summarizes the data that was stored during this test. The logging rate was $5 \mathrm{ft} / \mathrm{min}$ for the first two files shown in the table and was $10 \mathrm{ft} / \mathrm{min}$ for the last file.

Table IV.1. Summary of the data recorded during the Baca-3 well test of the HT-BHTV system.

\begin{tabular}{lrrrrr}
\hline $\begin{array}{l}\text { File } \\
\text { Name }\end{array}$ & $\begin{array}{c}\text { Start } \\
\text { Depth } \\
\text { (ft) }\end{array}$ & $\begin{array}{c}\text { Stop } \\
\text { Depth } \\
\text { (ft) }\end{array}$ & $\begin{array}{c}\text { Logged } \\
\text { Depth } \\
\text { (ft) }\end{array}$ & $\begin{array}{c}\text { Logging } \\
\text { Time } \\
\text { (hrs) }\end{array}$ & $\begin{array}{c}\text { No. } \\
\text { Records }\end{array}$ \\
\hline BACA001 & 1889.64 & 1780.05 & 109.59 & 0.35 & 3739 \\
BACA002 & 1010.10 & 899.99 & 110.11 & 0.36 & 3907 \\
BACA003 & 879.95 & 659.48 & 184.47 & 0.32 & 3312 \\
Totals: & & & 404.17 & 1.03 & 10958 \\
\hline
\end{tabular}

The purpose of the field tests was to flush out any problems that would develop in an actual fielding environment that did not materialize in the laboratory testing of the tool. In this test, we found that the software did not catch all the depth values from the counter. In fact, there were long periods when no new depth was transferred from the counter. This problem developed from a combination of the long conversion time in the counter and the longer computational time required by the software for some of the ac- 
quired data. This difficulty forced us to develop the buffer system for the depth counter which was described in the previous section. The range data from the televiewer showed some places where the casing in the hole was either badly corroded or scaled or showed the buildup of a mud cake.

\section{IV.2. Salton Sea Well Tests}

For the Salton Sea well tests, a more complete software package was available than that used in the Baca-3 test. The software now included the buffer system for the depth counter but did not include the algorithm for obtaining the amplitude information from the digitized waveform. Rather, the range information obtained from the digitized waveform was stored in both the Range and the Magnitude arrays.

The BHTV tool was operated in two Unocal wells: IID-11 and Sinclair-22. The first well we entered was Sinclair-22. Our plan was to lower the tool to a depth having a high temperature and to $\log$ up the hole. As the tool was lowered down the well, at a velocity of $50 \mathrm{ft} / \mathrm{min}$, data from the tool was displayed but, unfortunately, not stored on the hard disk. The data clearly showed the casing joints or collars at about $40 \mathrm{ft}$ intervals. At a depth of $3000 \mathrm{ft}$, we were stationary for perhaps 30 to 60 minutes as we prepared to begin the log. When we again monitored the temperature of the BHTV tool, we noticed that the heat sink temperature was about 30 degrees $C$ higher than the electronics temperature. Also at this time we found that the tool would no longer rotate. We immediately began to pull the tool out of the hole. During this period, we saw both the heat sink and electronics temperature inside the tool increase. The heat sink temperature rose to a maximum value of $117^{\circ} \mathrm{C}$ while the electronics temperature maximum was $74^{\circ} \mathrm{C}$. Upon removal of the tool from the well, we discovered that the teflon window had collapsed around the transducer and that a bulkhead seal had failed causing the hot oil from the mechanical section of the tool to enter the electronics section. This produced the large temperature differential between the heat sink and electronics temperature sensors. The oil had to be completely removed from the electronics before continuing with the logging operation.

These results demonstrate the usefulness of the two internal temperatures in the HT-BHTV tool. Obviously, a single internal temperature would give an indication when the temperature in the tool is getting too high for the proper functioning of the electronics. But the two internal temperatures provide a rather unique diagnostic of a seal failure as shown above. We knew at the time that there existed a problem in the tool. However, we did not realize at the time that both the heat sink and the electronics temperatures were correct. These temperatures gave us a warning of the failure of the seal

Following the resolution of these problems, we moved to the IID-11 weII. This well was logged following a caliper log performed by a commercial logging company. The scale buildup in this well had reduced its size from a nominal 
seven inches to between 5.5 to 5.75 inches. At this small diameter, it was difficult to obtain a good response from the transducer because of the interference with the blanking of the boot pulse (cf Figure II.7). However, a substantial amount of data was recorded. The data recorded here and in the sinclair-22 well are summarized in Table IV.2. The software behaved well for most of the logging operation with only minor problems developing. One of the problems involved the temporary storage of the data on the virtual disk of the computer. Most of the memory became inaccessible to the software for data storage. The problem was solved by erasing the temporary file created before data was stored to a new file. Later analysis of this problem showed that the file on the virtual disk was not closed before the new data was written to it. The data from this well showed little in the way of features though playback of the data did show a correlation between this data and the caliper log of the well.

The following day we returned to the Sinclair-22 well. The complete set of data recorded in this well is summarized in Table IV.2. We obtained a substantial amount of data from this well with only minor problems from either

Table IV.2. Summary of the data recorded during the Salton Sea test of the High Temperature Borehole Televiewer. The data required more than 198 million bytes of storage.

\begin{tabular}{|c|c|c|c|c|c|}
\hline $\begin{array}{l}\text { File } \\
\text { Name }\end{array}$ & $\begin{array}{c}\text { start } \\
\text { Depth } \\
(f t)\end{array}$ & $\begin{array}{l}\text { stop } \\
\text { Depth } \\
\text { (ft) }\end{array}$ & $\begin{array}{r}\text { Logged } \\
\text { Depth } \\
\text { (ft) }\end{array}$ & $\begin{array}{l}\text { Logging } \\
\text { Time } \\
\text { (hrs) }\end{array}$ & $\begin{array}{l}\text { No. } \\
\text { Records }\end{array}$ \\
\hline $\begin{array}{l}\text { IID11_A } \\
\text { IIDII_B } \\
\text { IIDI1_C } \\
\text { IIDII_D }\end{array}$ & $\begin{array}{r}81.59 \\
666.55 \\
2503.79 \\
799.97\end{array}$ & $\begin{array}{r}666.36 \\
2600.39 \\
2397.01 \\
460.87\end{array}$ & $\begin{array}{r}584.77 \\
1933.84 \\
106.78 \\
339.10\end{array}$ & $\begin{array}{l}0.43 \\
1.45 \\
0.39 \\
1.22\end{array}$ & $\begin{array}{r}3907 \\
12953 \\
3389 \\
9862\end{array}$ \\
\hline $\begin{array}{l}\text { SINC22_A } \\
\text { SINC22-B } \\
\text { SINC22-C } \\
\text { SINC22-D } \\
\text { SINC22 -E } \\
\text { SINC22-F } \\
\text { SINC22_G }\end{array}$ & $\begin{array}{r}196.47 \\
4037.77 \\
5530.04 \\
5360.02 \\
5401.08 \\
4697.39 \\
4211.89\end{array}$ & $\begin{array}{l}4003.51 \\
3903.13 \\
5359.93 \\
5437.45 \\
4697.53 \\
4353.77 \\
3799.95\end{array}$ & $\begin{array}{r}3807.04 \\
134.64 \\
170.11 \\
77.43 \\
703.55 \\
343.62 \\
411.94\end{array}$ & $\begin{array}{l}0.94 \\
0.46 \\
0.35 \\
0.34 \\
2.34 \\
1.13 \\
1.01\end{array}$ & $\begin{array}{r}5950 \\
4057 \\
1217 \\
2489 \\
15601 \\
7801 \\
8624\end{array}$ \\
\hline Totals: & & & 4805.78 & 10.06 & 75850 \\
\hline
\end{tabular}


the electronics or the software. However, we did lose the well temperature after traversing the high temperature region of the well and eventually we did lose all the temperatures from the tool. The well temperature was lost because the sensor was disconnected inside the tool. The loss of the other temperatures was caused by the failure of one of the lines in the logging cable. The data showed many features of interest especially several fractures in the open hole section of the well. Problems developed, however, with the mechanical section of the tool. In several instances, the tool rotation would stop only to restart at a later time. Increasing the motor current would sometimes cause the rotation to return. When the tool did not rotate, the software did not acquire or store any data from the tool. Note that the problem with the tool rotation did not start until after the tool passed through the high temperature zone.

The data obtained from the open hole section of the sinclair-22 well showed many features having structures expected of fractures or breakouts. Figure IV.1 shows data near $5380 \mathrm{ft}$ which illustrates the sinusoidal pattern of a fracture intersecting the wellbore at some angle. One section of the fracture appears to be open which is shown by the black area on the figure. Figure IV.2 shows another feature resembling a fracture at a depth near 5418 $\mathrm{ft}$. In this figure a dual display showing both the range and magnitude data is illustrated. Recall that the magnitude algorithm was not incorporated into the software for this test; both the range and magnitude displays in this and the next figure show only the range data. This figure demonstrates how adjusting the display window can highlight certain features in the data. In the magnitude display (the right display in the figure), the display window was adjusted so that only a single color is shown. Some of the features of the fracture are clearer than in the standard range display. Finally, Figure IV.3 illustrates a unique feature of this display system. Shown here is a possible breakout at a depth of $5342 \mathrm{ft}$. The magnitude display on the left shows the data as it would appear when the display window is set to the same values as the range window. The green stripes are due to $60 \mathrm{~Hz}$ noise picked up by the cable. The range display on the right shows the effect of adjusting the minimum value of the display window to $80 \mu \mathrm{s}$ rather than $70 \mu \mathrm{s}$. The noise disturbing the breakout pattern has been removed showing that the display window can be used to filter the data returned by the tool.

The field tests of the HT-BHTV tool exercised the software and pointed out problems requiring correction. The tool was tested in a particularly harsh environment in the Salton Sea wells and, except for the failure of a mechanical section, performed well. A large amount of data was obtained using the software. This data can now be replayed and studied in more detail than is possible during the logging operation. However, many features were viewed during the $\log$ and this demonstrates the usefulness of the real time display of the data during the $\log$ of a well. 


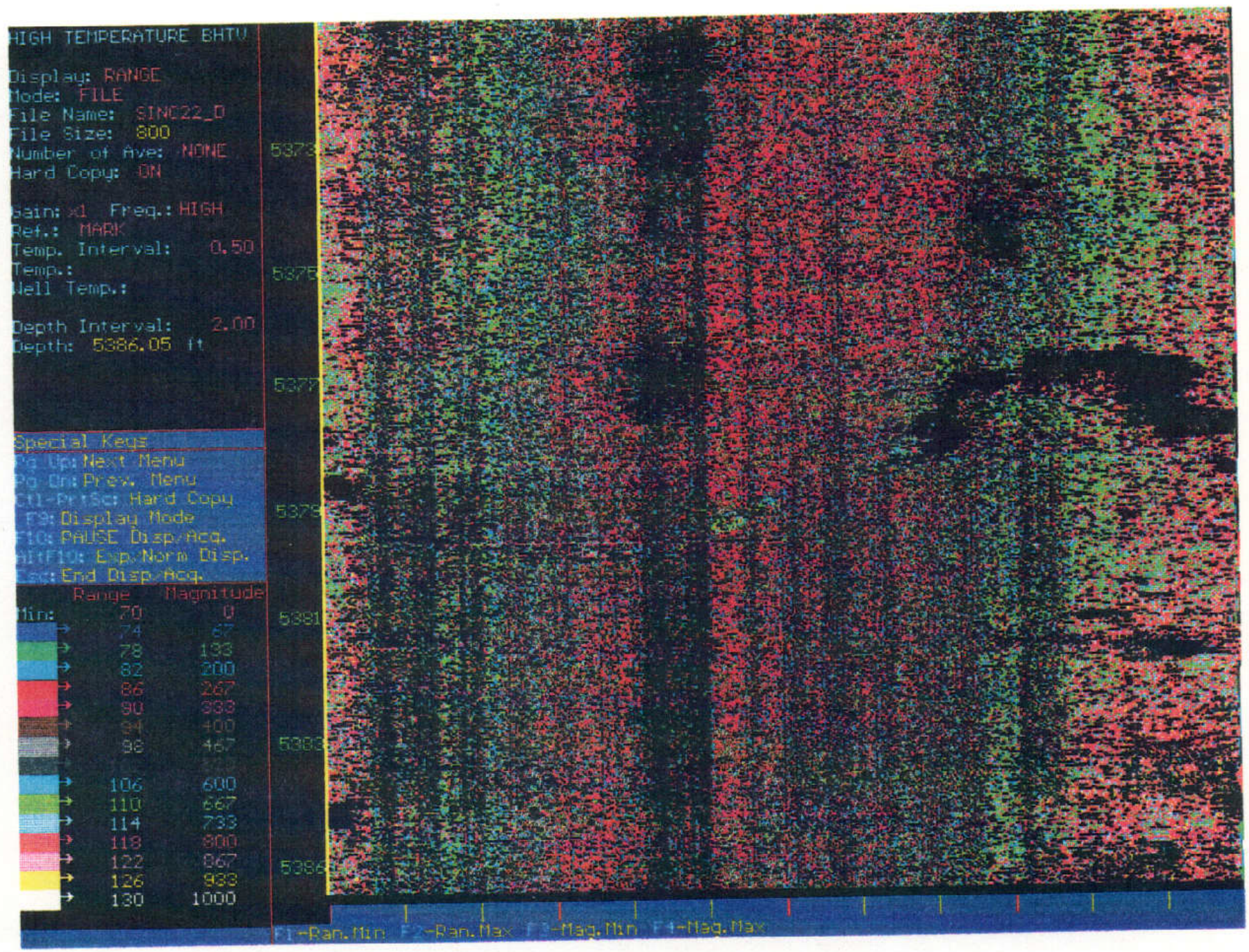

Figure IV.1. HT-BHTV data obtained during the logging of the Sinclair-22 well in the Salton Sea Geothermal area illustrating a potential fracture. The vertical stripes are due to $60 \mathrm{~Hz}$ noise picked up through the logging cable. The digitizer gain was set to $\mathrm{x} 1$; sync threshold set to -2.441 volts; range threshold set to 0.498 volts; range window set to $70 \mu \mathrm{s}$ to $130 \mu \mathrm{s}$. 


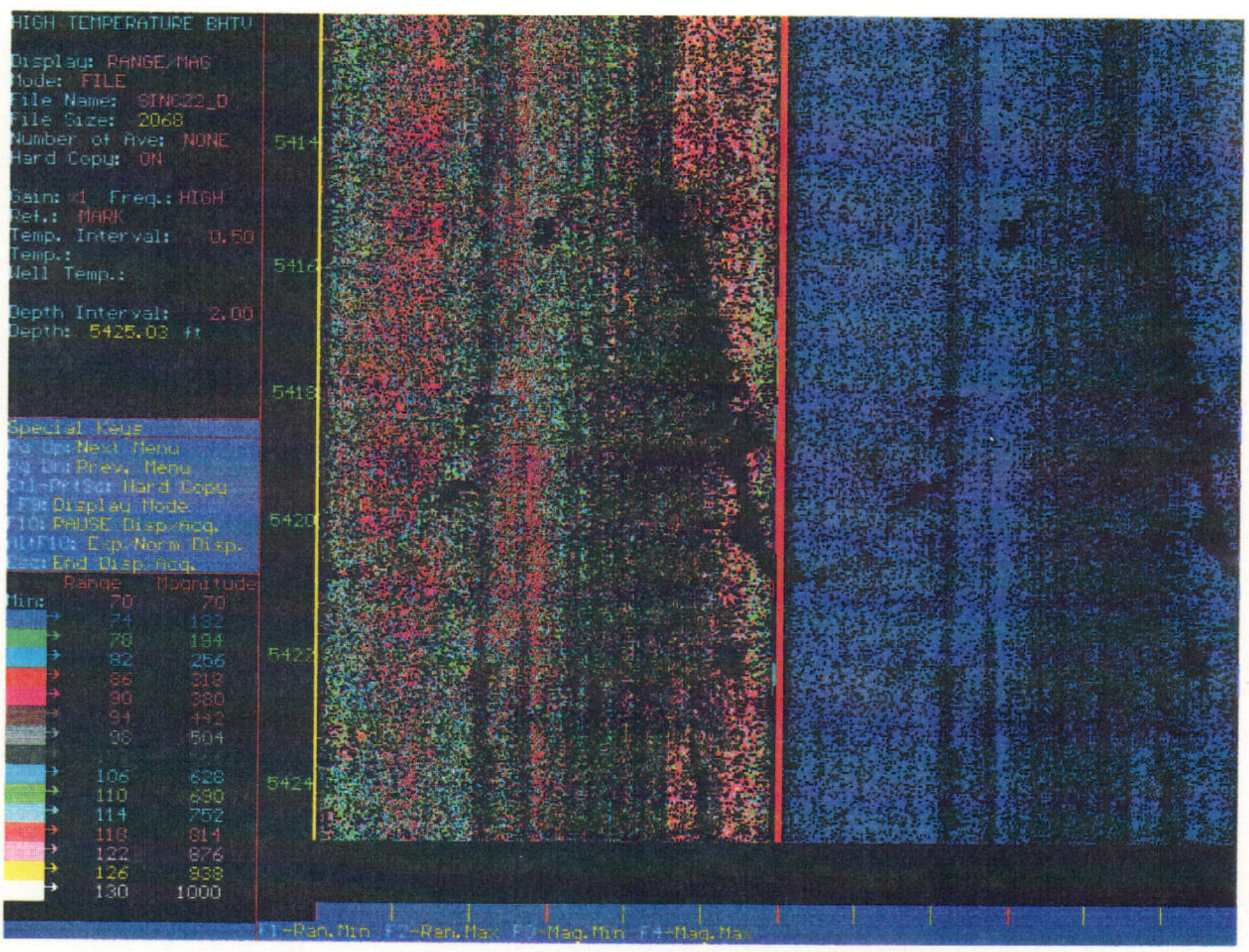

Figure IV.2. HT-BHTV data obtained during the logging of the Sinclair-22 well in the Salton Sea Geothermal area illustrating a the effect produced by changing the display window. The digitizer gain was set to $\mathrm{x} 1$; sync threshold set to -2.441 volts; range threshold set to 0.498 volts; range window set to $80 \mu \mathrm{s}$ to 130 $\mu \mathrm{s}$. 


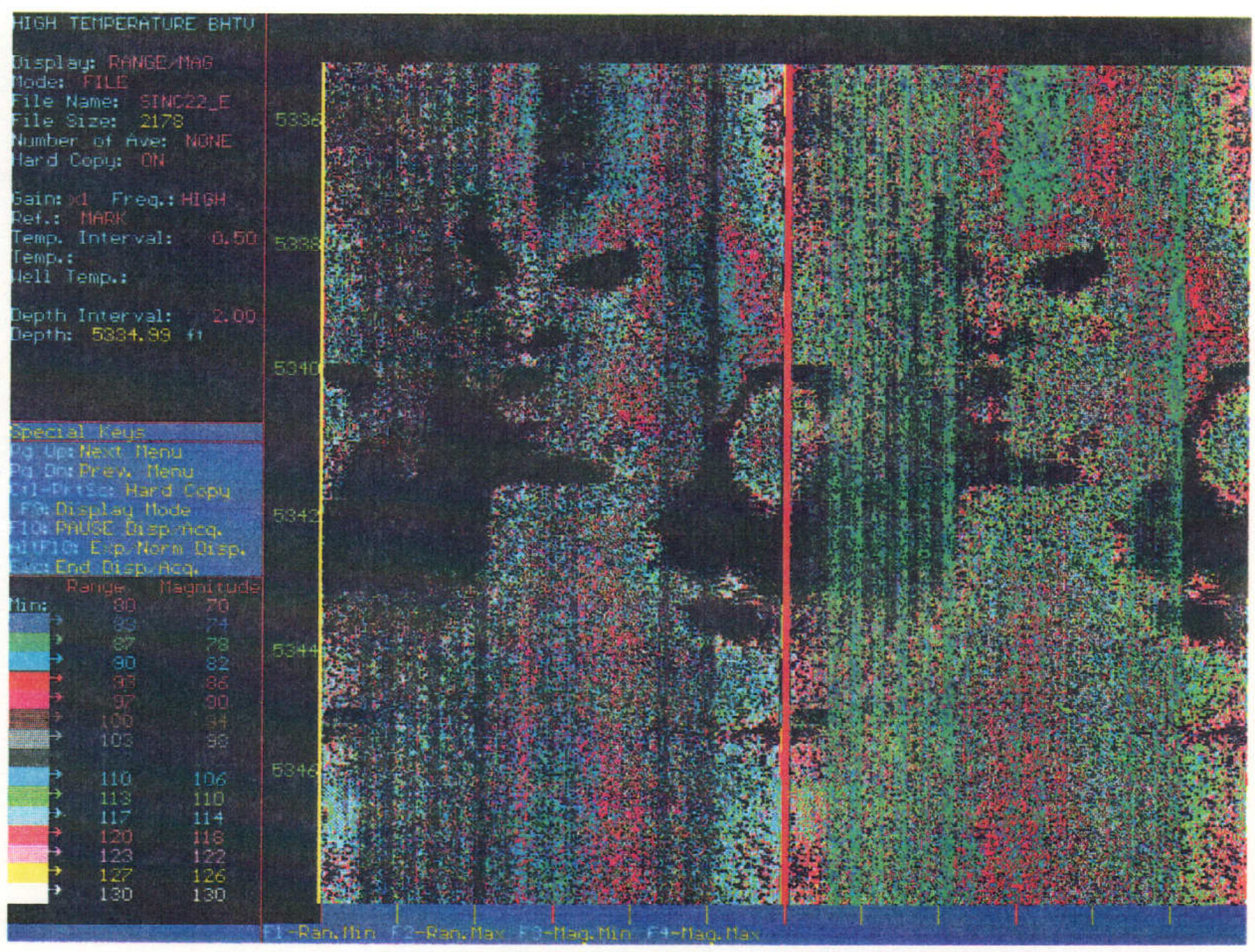

Figure IV.3. HT-BHTV data obtained during the logging of the Sinclair-22 well in the Salton Sea Geothermal area illustrating the filtering operation of the display window. The digitizer gain was set to $\mathrm{x} 1$; sync threshold set to -2.397 volts; range threshold set to 0.498 volts; range window set to $70 \mu \mathrm{s}$ to $130 \mu \mathrm{s}$. 


\section{SUGGESTIONS FOR SOFTWARE AND HARDWARE YODIFICATIONS}

The software described in this User Manual has been shown to operate as desired in the field providing a real-time display of the televiewer data. As with any complex system, ideas for improvements always come up but are set aside because of other pressing jobs which must be done. In this section, some of those ideas which were put aside are listed for future reference in the event that modifications to the software/hardware of this system are desired. Suggested modifications to the HT-BHTV data acquisition system fall into two broad categories: software and hardware changes.

\section{Suggested Software Modifications}

- Dual display for both the range and magnitude data. The current software can display the range, magnitude, or the range and magnitude on a split screen. It is desirable to have the capability to display either the range or the magnitude in a split screen mode so that the display window in one of the screens may be adjusted to emphasize some particular feature of the data as was demonstrated in Figures IV.2 and IV.3.

- A Help Display for each menu, describing the default settings and allowed values of each menu item, would make the program easier to use. In effect, this would eliminate the need for the User Manual when using the software.

- The software presently uses the same time window for extracting the range and amplitude data from the digitized waveform. A separate time window for the magnitude data would make the software more versatile.

- The addition of digital filtering algorithms which can operate on the data when the data are redisplayed would eliminate some of the noise in the acquired data.

- User modification of the color palette to a color scheme different from the default code would prove useful in highlighting different features in the display.

- Averaging the data lines rather than displaying all the data would provide the user with alternative methods to observe features in the televiewer data.

- The software can now only operate in the Data-Driven acquisition mode. The addition of the coding to allow the Depth-Driven acquisition mode would provide the user with a useful option when acquiring data from the tool. 
- If changes occur during a logging operation that require an adjustment of the tool control or data acquisition parameters, the user has no recourse but to begin a new file. The code should be modified to allow the user to make these adjustments from the Data Acquisition/Display operation and remain in the current file. This modification requires that the software store and, in some manner, keep track of the new tool control and data acquisition parameters.

\section{Suggested Hardware Modifications}

- Faster computers, e.g., $33 \mathrm{MHz}$ rather than $20 \mathrm{MHz}$, are available. A faster computer system could allow more computations on the televiewer data.

- High capacity mass storage devices that are not unique to Compaq computers would allow more people to have access to the televiewer data. For example, high capacity WORM (Write Once Read Many) drives for IBM compatible systems are available.

- A faster digitizing board is required. The current system has a time resolution of $10 \mu \mathrm{s}$. New ADC boards are available which have a resolution of $1 \mu \mathrm{s}$. However, these boards have their own memory and do not use DMA. Additional software development is necessary to effectively use these boards in a high data rate continuous operation. 


\section{REFERENCES}

1. Joseph R. Hearst and Philip H. Nelson, Well Logging for Physical Properties, McGraw-Hil1, New York, 1985.

2. Ralph Wiley, "Borehole Televiewer - Revisited," SPWLA Twenty-First Annual Logging Symposium, July 1980, pp. 1-16.

3. R. A. Plumb and S. M. Luthi, "Application of Borehole Images to Geologic Modeling of an Eolian Reservoir," Paper SPE 15487, presented at the 61st Annual Technical Conference and Exhibition of the SPE, New Orleans, Oct. 1986.

4. Fred. E. Heard and Tom J. Bauman, "Development of a Geothermal Acoustic Borehole Televiewer," Sandia National Laboratories Report SAND83-0681, August 1983.

5. J. C. Dunn, "The Geothermal Drilling Organization, "Geothermal Resources Council Transactions Vol. 11, p. 33, 1987.

6. SY-TOS Tape Operating System User's Guide, Revised Edition (September 1987), Sytron Corp., Marlboro, MA, 1987.

7. Turbo Pascal Owner's Handbook, Version 4.0, Borland International, Inc., Scott's Valley, CA, 1987.

8. Stephen K. O'Brien, Turbo Pascal: The Complete Reference, Osborne McGraw-Hill, Berkeley, CA, 1988.

9. Charles C. Edwards, Advanced Techniques in Turbo Pascal, Sybex, Inc., Alameda, CA, 1987.

10. Douglas S. Stivison, Turbo Pascal Library, Sybex, Inc., Alameda, CA, 1986.

11. J. S. Mallozzi, Turbo Pascal for Program Design, McGraw-Hill, New York, 1988 .

12. Peter F. Grofton, Mastering Serial Communications, Sybex, Inc., Alameda, CA, 1986.

13. Samuel D. Stearns and Ruth A. David, Signal Processing Algorithms, Prentice-Hall, Inc., Englewood Cliffs, NJ, 1988. 


\section{REFERENCES}

14. Compag DeskPro $386 / 20$ Personal Computer Technical Reference Guide Volumes I and II, Compaq Computer Corporation, 1987.

15. DAS-20 Manual, Metrabyte Corporation, Taunton, MA, 1987.

16. Turbo Pascal Data Acquisition and Control Tools for Metrabyte DAS-20, Rev. 4.02, IPC-TP-019, Quinn-Curtis, Newton, MA.

17. HP PaintJet Color Graphics Printer User's Guide, Hewlett-Packard Corp., San Diego, CA, Third Edition, 1989. 


\section{APPENDIX A}

Hardware Requirements of the HT_BHTV System

\section{Computer}

Compaq Deskpro 386/20

includes the following cards and drives:

135 Megabyte Tape Drive

300 Megabyte Hard Disc Drive

2 RS-232 Serial Ports

1 Parallel Port

Compaq Video Graphics Controller Board

13 Megabytes RAM

Metrabyte DAS-20 High Performance Analog \& Digital Interface Board

\section{Computer Peripherals}

Hewlett-Packard PaintJet Color Graphics Printer

NEC Multisyne Monitor

\section{Depth Counter}

Red Lion Controls Gemini 2000 Counter with Model GCM 232 Serial Converter Module

Red Lion Controls Rotary Pulse Generator Model RGPC-46-1-0500

Temperature Data Acquisition System

IBM PC-XT Compatible Computer with Monitor

1 RS-232 Serial Port 
DISTRIBUTION

DOE/TIC-4500-UC253 (10)

Tom Anderson

Drilling Fluid Consultants

17726 Sw Overlook Ln.

Lake Oswego, OR 97034

Ed Bingman

Shell Oil Company

Two Shell Plaza

P. O. Box 2099

Houston, TX 77001

Jim Combs

Geothermal Resources Int'1., Inc.

1825 S. Grant, Suite 900

San Mateo, CA 94402

Mel Friedman, Dean

Texas A\&M University

Dept. of Geosciences

College Station, TX 77843

James Langford

Security Division

Dresser Industries

P. O. Box 2467

Dallas, TX 75224

B. J. Livesay

Livesay Consultants

2616 Angell Ave.

San Diego, CA 92122

Roger McCann

Mobil Research \&

Development Corporation

Dallas Research Center

13777 Midway Rd.

Dallas, Texas 75224

Larry Matson

Stratabit

600 Kenrick, Suite Al

Houston, TX 77060
Gene Polk

P. O. Box 280

Sandia Park, NM 87047

Steve Pye

UNOCAL Geothermal

461 S. Boylston

Los Angeles, CA 90017

Gene A. Suemnicht

UNOCAL Geothermal

3576 Unocal Place, P.O. Box 6854

Santa Rosa, CA 95406

Lawrence C. Lynnworth

Panametrics

221 Crescent street

Waltham, MA 02254

Oren Tranbarger

Southwest Research Institute.

6220 Culebra Road

San Antonio, TX 78284

Colleen Barton

Stanford University

Dept. of Geophysics

Stanford, CA 94035

George Chappell

$M-W$ Instruments

4230 Shilling Way

Dallas, TX 75237

David Faulder

P.0. Box 1625

Mail Stop 2107

Idaho Falls, ID 83415

George P. Tennyson

DOE/ALO

P. O. Box 5400

Albuquerque, NM 87115 
U. S. Dept of Energy (3)

Geothermal Technologies Div.

Attn: Lew Pratsch

Gladys Hooper

Marshall Reed

Forrestal Bldg., CE-324

1000 Independence Ave., SW

Washington, DC 20585

Sandia Internal

$\begin{array}{ll}1512 & \text { R. D. Meyer } \\ 3141 & \text { S. A. Landenberger (5) } \\ 3141-1 & \text { C. L. Ward for DOE/OSTI (8) } \\ 3151 & \text { W. I. Klein (3) } \\ 6200 & \text { V. L. Dugan } \\ 6250 & \text { R. K. Traeger } \\ 6252 & \text { J. C. Dunn } \\ 6252 & \text { I. E. Duda (10) } \\ 6252 & \text { J. T. Finger } \\ 6252 & \text { D. A. Glowka } \\ 6252 & \text { R. D. Jacobson } \\ 6252 & \text { S. Knudsen } \\ 6252 & \text { G. E. Loeppke } \\ 6252 & \text { P. C. Lysne } \\ 6252 & \text { J. E. Uhl } \\ 6252 & \text { R. P. Wemple } \\ 6258 & \text { P. J. Hommert } \\ 9310 & \text { J. D. Plimpton } \\ 9313 & \text { S. R. Dolce } \\ 9215 & \text { M. J. Shortencarier } \\ 8524 & \text { J. R. Wackerly }\end{array}$



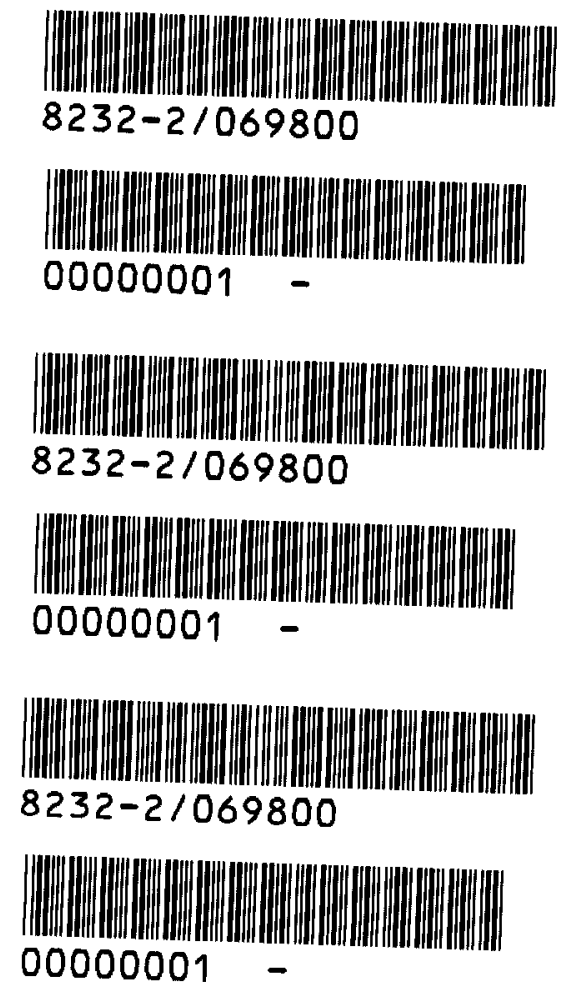


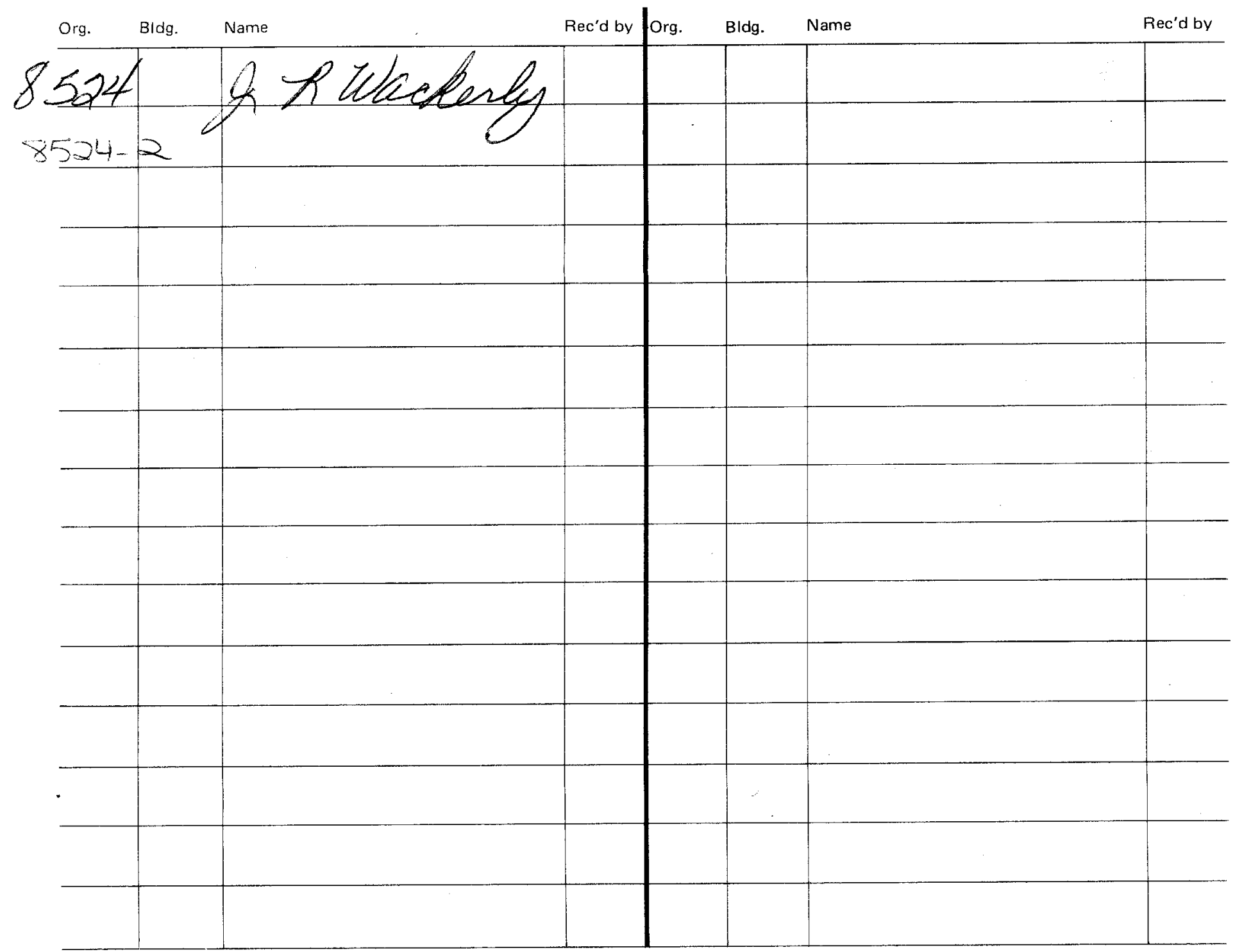

